\section{Pacific Northwest}

National Laboratory

Operated by Battelle for the

U.S. Department of Energy

\title{
Liquid Spills on Permeable Soil Surfaces: Experimental \\ Confirmations
}

\author{
C. S. Simmons \\ J. M. Keller
}

September 2005

Prepared for the U.S. Department of Energy under Contract DE-AC05-76RL01830 


\section{DISCLAIMER}

This report was prepared as an account of work sponsored by an agency of the United States Government. Neither the United States Government nor any agency thereof, nor Battelle Memorial Institute, nor any of their employees, makes any warranty, express or implied, or assumes any legal liability or responsibility for the accuracy, completeness, or usefulness of any information, apparatus, product, or process disclosed, or represents that its use would not infringe privately owned rights. Reference herein to any specific commercial product, process, or service by trade name, trademark, manufacturer, or otherwise does not necessarily constitute or imply its endorsement, recommendation, or favoring by the United States Government or any agency thereof, or Battelle Memorial Institute. The views and opinions of authors expressed herein do not necessarily state or reflect those of the United States Government or any agency thereof.

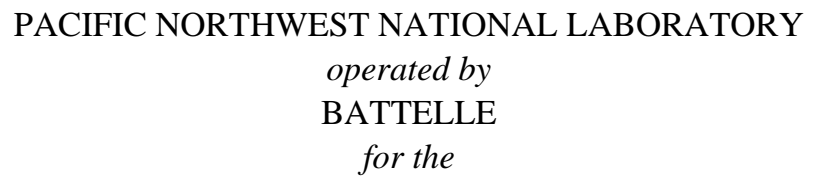

UNITED STATES DEPARTMENT OF ENERGY

under Contract DE-ACO5-76RL01830 


\title{
Liquid Spills on Permeable Soil Surfaces: Experimental Confirmations
}

\author{
C. S. Simmons \\ J. M. Keller
}

September 2005

Prepared for

the U.S. Department of Energy

under Contract DE-AC05-76RL01830

Pacific Northwest National Laboratory

Richland, Washington 99352 


\section{Summary}

Spills occur wherever people handle liquids. Understanding spills can give insights into activities at facilities where liquids are being handled. This work looks at the relationship between the area of a spill and the volume spilled on a permeable soil surface. The spreading of a liquid spill depends on its physical characteristics and on the surface properties. In some circumstances, it may be possible to help identify an unknown liquid involved in a spill by observing its spreading behavior. This experimental work improves and validates the predictive capability of a previously developed model. At this stage of the research on spills, only smooth, inclined, sample soil surfaces are studied with an emphasis placed on spills of non-aqueous or organic liquids associated with motor vehicle use (e.g., antifreeze, transmission fluid, brake fluid). This work achieves a better understanding of non-aqueous liquid spill behavior on soils.

Pacific Northwest National Laboratory performed experiments to test the validity of a mathematical spill model for predicting the simultaneous over-surface flow and liquid infiltration into a soil substrate. Both water-miscible and water-immiscible liquids were spilled on tilted smooth soil surfaces. The spilled liquids covered a range of physical properties defined by their viscosity, density, and surface tension. The example liquids are water-diluted corn syrup, pump oil, antifreeze coolant, and dodecane (a purified form of kerosene or jet fuel). The soils investigated are a sand and a silt loam, constituting a descriptive range of typical soil properties. Infiltration rate into the sand is high, whereas the silt loam is much less permeable.

Experiments were conducted at a smaller 30-centimeter size scale and a larger mesoscale of approximately 1 meter to compare the influence of scale on spill progression. The spill model depends on the simplified Green-Ampt equation defined in section four to describe infiltration into a soil. A number of methods were employed for both measuring infiltration and optimizing the model fit to investigate different calibration procedures. A fluid-media scaling principle is applied to estimate the model parameters for different liquids, based on infiltration information for a standard liquid, usually water. Using the Green-Ampt infiltration model made it possible to avoid implementing a more mechanistically complex multiphase simulator coupled to the over-surface spill propagation model. Moreover, using the Green-Ampt model avoided a more complicated parameter representation of non-aqueous liquid flow in soils. Thus, the Green-Ampt model is demonstrated to simplify the modeling of vertical infiltration.

The progression of spills on soil surfaces during experiments is captured using digital photography. Conversion of pixels to area allowed the measurement of spill surface area progression. Water-diluted corn syrup spills on sand at tilts of 2.4 degrees and 4.8 degrees produced similar total spill areas and infiltration times but had differing spill shapes. Spill shape became more elongated with increasing tilt, as predicted in previously reported model runs. Experimental spill areas were largely dependent on soil permeability and liquid viscosity, with larger spill areas being produced as soil permeability decreased and liquid viscosity increased. Irregularly shaped (non-elliptical) spills produced areas nearly equal to those of replicate spills having more regular patterns. Some liquid spills infiltrated irregularly over the spreading area as a result of variability in hydraulic properties of the soil pack, even though care was taken to produce a uniform soil pack. An important observation is that spills tended to produce a fingershaped protrusion at the down-slope edge as they progressed. This feature's formation is believed to be 
related to surface tension causing contraction of the spill's width at its leading edge A lack of soil wetting at a spill's leading edge may also contribute to the development of a finger frontal protrusion.

Model simulations of spill experiments accurately predicted spill area when soil parameters were appropriately adjusted or calibrated. The maximum error in predicted spill areas ranged from $4 \%$ to $25 \%$, depending on model calibration. The model predicted faster spill progressions than observed, and predicted spills are often wider and less elongated than observed. Model prediction shortcomings are caused by the inability to describe finger formation due to neglecting surface tension in the model. Future spill model formulations require inclusion of surface tension effects to describe fingering. Nonetheless, the spill experiments show that the spill model captures the primary physical relationships between liquid and soil properties controlling spill progression. 


\section{Acknowledgments}

The authors would like to acknowledge project manager, Jeffrey L. Hylden, for supporting this work and for his technical reviews. The authors would also like to thank Joanne Stover for her editorial support and Kathy Neiderhiser for her document formatting support. 



\section{Contents}

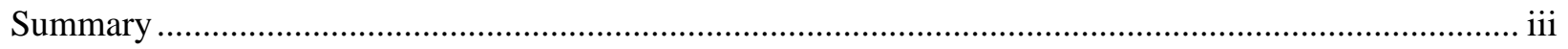

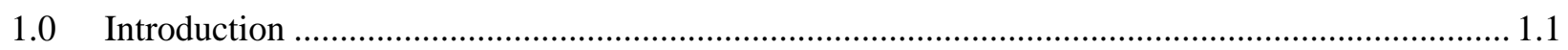

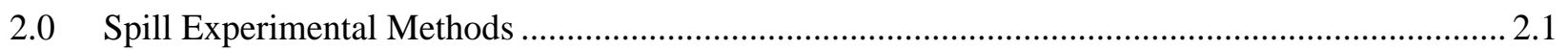

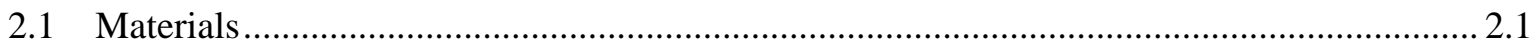

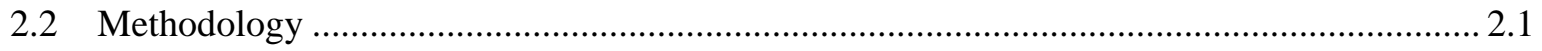

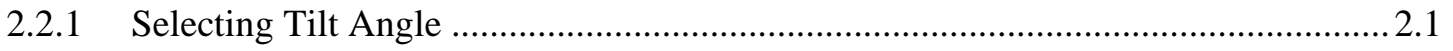

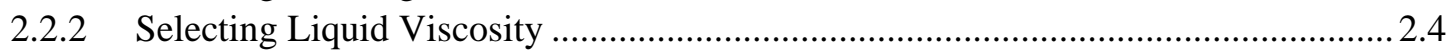

2.2.3 Calibrating the Green-Ampt Infiltration Model ...................................................... 2.5

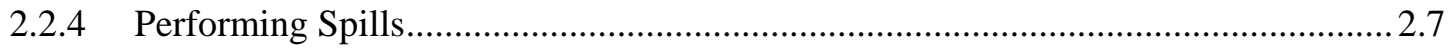

3.0 Experiment Results: Measuring Spreading Area Progression .................................................... 3.1

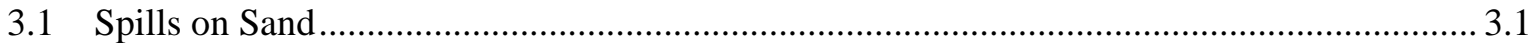

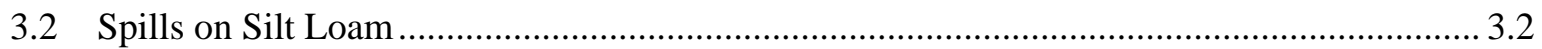

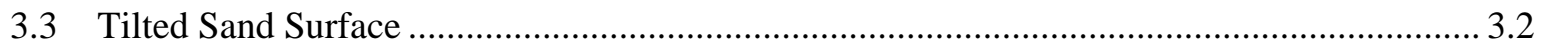

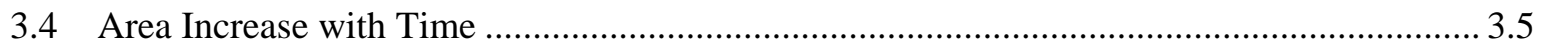

4.0 Infiltration Parameters and Fluid-Media Scaling................................................................. 4.1

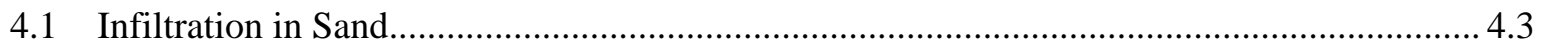

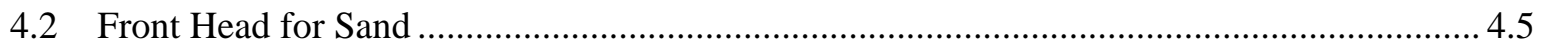

4.3 Infiltration Parameters for Non-Aqueous Liquids in Sand................................................. 4.6

4.4 Infiltration Parameters for Non-Aqueous Liquids in Silt Loam........................................ 4.11

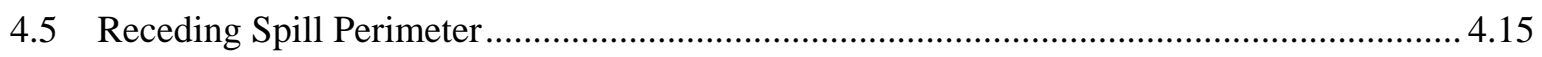

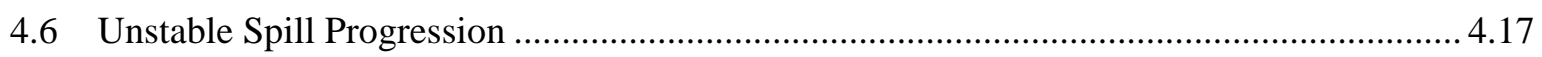

5.0 Comparing Observed Spills with Model Simulations ............................................................ 5.1

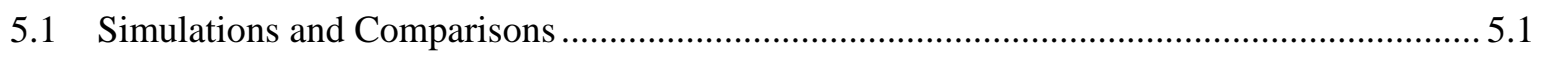

5.1.1 Cut Corn Syrup Spill on Sand ........................................................................... 5.1

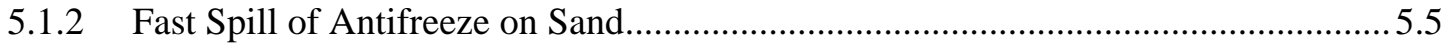

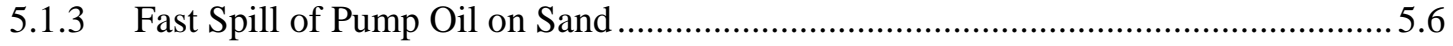

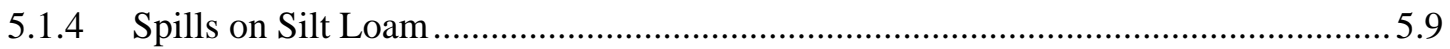

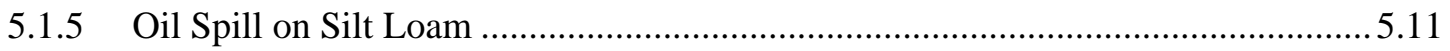

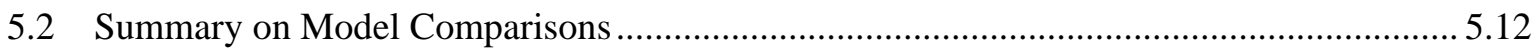

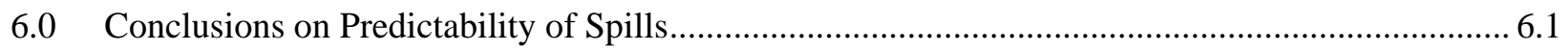

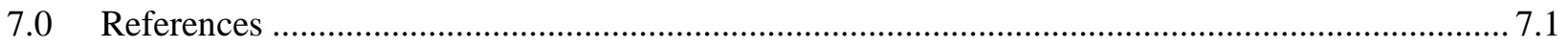




\section{Figures}

Figure 2.1. Oil Spill on Smooth Sand Surface. Pump oil volume is $600 \mathrm{ml}$, and the surface is tilted 5 degrees. Tray is about $1-\mathrm{m}$ long and $66-\mathrm{cm}$ wide.

Figure 2.2. $\quad$ Spill of Cut Corn Syrup 3:1 Water on Slightly Moist Sand for Tilt of 5 Degrees. Volume is $60 \mathrm{ml}$ poured over 18 seconds. Spill image is 10 seconds after spill began. ... 2.3

Figure 2.3. Spill of Cut Corn Syrup 3:1 Water on Slightly Moist Sand with Tilt of 2.5 Degrees. Volume is $60 \mathrm{ml}$ poured during 15 seconds. Spill image is 10 seconds after spill began. 2.3

Figure 2.4. Spill of Cut Corn Syrup on Slightly Moist Sand with Tilt of 2.5 Degrees. Spill is shown after 50 seconds corresponding to Figure 2.3.

Figure 2.5. Water Infiltration into Sand Column. Water is dyed red with food coloring. Time is 2.3 seconds after start of addition of water to surface.

Figure 3.1. Pump Oil Spill on Sand with Fast Pour of $400 \mathrm{ml}$. Tilt is 4.8 degrees. (Date: April 20, 2005)

Figure 3.2. Antifreeze Spill on Sand with Fast Pour of $400 \mathrm{ml}$. Tilt is 4.8 degrees.

(Date: April 20, 2005)

Figure 3.3. Pump Oil Spill on Silt Loam with Fast Pour of $400 \mathrm{ml}$. Tilt is 2.4 degrees. Pour is 11 seconds. (Date: May 16, 2005).......

Figure 3.4. Antifreeze Spill on Silt Loam with Fast Pour of $400 \mathrm{ml}$. Tilt is 2.4 degrees. Pour is 16 seconds. (Date: May 16, 2005).

Figure 3.5. Cut Corn Syrup 3:1 Water Spill on Sand with Tilt 2.4 Degrees. Slow pour of $600 \mathrm{ml}$. (Date: April 8, 2005)

Figure 3.6. Cut Corn Syrup 3:1 Water on Sand with Tilt 4.8 Degrees. Slow pour of $600 \mathrm{ml}$. (Date: April 8, 2005)

Figure 3.7. Spill Area Progression in Time

Figure 3.8. Spill Area Progression for Cut Corn Syrup Spills on Tilted Sand .. 3.5

Figure 4.1. Apparent Water Content in Sand Column with Constant Head 4.4

Figure 4.2. Green-Ampt Model Fit to Visible Wetting Front Depth. Curve is calculated with given parameters for constant head.

Figure 4.3. Green-Ampt Model Fit to Upward Imbibing of Water in Sand. Dashed line is computed model using shown parameters. Circles are data. 
Figure 4.4. Parameters for Green-Ampt Infiltration Model for Cut Corn Syrup in Sand.

Solid curve is model calculation. Circles are data.

Figure 4.5. Infiltration Measurements of Water into Silt Loam. Two stages of infiltration are shown: 1) rising head during pouring and 2) falling head (circles) as liquid sinks into surface.

Figure 4.6. $\quad$ Pouring Rate of Water on Silt Loam Surface. Amount poured is equivalent height of liquid over infiltration tube's cross sectional area. Straight line shows a constant rate from start to finish. Circles indicate actual data.

Figure 4.7. Green-Ampt Infiltration Model Fit for Water in Silt Loam. Data are circles.

Solid line is model based on parameters for first stage rising head.

Figure 4.8. Front Depth for Water in Silt Loam for Falling Head Stage.

Figure 4.9. Spill of Antifreeze on Sand Surface Tilted 4.8 Degrees. Shown at end of a 10-second pouring of $400 \mathrm{ml}$. (Date: April 22, 2005)

Figure 4.10. Spill of Antifreeze on Sand Surface Tilted 4.8 Degrees. Surface liquid is shown 16 seconds after start of pour: 6 seconds after end of pour. (Date: April 22, 2005).......

Figure 4.11. Spill of Antifreeze on Tilted Sand Surface. Surface liquid is shown 9 seconds after end of pour. (Date: April 22, 2005)

Figure 4.12. Spill of Antifreeze on Sand Surface Inclined 4.8 Degrees. Pour is 6 seconds in duration and $400 \mathrm{ml}$. (Date: April 22, 2005).....

Figure 5.1. S Spill Contours of 3:1 Cut Corn Syrup on Sand Surface Tilted 4.8 Degrees. Liquid level above surface is shown on left, depth on right. All units are $\mathrm{cm}$. Spill is $600 \mathrm{ml}$ with duration of 150 seconds.

Figure 5.2. Spill Contours of Cut Corn Syrup on Sand. Regions are shown 41 seconds after the end of pouring.

Figure 5.3. Volume of Total Liquid Spilled and on Surface. Amounts are for the spill of cut corn syrup on a sand surface tilted 4.8 degrees, $600 \mathrm{ml}$ poured during 150 seconds.

Figure 5.4. Spill Area of Cut Corn Syrup on a Sand Surface. Wet area on the surface is shown as a solid red curve.

Figure 5.5. Spill Dimensions for Cut Corn Syrup on Sand Tilted 4.8 Degrees. Simulation based on front head of $20 \mathrm{~cm}$. Spill volume is $600 \mathrm{ml}$ over 150 seconds.

Figure 5.6. Spill Dimensions of Cut Corn Syrup on Less-Tilted Sand. Tilt angle is 2.4 degrees.

Pour is $600 \mathrm{ml}$ during 150 seconds. 
Figure 5.7. Spill Dimensions of Antifreeze on Sand Surface Tilted 4.8 Degrees. Pour is $400 \mathrm{ml}$ during 4 seconds. Simulation is based on front head of $25 \mathrm{~cm}$.

Figure 5.8. $\quad$ Spill Area Progression for Antifreeze on Sand. Red Xs are area data and solid red curve is the model. The blue dash curve is based on an elliptical area with length and width dimensions as simulated.

Figure 5.9. Spill Dimensions of Oil on Sand Surface Tilted 4.8 Degrees. Pour is $400 \mathrm{ml}$ during 7 seconds. Red and blue curves indicate length and width, respectively.

Figure 5.10. Spill Area Progression of Oil on Sand. Pour is $400 \mathrm{ml}$ during 7 seconds. Front head is $25 \mathrm{~cm}$. Dotted line indicates an equivalent elliptical area based on predicted dimensions.5.8

Figure 5.11. Oil Spill Contours on Sand for Liquid Height and Depth

Figure 5.12. Spill Dimensions of Antifreeze on Silt Loam Tilted 2.4 Degrees. Pour is $400 \mathrm{ml}$ during 16 seconds.

Figure 5.13. Spill Area of Antifreeze on Silt Loam. Dashed line is an equivalent elliptical area with the major dimensions as simulated.

Figure 5.14. Spill of Antifreeze on Silt Loam Tilted 2.4 Degrees. Pour is $300 \mathrm{ml}$ during 19 seconds.

(Date: May 17, 2005)

Figure 5.15. Oil Spill Amount on Silt Loam. Front head is $67 \mathrm{~cm}$. Viscosity of the oil over the surface is made a factor of 10 greater. Spill of $400 \mathrm{ml}$ is 11 seconds.

Figure 5.16. Oil Spill Dimensions on Silt Loam. Surface viscosity is amplified by a factor of $10 \ldots . . .5 .13$

Figure 5.17. Spreading Area of Oil Spill on Silt Loam. Dot curves are elliptical areas based on major extents of the spill.

Figure 5.18. Oil Spill Contours on Silt Loam. Pour was 11 seconds and vanished in 380 seconds.... 5.14

\section{Tables}

Table 2.1. List of Liquid Spills Performed in Tray 96 cm x 66 cm x 10.5 cm............................... 2.7

Table 4.1. Hydraulic Parameters for Sand using Green-Ampt Model............................................... 4.5

Table 4.2. Green-Ampt Model Parameters from Imbibing Liquids in Sand ................................... 4.6

Table 4.3. Parameters for Green-Ampt Model fit to Infiltration of Corn Syrup and 3:1 Cut Corn Syrup in Sand 4.8

Table 4.4. Infiltration Parameters for Oil and Antifreeze in Sand 4.8 
Table 4.5. Apparent Viscosity and Permeability for Liquid Infiltration in Sand. Values are based on conductivity for porosity of 0.43 .

Table 4.6. Front Head for Liquid Infiltration Tests in Sand. Height max is equivalent to the amount of liquid applied in each specific tube.

Table 4.7. Attributes of Infiltration Tests in Silt Loam ............................................................... 4.14

Table 4.8. Infiltration Model Parameter Estimates for Silt Loam ................................................ 4.15 


\subsection{Introduction}

Spills of non-aqueous liquids on soil surfaces commonly constitute an environmental concern. Identifying the potential environmental impact or the hazard associated with a spill could be improved if the observed affected area could be related to the amount of liquid involved. Predictive tools for assessing the quantity of a spill on a soil from the observed spreading area could contribute to improving remediation when it is necessary. On a permeable soil, the visible spill area only hints about the amount of liquid that might reside below the surface. An understanding of the physical phenomena involved with spill propagation on a soil surface is key to assessing the liquid amount possibly present beneath the surface. The objective of this study is an improved prediction capability for spill behavior.

Experiments were conducted by Pacific Northwest National Laboratory (PNNL) to examine the physical phenomena of non-aqueous liquid spill propagation over tilted smooth soil surfaces. The organic liquids studied included both miscible and immiscible types relative to water. Such spill experiments performed at the mesoscale (1 meter length) have never been reported in the hydrologic sciences, and they provide a unique set of observations. The spills tested the validity of a mathematical spill model for predicting the simultaneous over-surface flow and liquid infiltration into a soil substrate. The experimental objective was to create smooth soil surfaces (i.e., flat) that manifested only the most fundamental physical mechanisms. In particular, it was desirable that surface irregularities such as grooves or channels did not influence the spill propagation. This approach allowed only mechanisms controlled by gravity, density, viscosity, and capillarity to act.

The scaling of the spill phenomena from a smaller size to the mesoscale was also tested. Assuming that scaling-up is valid, then the results given here could be readily extrapolated to macro-size scales associated with spills on actual landscapes. It is expected or hypothesized that the spill propagation model tested here can be extended to incorporate topographical influences in a general way, similar to the mathematical formulations now used to describe overland flow of runoff water. These spill demonstrations showed that spreading shape is highly influenced by slight irregularities in the input or spillsource geometry. Such irregularities create a challenge to producing an identical spill distribution even when the volumes involved and rates of liquid spilled are nearly the same. In other words, spills usually have a certain random character in their size distribution.

The expected behavior of ideal spills on soil surfaces was reported previously by Keller and Simmons (2005). In that report, particular soils and non-aqueous liquids were identified for study. A selected few of the identified materials (liquids and soils) are employed in these experiments. The spill propagations of water-diluted corn syrup, a pump oil, antifreeze coolant, and dodecane over a sand and a silt loam soil were tested. Dodecane is a low-viscosity and low-density liquid, which can be viewed as a surrogate for kerosene or jet fuel. Pump oil can stand in for engine oil, a typical transmission fluid, or brake fluid. Antifreeze is mainly ethylene glycol. Both antifreeze and corn syrup, of course, are miscible 
with water and may tend to interact somewhat differently than immiscible liquids with a soil including a small initial amount of water. The sand and silt loam always contained a small amount of water to better manage packing them to form a smooth surface.

The propagation of a liquid spill over smooth soil involves both spreading and infiltration into the subsurface. A modeling challenge is to predict the size of the spill area as a result of the volume of liquid applied. This area is the spill signature that is a visible indicator of the event. Of course, the spill area dynamically progresses as the spilled volume increases with time. It is believed that the same phenomena would apply to untested soils and liquids, except for the interactions of organic liquids with clay-type media, such as montmorillonite. The infiltration behavior in clays of certain organic liquids may fall outside the usual regime of capillary mechanisms. 


\subsection{Spill Experimental Methods}

\subsection{Materials}

The liquids and soils were selected based on a preliminary study of their physical properties and how those properties would influence liquid spreading. The sand soil used is not exactly either Quincy sand or Accusand reported by Keller and Simmons (2005). The sand (named Beaver Bark) was an intermediate with a more graded particle-size distribution. It was chosen because of its availability and uniformity. The particle-size distribution and water retention curve of Beaver Bark sand, which were measured specifically, are provided in Appendix B. (Beaver Bark is the name of a landscape materials supply company.) Warden silt loam, which is much finer than the sand and hence less conductive, was used as planned. However, the specific hydraulic conductivity of this silt loam as sieved had to be re-measured and is different than originally reported by Keller and Simmons (2005). Specific permeabilities of the sand and silt loam are determined and given as part of the spill testing discussed by this report.

The liquids used were diluted corn syrup, pump oil, antifreeze, and dodecane. Corn syrup was diluted 3-to-1, or 1-to-1 by volume, with water to produce liquids with a range of viscosity and density. Dodecane was used to study mainly infiltration behavior but not used in a large quantity to create a spill. Cut corn syrup ( 3 parts syrup and 1 part water by volume) has a viscosity of about 55 times that of water, and pump oil has similar viscosity, but lower density and surface tension. Dodecane, on the other hand, can be used to examine a liquid with viscosity approximately equal to water, but less dense.

\subsection{Methodology}

Soils were packed into baking pan trays $31 \mathrm{~cm} \times 20 \mathrm{~cm} \times 4 \mathrm{~cm}(\mathrm{~L}, \mathrm{~W}, \mathrm{D})$ and a mesoscale-size plastic tray of rectangular shape $(96 \mathrm{~cm} \times 66 \mathrm{~cm} \times 10 \mathrm{~cm})$. The surface was made flat and smooth by rolling a large cylindrical tube over the pan or tray edge while filling it with soil until the soil surface was even with the container edge. Other methods, such as scraping the surface flat, were found to be less effective for creating an even or smooth surface. The evenness was tested by observing the behavior of spill spreading in the smaller-size pans.

An example spill of pump oil is shown in Figure 2.1 for the mesoscale-size tray. Typically, liquid is poured through a funnel and allowed to begin spreading on a small hexagon shaped plastic pad placed on the soil surface. The pad prevents the liquid from scouring the soil surface at the point of application. The spill is seen to propagate down-slope. The size of the funnel opening determines the rate of application.

\subsubsection{Selecting Tilt Angle}

A challenge of the spill tests was finding conditions which manifested the ideal spreading behavior. It was known at the outset that if the fluid was not sufficiently viscous or if the tilt of the surface was too great, then the spreading would not conform to the limited conditions of the theoretical spill model. Corn syrup was selected as a safe and disposable liquid to work with because it could be diluted with water to adjust its viscosity. A cut corn syrup with 3 volumes syrup to 1 volume of water was chosen as a test liquid. As determined later, the cut corn syrup has a viscosity about 55 times greater than water, while the 


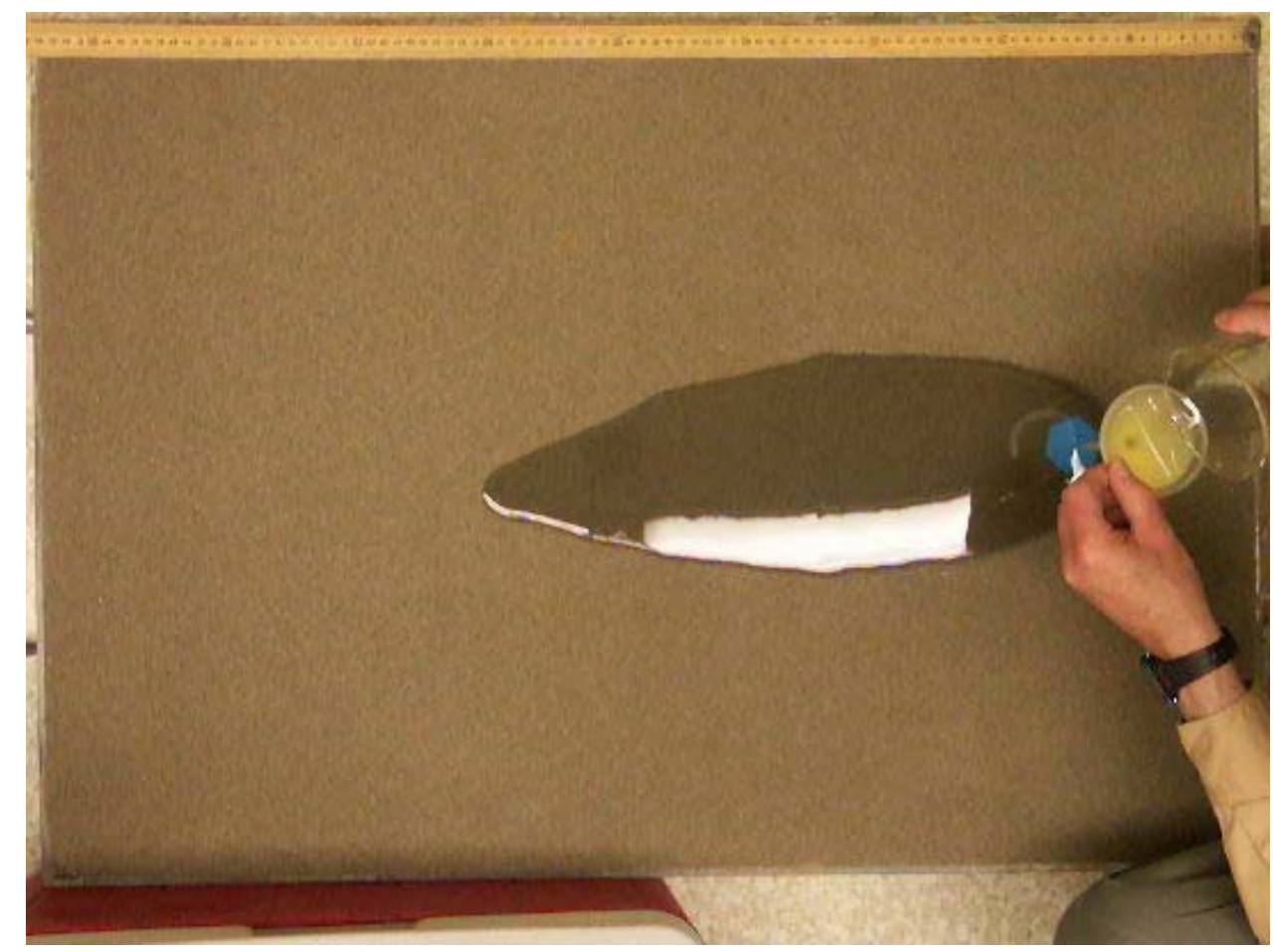

Figure 2.1. Oil Spill on Smooth Sand Surface. Pump oil volume is $600 \mathrm{ml}$, and the surface is tilted 5 degrees. Tray is about 1-m long and 66-cm wide.

surface tension is about $60 \%$ that of water. These liquid properties were determined by considering the infiltration behavior, as discussed later.

Figure 2.2 is a picture of a small spill of $60 \mathrm{ml}$ of cut corn syrup while being poured onto sand, taken after only 10 seconds. The tilt, about 5 degrees, is sufficiently large to cause a narrow rivulet. The flow pooled at the bottom edge of the pan after 15 seconds over the total spill duration of 126 seconds used to empty the source beaker. The pan length is about $32 \mathrm{~cm}$. It can be seen in the photo that the liquid is not wetting the sand surface and has a steep angle of contact along the liquid boundary.

In contrast, Figure 2.3 shows a similar spill rate onto a less-tilted sand surface, at about 2.5 degrees. For Figure 2.2, the spill sunk into the sand totally after 103 seconds, whereas it sunk in after only 66 seconds for the less-tilted spill (Figure 2.3), which remained within the length limits of the pan. In Figure 2.2, the spill rivulet detected a slight lateral tilt, which caused it to make a sideways excursion, but returned nearly to the center line. In Figure 2.3, the lateral and longitudinal spread seemed nearly symmetrical. Notice that the white reflection of overhead light occurs mainly at the curving liquid surface as it meets the sand surface. Because the $60-\mathrm{ml}$ spills are sufficiently small and slow, there was no need to pour liquid onto a pad, as seen in Figure 2.1, to avoid surface erosion. 


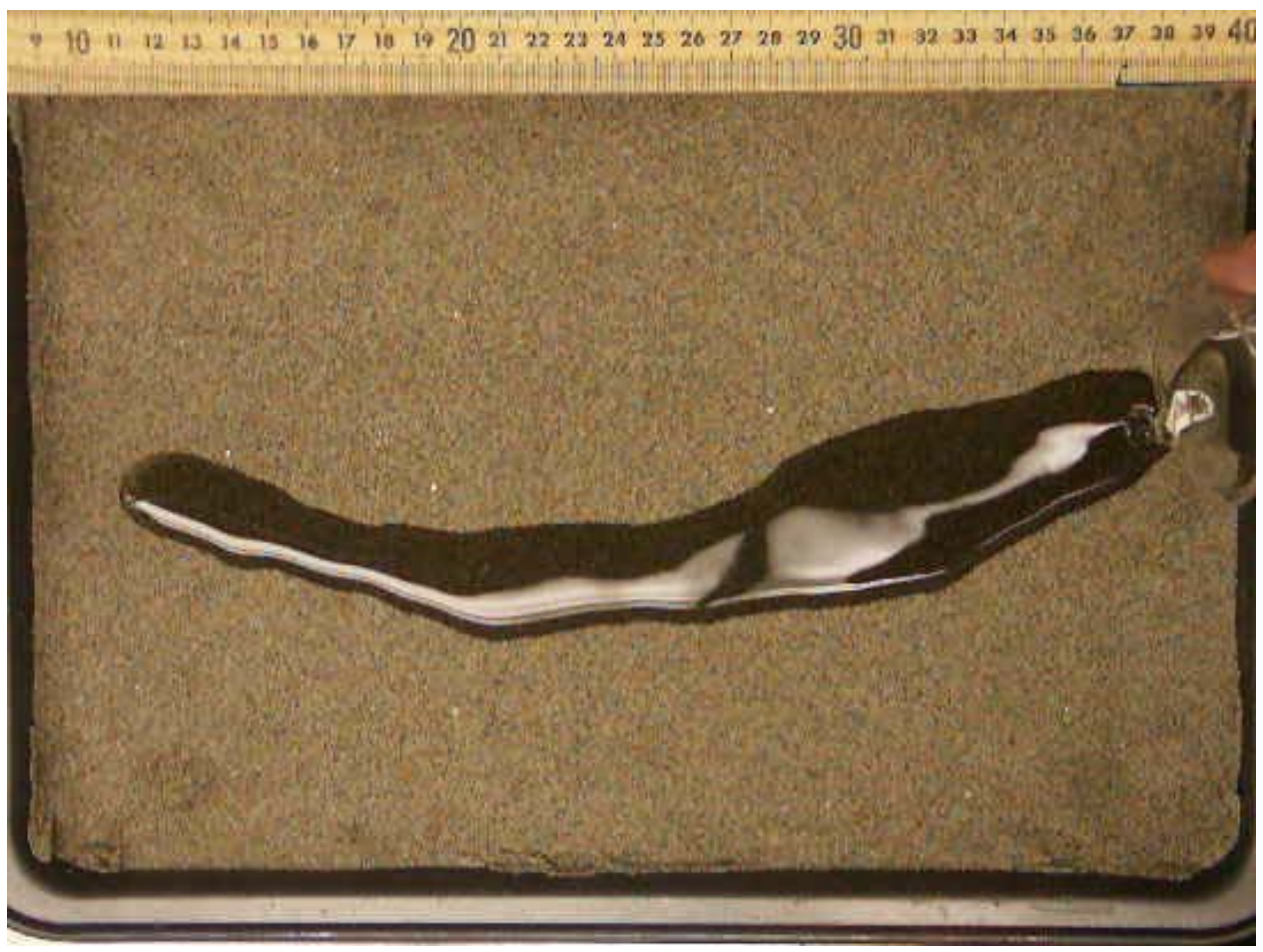

Figure 2.2. Spill of Cut Corn Syrup 3:1 Water on Slightly Moist Sand for Tilt of 5 Degrees. Volume is $60 \mathrm{ml}$ poured over 18 seconds. Spill image is 10 seconds after spill began.

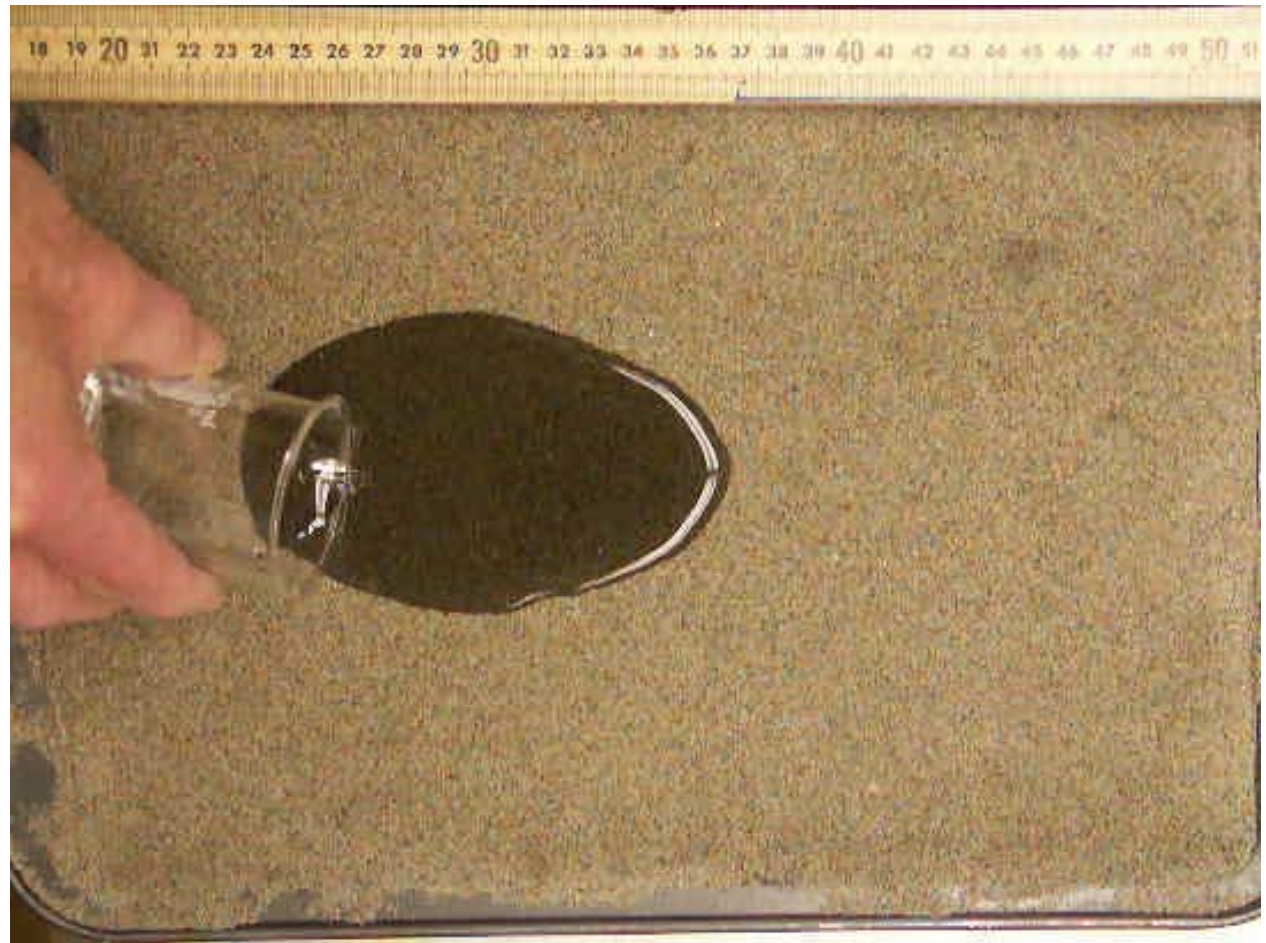

Figure 2.3. Spill of Cut Corn Syrup 3:1 Water on Slightly Moist Sand with Tilt of 2.5 Degrees. Volume is $60 \mathrm{ml}$ poured during 15 seconds. Spill image is 10 seconds after spill began. 
Final stages of the spill's spreading, as displayed in Figure 2.3, is shown by Figure 2.4. A small liquid puddle remains on the downhill end of the wetted region where liquid has sunk (infiltrated) into the sand. After 66 seconds, the liquid was infiltrated entirely. As the liquid sinks in during spreading, the remaining puddle is often uneven or irregular in shape, reflecting variation of subsurface penetration. This shape variation is caused by variation in the sand medium's permeability, because perfect packing could not be achieved. Clearly, after the photo of Figure 2.3, the spreading area continued to increase when pouring was finished.

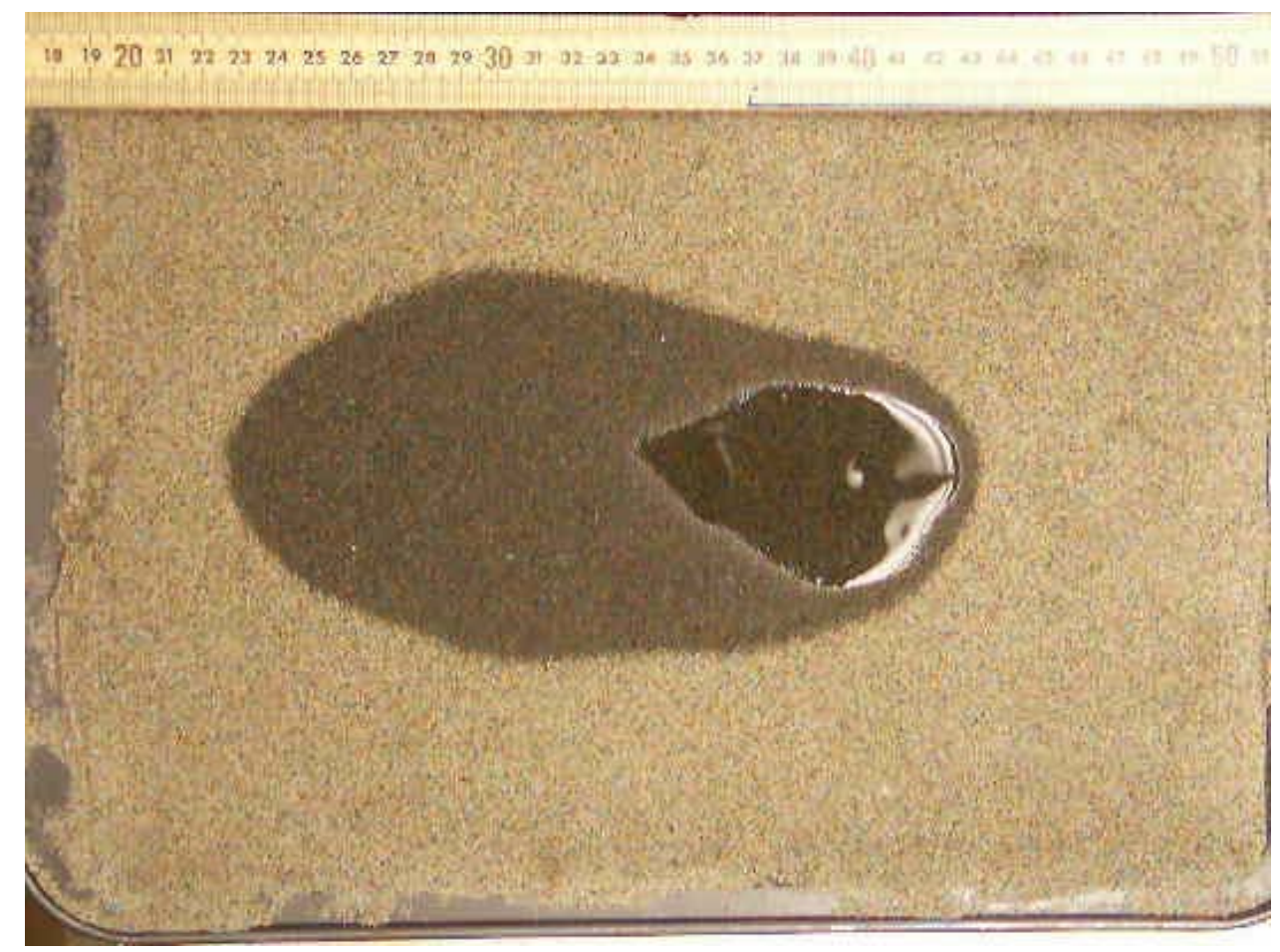

Figure 2.4. Spill of Cut Corn Syrup on Slightly Moist Sand with Tilt of 2.5 Degrees. Spill is shown after 50 seconds corresponding to Figure 2.3.

From Figures 2.2 through 2.4, it was concluded that the tilt angle should not exceed about 5 degrees for a liquid with viscosity less than that of cut corn syrup (3:1). Figure 2.1 shows that the spilling of pump oil at the given rate for the larger scale surface was feasible. Usually, the experimental approach was to perform small-scale, pan-size spill tests before attempting the mesoscale-size spills, because it was important to determine in advance that a mesoscale-size spill would fit in the 1-meter long tray.

\subsubsection{Selecting Liquid Viscosity}

Another reason for adjusting the cut corn syrup's water dilution ratio was to produce a liquid viscosity that slows the infiltration rate to a time scale commensurate with the spreading rate. For instance, if water had been poured on the selected sand, the water would not have spread much, due to infiltration. Therefore, to demonstrate the coupling of spreading and infiltration, the viscosity of the liquid had to be selected in an appropriate range for a particular soil surface. For instance, pump oil 
has a viscosity of about 58 times that of water, whereas pump oil density is $0.86 \mathrm{~g} / \mathrm{ml}$ compared with about $1.28 \mathrm{~g} / \mathrm{ml}$ for the cut corn syrup. As a consequence, cut corn syrup is drawn down-slope more rapidly than pump oil.

When using the much less permeable Warden silt loam, it was feasible to use a much less viscous liquid, such as 1-to-1 water-diluted corn syrup. Subsequently it was found that the 1-to-1 cut corn syrup would produce unstable, or fingered, spreading on a tilted surface and not fall within the prediction regime of the mathematical spill model. Antifreeze, with a viscosity of about 6 to 8 times that of water, could be used on a tilted silt loam surface, provided that the tilt angle was about 2.5 degrees or less.

\subsubsection{Calibrating the Green-Ampt Infiltration Model}

Infiltration of liquid into the soil surface ultimately determines the area covered by a spilled volume. Conceptually, the more rapid infiltration occurs, the smaller will be the area covered by any particular liquid volume. The Green-Ampt model provides a simplified mathematical description of strictly vertical liquid flow. This model accounts for permeability of the soil, liquid density, and viscosity and capillary absorption by the soil of the particular liquid. The model's formulation, as coupled with the over-surface spreading, is described by Keller and Simmons (2005), which contains a detailed mathematical description of its parameters. Because the model is not a true solution of the exact multiphase flow equations that describe liquid infiltration into a soil, its parameters must be estimated to be consistent with observed liquid intake. The model requires the liquid's conductivity in the specific soil, the effective porosity occupied by liquid as it enters the pore volume, and the suction head acting at the wetting front, which quantifies the influence of capillarity. The standing head of liquid above the soil surface and the front suction head determine the time-dependent hydraulic gradient. Using Darcy's law for conduction, the hydraulic gradient determines the infiltration rate. Required infiltration model parameters can usually be estimated by means of separate or independently obtained measurements. However, the model's effective parameters are also obtainable by fitting it to measurements of actual infiltration rates.

To measure infiltration rate, a small transparent tube can be put vertically into the soil extending below the surface, as shown in Figure 2.5. Liquid is poured into the upper part of the tube not filled with soil. The liquid begins to infiltrate, and once the addition of liquid stops, the liquid height declines. Direct measurements of how rapidly the liquid level declines in a particular tube can be fitted to the model equations to estimate unknown model parameters. This procedure was repeated many times to confirm its validity and to test the concept of fluid-medium scaling, which can be used to translate the infiltration behavior of water into that consistent with another liquid. Fluid-medium scaling is also described in more detail by Keller and Simmons (2005).

Section 4 and Appendix A of this report describe more mathematical details of the Green-Ampt infiltration model and methods for its calibration to the experimental soils.

Figure 2.5 shows water, dyed red with food coloring, being poured into the top of a small sand-filled column. The red marks along the tube are spaced by $2 \mathrm{~cm}$; the first mark is hidden in the descending liquid pour stream, which accumulates across the tube cross section above the sand surface. The wetting front (dark area below red) is seen to have moved downward about $2 \mathrm{~cm}$ after 2.3 seconds of pouring. The addition of the $10 \mathrm{ml}$ of water was completed in 3 seconds, and the infiltration was finished after 16.9 seconds. Infiltration was finished when the surface liquid had entirely vanished into the sand, as shown by movie frames acquired at 30 per second. This high-resolution tracking of the infiltration front 


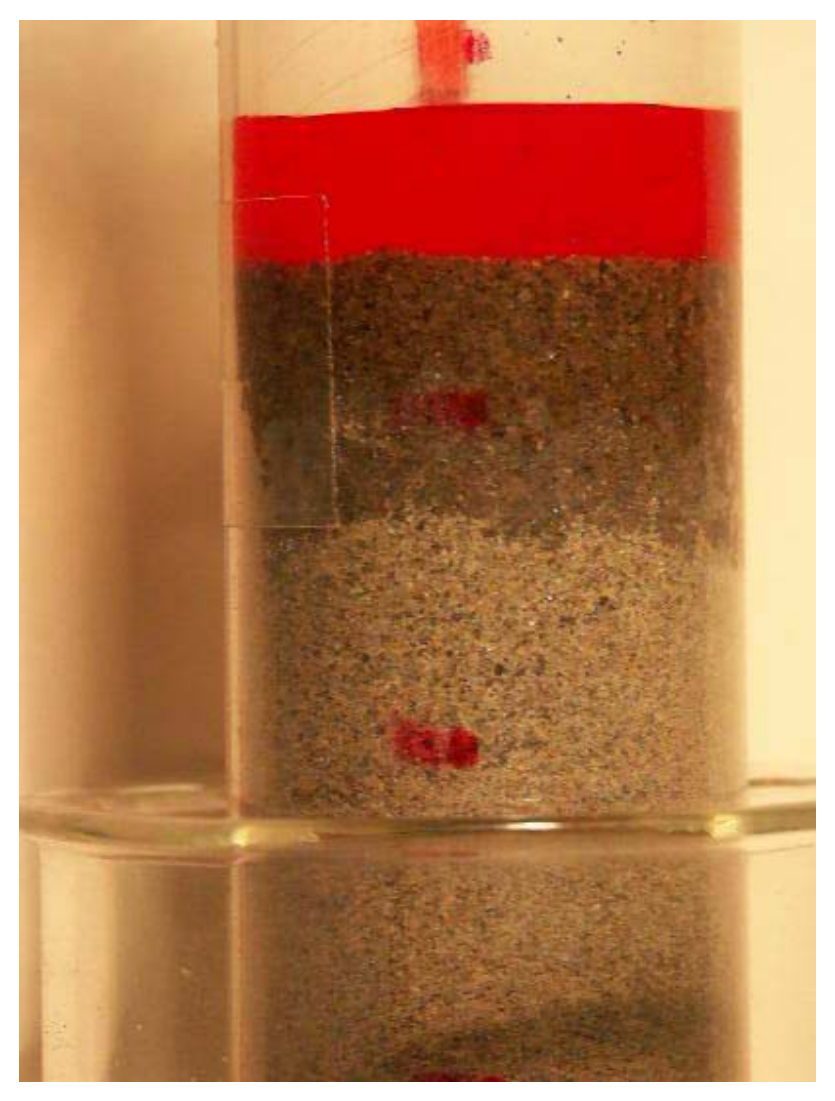

Figure 2.5. Water Infiltration into Sand Column. Water is dyed red with food coloring. Time is 2.3 seconds after start of addition of water to surface. Pour of $10 \mathrm{ml}$ water lasts about 3 seconds and infiltrates after 16.9 seconds from start.

and liquid remaining on the surface can be used to calibrate the infiltration model. The column is constructed from a thin, curved plastic sheet cut from a water bottle. This column stands in a small glass beaker with its rim shown.

Two methods were used to measure the decline of liquid in an infiltration tube. The first method by eye used a ruler $\left(64^{\text {th }}\right.$ inches resolution) to measure the liquid level decline as a function of time. A second method involved measuring video pictures of the liquid level as it changed with time, during and after when liquid was poured into an infiltration tube. The first method could only be used as long as the infiltration was slow enough as is obtained with a highly viscous liquid. The video method (Figure 2.5) required only rapid enough picture taking, with a time stamp on each frame. The video method also had the advantage of allowing the liquid level above surface and infiltration depth below to be measured simultaneously for a tube of soil medium withdrawn from the soil profile.

The estimation of parameters for the Green-Ampt infiltration model and a demonstration of the fluidmedia scaling principle are discussed in Section 4 after describing some of the spills that motivated measuring the absorption properties of the soil and liquid combinations. 


\subsubsection{Performing Spills}

Soil, either sand or silt loam, was packed into pans or plastic tray, and the surface was rolled flat and smooth. Liquids were usually poured onto a small plate area with hexagon shape. The pouring was done through a funnel of three sizes, determining how fast the spill would take place. The pan or tray was usually tilted by 3 to 5 degrees from the horizontal to promote downhill spreading. Time lapse photography was employed to record each spill. From the spill movie, it was possible to determine how long liquid poured onto the source location.

The list of mesoscale-size spills is given in Table 2.1 along with their conditions. Pouring time is the time required to apply the given volume; vanish time is how long was required for infiltration to be complete. Vanish time was determined from the beginning of a pour, so the measurement includes the pouring period as well.

Table 2.1. List of Liquid Spills Performed in Tray $96 \mathrm{~cm}$ x $66 \mathrm{~cm}$ x $10.5 \mathrm{~cm}$

\begin{tabular}{|c|c|c|c|c|c|c|c|}
\hline $\begin{array}{l}\text { Date } \\
2005\end{array}$ & Liquid $_{a}$ & $\begin{array}{c}\text { Volume } \\
\text { (ml) }\end{array}$ & $\begin{array}{l}\text { Pouring } \\
\text { Time (sec) }\end{array}$ & $\begin{array}{c}\text { Vanish } \\
\text { Time } \\
\text { (sec) }\end{array}$ & Soil & $\begin{array}{c}\text { Tilt } \\
\text { Angle }\end{array}$ & $\begin{array}{c}\text { Area } \\
\text { Final } \\
\text { (sq cm) }\end{array}$ \\
\hline April 8 & 3:1 CC Syrup & 500 & 126 & 228 & Sand & 2.4 & 951 \\
\hline April 8 & 3:1 CC Syrup & 600 & 146 & 212 & Sand & 2.4 & 790 \\
\hline April 8 & 3:1 CC Syrup & 600 & 185 & 218 & Sand & 4.8 & 943 \\
\hline April 20 & Pump Oil & 600 & 321 & 472 & Sand & 4.8 & 1110 \\
\hline April 20 & Pump Oil & 400 & 7 & 80 & Sand & 4.8 & 1531 \\
\hline April 20 & Antifreeze & 400 & 4 & 15 & Sand & 4.8 & 1243 \\
\hline April 22 & 3:1 CC Syrup & 400 & 6 & 42 & Sand & 4.8 & 1245 \\
\hline April 22 & Antifreeze & 400 & 6 & 16 & $\begin{array}{l}\text { Sand } \\
\end{array}$ & 4.8 & 1043 \\
\hline April 22 & Antifreeze & 400 & 9 & 21 & Sand & 4.8 & 956 \\
\hline April 26 & 1:1 CC Syrup & 400 & 9 & 14 & Sand & 4.8 & 772 \\
\hline April 26 & Water & 400 & 9 & 10 & Sand & 4.8 & 553 \\
\hline May 16 & Pump Oil & 400 & 11 & 381 & Silt loam & 2.4 & 2248 \\
\hline May 16 & Antifreeze & 400 & 16 & 105 & Silt loam & 2.4 & $1789_{b}$ \\
\hline May 17 & Antifreeze & 300 & 19 & 104 & Silt loam & 2.4 & 1516 \\
\hline
\end{tabular}




\subsection{Experiment Results: Measuring Spreading Area Progression}

Spreading area at any time during a movie (see Figure 2.1 for instance) was determined by mapping out the boundary of the wetted region and then computing the area enclosed by the boundary curve. A pixel map of each curve was converted into actual dimensions before finding the area.

\subsection{Spills on Sand}

Spills were performed first on a sand surface because this was expected to give the greatest challenge of matching spreading and infiltration rates. Maps of the progression area were obtained for pump oil and antifreeze poured onto the sand. A pouring rate of $400 \mathrm{ml}$ over 4 to 7 seconds was viewed as a fast spill, when compared with $600 \mathrm{ml}$ added during 146 to 185 seconds for 3:1 cut corn syrup. The surface of the mesoscale-size tray was tilted 4.8 degrees.

Figures 3.1 and 3.2 show the fast-poured spills of oil and antifreeze, respectively, on a tilted (4.8 degrees) sand surface.

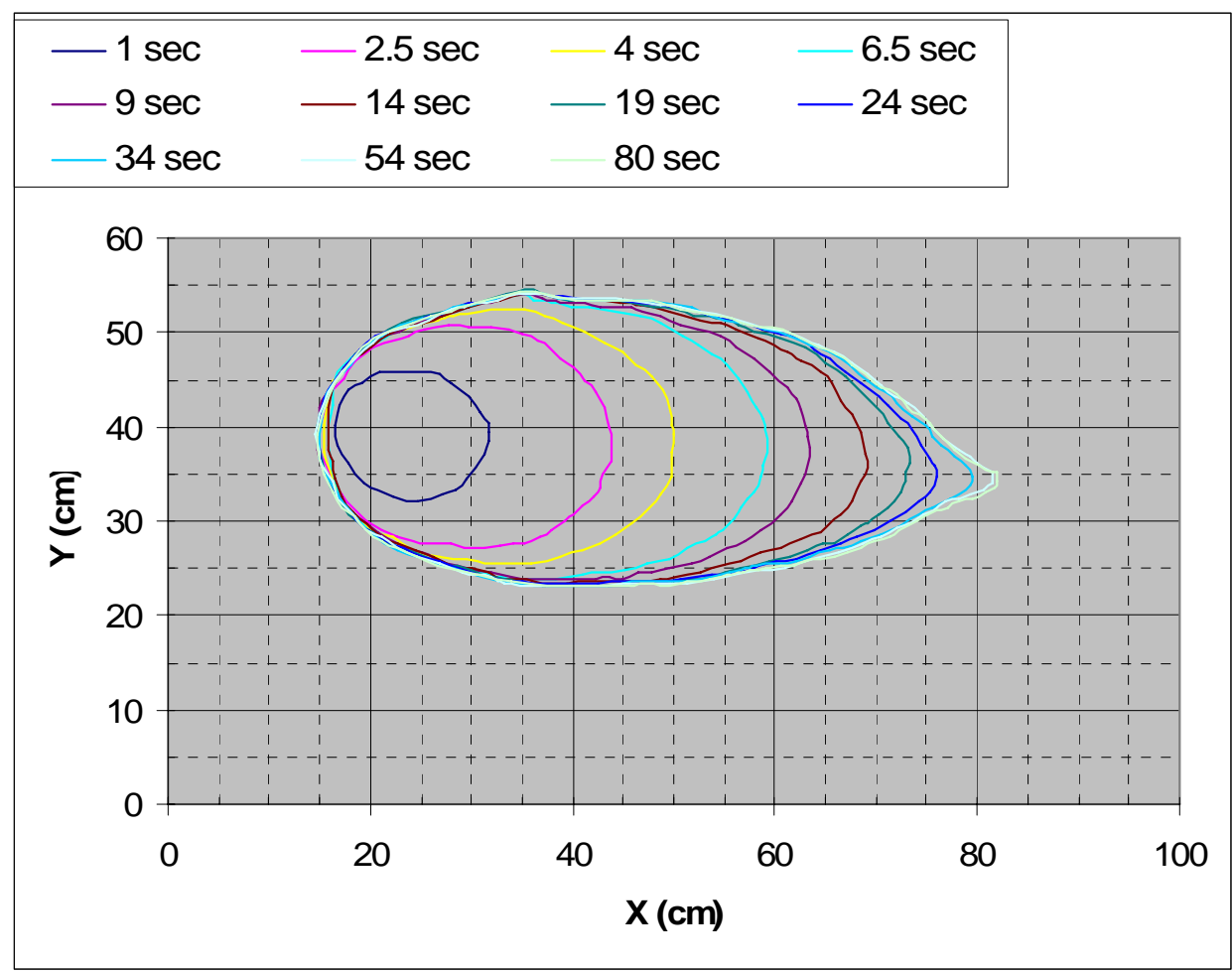

Figure 3.1. Pump Oil Spill on Sand with Fast Pour of $400 \mathrm{ml}$. Tilt is 4.8 degrees. (Date: April 20, 2005) 


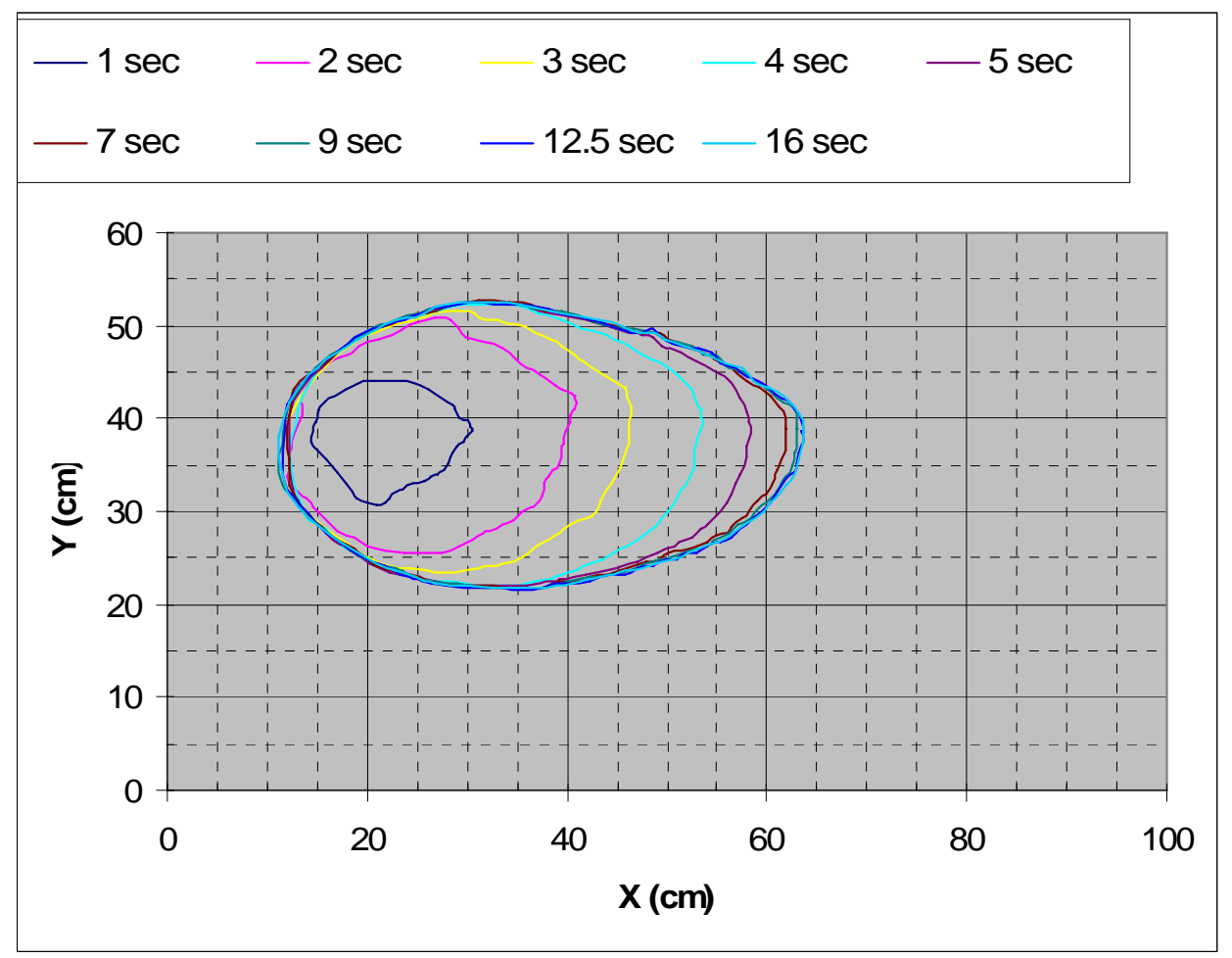

Figure 3.2. Antifreeze Spill on Sand with Fast Pour of $400 \mathrm{ml}$. Tilt is 4.8 degrees. (Date: April 20, 2005)

\subsection{Spills on Silt Loam}

Because the silt loam soil surface was much less permeable than the sand, it was expected that a spill would penetrate less into this soil and spread to a larger area as well as propagate downhill over larger distances. Therefore, after testing, the silt loam surface was tilted only 2.4 degrees to perform a spill.

Figures 3.3 and 3.4 show the fast-poured spills of oil and antifreeze, respectively, on the tilted (2.4 degrees) silt loam surface.

\subsection{Tilted Sand Surface}

To demonstrate the influence of increasing tilt on spill propagation, two 3-to-1 cut corn syrup spills on sand were done. Figures 3.5 and 3.6 show the two spills of $600 \mathrm{ml}$ for angles 2.4 and 4.8 degrees, in succession. The spills were performed at a slower spill rate (more than 100 seconds pour) as indicated in Table 2.1. It is apparent in these figures that the spill is more elongated for the greater tilt. For slower pouring, the spill propagation time is similar to the pouring time. Propagation, however, is more coupled to the pouring rate when the rate is slower ( $>100$ seconds pour) than the faster spills ( $<10$ seconds pour), which tend to propagate a substantial time after the pour is finished. 


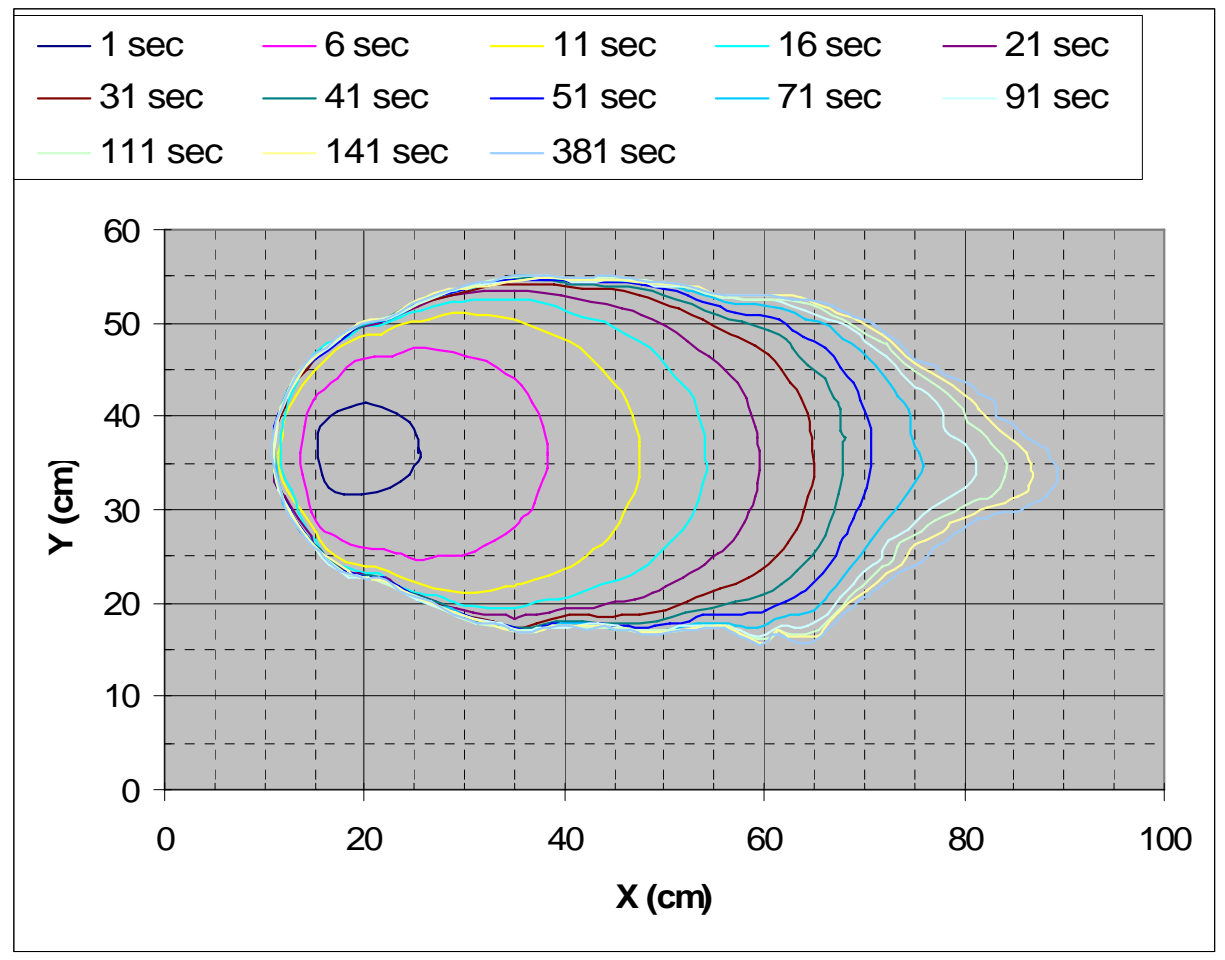

Figure 3.3. Pump Oil Spill on Silt Loam with Fast Pour of $400 \mathrm{ml}$. Tilt is 2.4 degrees. Pour is 11 seconds. (Date: May 16, 2005)

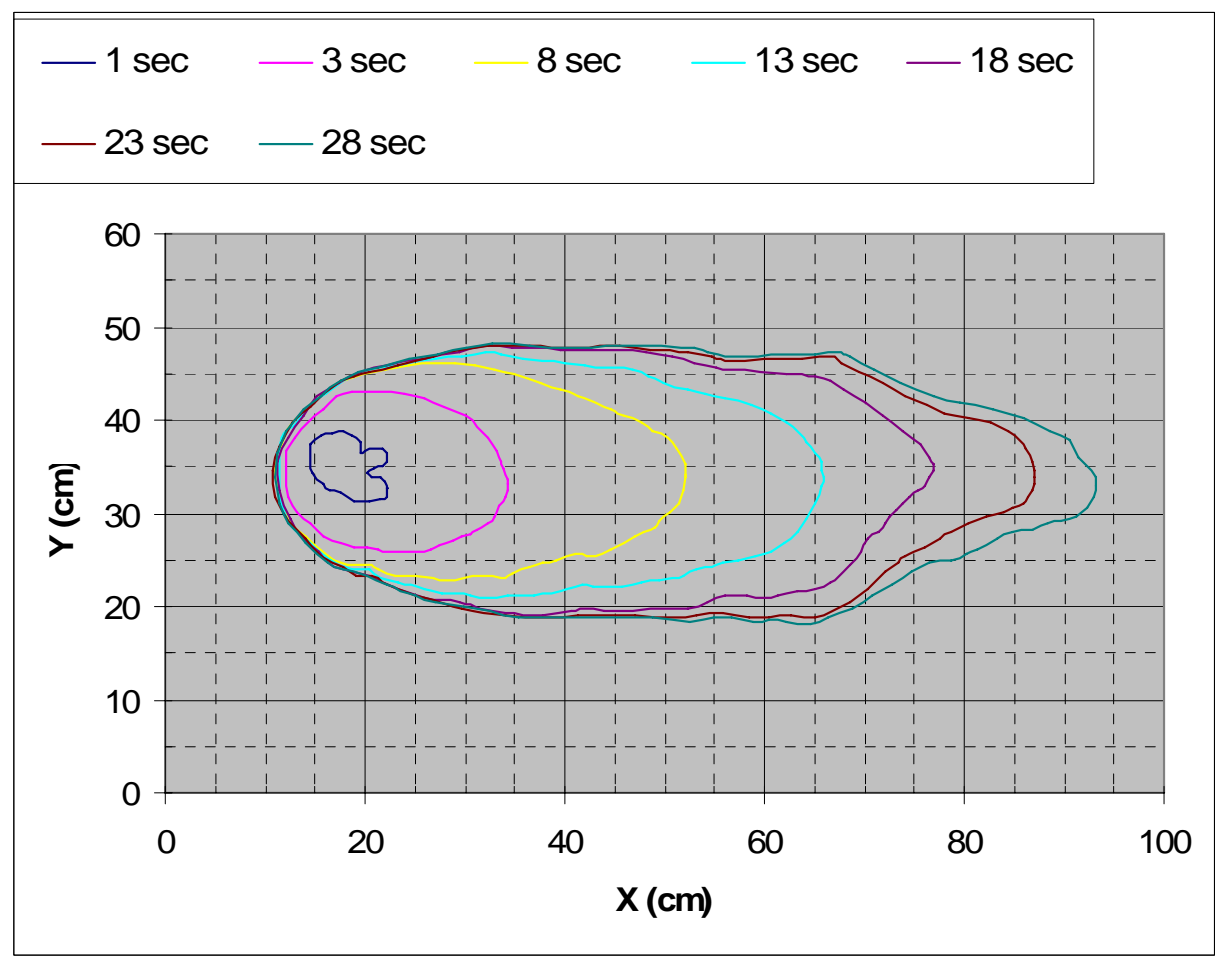

Figure 3.4. Antifreeze Spill on Silt Loam with Fast Pour of $400 \mathrm{ml}$. Tilt is 2.4 degrees. Pour is 16 seconds. (Date: May 16, 2005) 


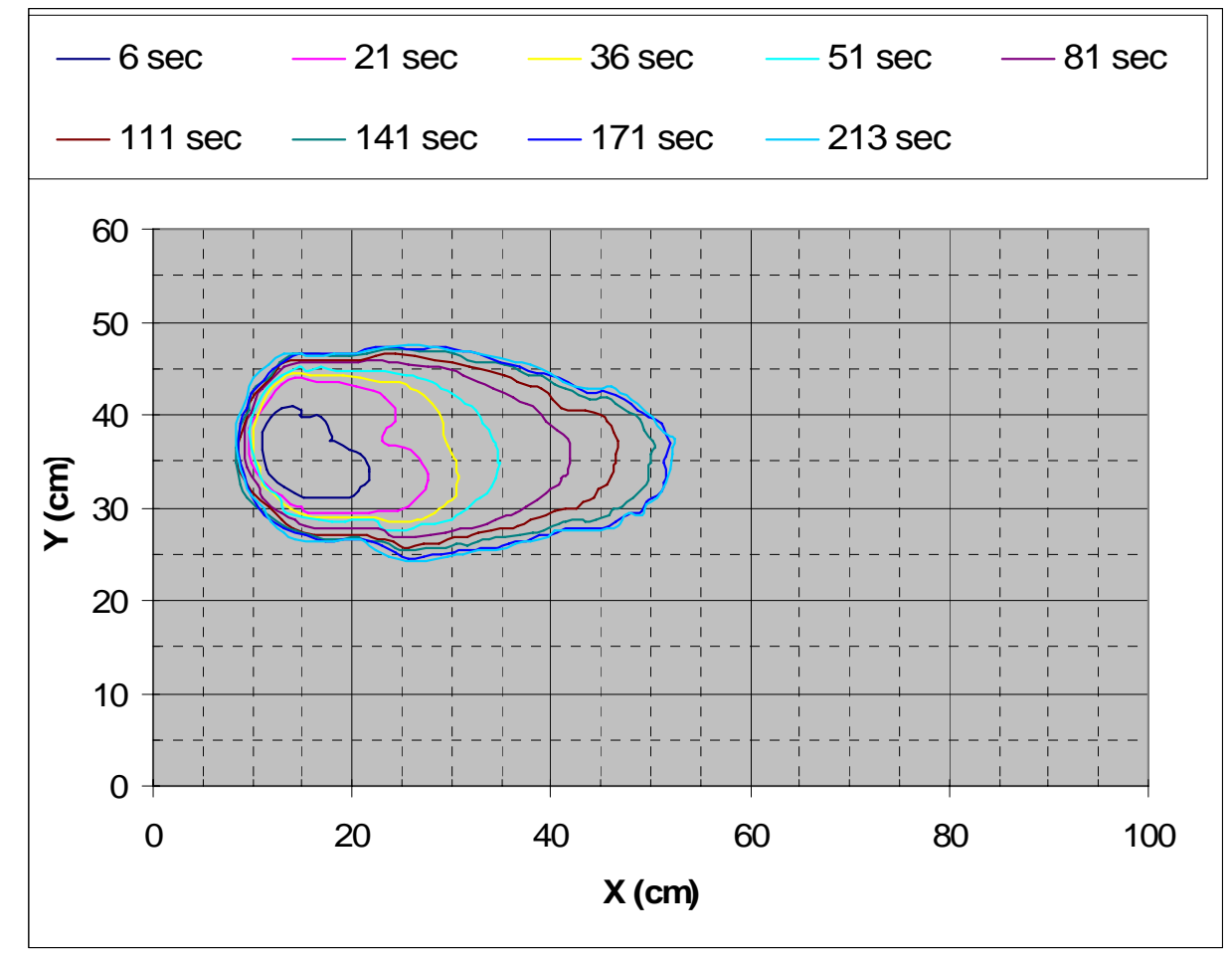

Figure 3.5. Cut Corn Syrup 3:1 Water Spill on Sand with Tilt 2.4 Degrees. Slow pour of $600 \mathrm{ml}$. (Date: April 8, 2005)

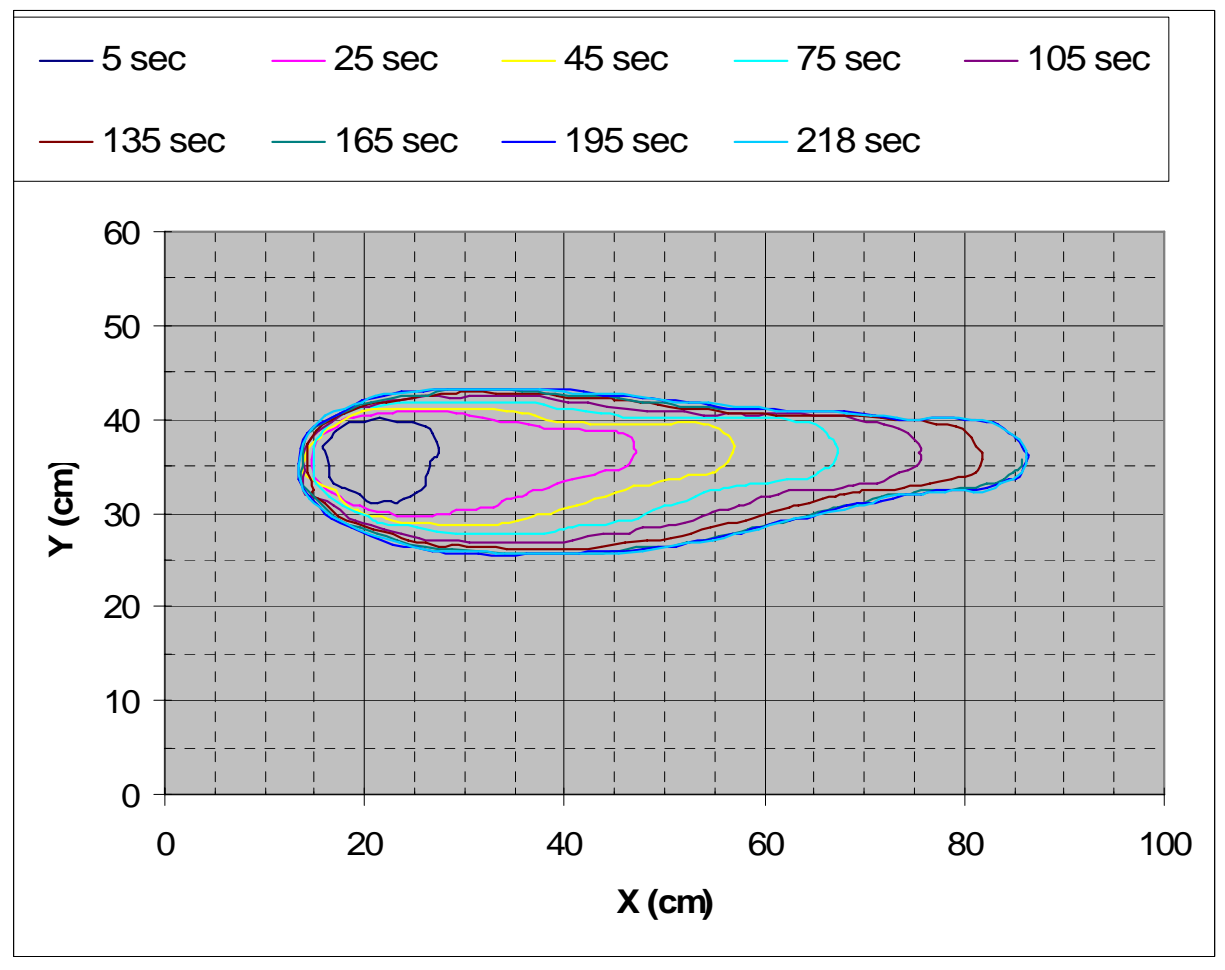

Figure 3.6. Cut Corn Syrup 3:1 Water on Sand with Tilt 4.8 Degrees. Slow pour of $600 \mathrm{ml}$. (Date: April 8, 2005) 


\subsection{Area Increase with Time}

The contour plots in Figures 3.1 through 3.4 can be expressed in terms of a progression of area size as a function of time since a spill began. Such areas are the main predictions obtained from the spill model applied for specific liquids and soils. Figure 3.7 shows the increase of spill area over time. Note that an additional spill of $300 \mathrm{ml}$ of antifreeze on silt loam is included in Figure 3.7. The 400-ml antifreeze spill reached the bottom boundary of the tray and pooled there, thus truncating the area's progression in time.

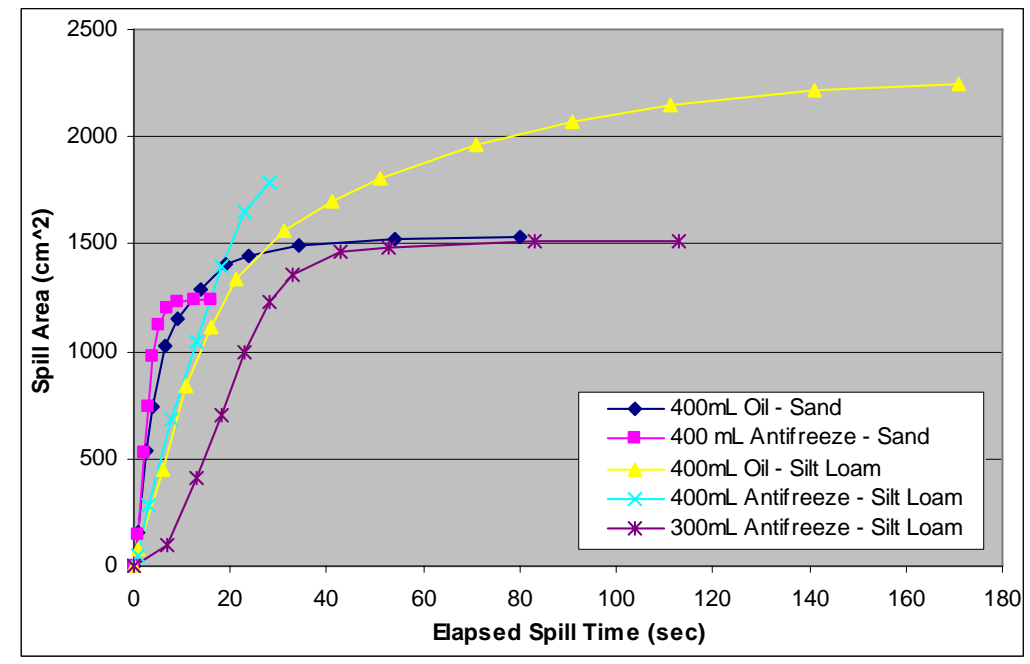

Figure 3.7. Spill Area Progression in Time

Figure 3.8 gives the area progressions for the cut corn syrup spills presented in Figures 3.5 and 3.6, showing the impact of increasing surface tilt. Apparently, the area produced at twice the tilt is only slightly larger for the steeper incline. The increase in elongation, however, is more dramatic. Both spills, regardless, take about the same time to vanish, or entirely infiltrate.

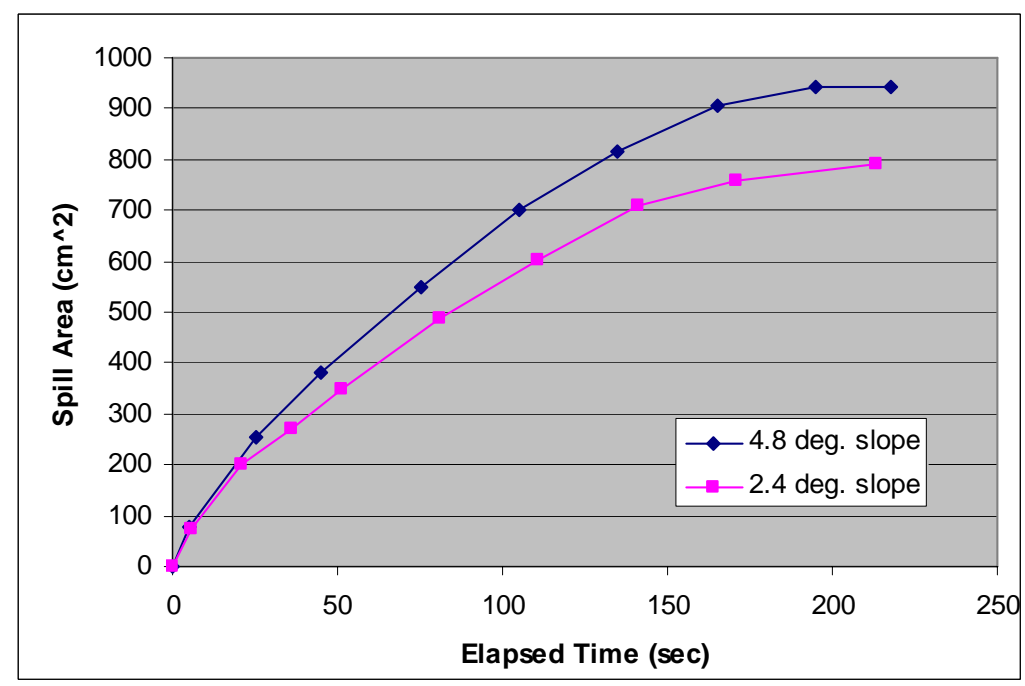

Figure 3.8. $\quad$ Spill Area Progression for Cut Corn Syrup Spills on Tilted Sand 


\subsection{Infiltration Parameters and Fluid-Media Scaling}

Over-the-surface spill propagation is essentially controlled by liquid density and viscosity, as well as the surface tilt. How long a spill can propagate before being absorbed depends on the soil permeability acting in conjunction with viscosity. Together, permeability and viscosity determine the specific liquid conductivity, which determines the rate of infiltration, further depending on the standing liquid height and capillary suction into the soil. The effectiveness of a soil for absorbing a particular liquid can be evaluated without ever actually performing a spill. All that is needed is an infiltration measurement, as described in Section 2.2.3, to obtain parameters for the Green-Ampt model. This model is used to diminish the liquid height, h, of a spill as it spreads over a soil surface. In this section, the validity of the fluid-media scaling principle is also demonstrated. Essentially, the fluid-media scaling principle allows the relevant parameters to be deduced from information about the infiltration of one standard liquid, such as water.

The Green-Ampt model for simple vertical infiltration is stated as follows

$$
\phi \cdot\left(\frac{\mathrm{d}}{\mathrm{dt}} \mathrm{z}\right)=\mathrm{K} \cdot\left(\frac{\mathrm{h}+\mathrm{h}_{\mathrm{f}}+\mathrm{z}}{\mathrm{z}}\right)
$$

where the liquid conductivity is

$$
K=\frac{k \cdot \rho \cdot g}{\mu}
$$

where

$$
\begin{aligned}
& \mathrm{k}=\text { permeability }\left(\mathrm{cm}^{2}\right) \\
& \rho=\text { liquid density }(\mathrm{gm} / \mathrm{ml}) \\
& \mathrm{g}=\text { acceleration of gravity } \\
& \mu=\text { liquid dynamic viscosity (poise }=1 \mathrm{gm} / \mathrm{cm}-\mathrm{sec}) \\
& \phi=\text { soil medium porosity (volume voids/volume total) } \\
& \mathrm{h}=\text { liquid head as height }(\mathrm{cm}) \\
& \mathrm{z}=\text { front depth }(\mathrm{cm}) \\
& \mathrm{h}_{\mathrm{f}}=\text { front head or capillary suction }(\mathrm{cm})
\end{aligned}
$$

In the model, the infiltrating front is assumed to saturate or fill the porosity, and front head is measured in terms of liquid head for the given liquid density. Solutions of this infiltration equation for various conditions of liquid input (boundary conditions) are derived in Appendix A. Various input conditions applied during the infiltration calibration tests are explain in that appendix.

The scaling principle is stated as

$$
h_{f}=h_{f}^{\prime} \cdot \frac{\sigma}{\sigma^{\prime}} \cdot \frac{\rho^{\prime}}{\rho}
$$


where $\sigma$ is the liquid surface tension (dynes/cm).

The prime on symbols in Equation 4.3 denotes a reference liquid, such as water. Equation 4.2 is also a scaling principle, which can be restated as

$$
k=\frac{K^{\prime} \cdot \mu^{\prime}}{\rho^{\prime} \cdot g}
$$

which is the statement that the permeability, presumed to be unchanged for a different liquid, can be determined by measuring conductivity (saturated value) for that reference liquid (water).

The infiltration of an organic liquid, such as an oil, into an already moist soil including water is a complicated multiphase flow process, generally requiring a mathematical theory much more complicated than Equation 4.1. Usually, complete information about the soil-liquid interaction given as liquid capillary retention and conductivity as a function of volumetric liquid content is needed to solve the problem of dynamic infiltration. Equation 4.1 constitutes a simplification because only a few effective parameters need to be defined. In particular, when a small concentration of water is initially present, then the porosity is only that part of the porous volume available for flow. That is, the available porosity is

$$
\phi_{\mathrm{a}}=\phi-\theta_{\mathrm{w}}
$$

where

$$
\theta_{\mathrm{W}}=\frac{\rho_{\text {bulk }}}{\rho_{\mathrm{W}}} \cdot \frac{\mathrm{w}}{1+\mathrm{w}}
$$

and bulk density of the soil including water and other non-aqueous liquid is

$$
\rho_{\text {bulk }}=\rho_{\mathrm{s}} \cdot(1-\phi)+\rho_{\mathrm{W}} \cdot \theta_{\mathrm{W}}+\rho_{\mathrm{o}} \cdot \theta_{\mathrm{o}}
$$

In equation 4.7, "s" refers to soil solids, "w" indicates water fraction, and "o" is the other liquid. The mass fraction of water relative to dry soil mass (not including any other liquid either) is $\mathrm{w}$ in Equation 4.6. Note that

$$
\rho_{\mathrm{W}} \cdot \theta_{\mathrm{W}}=\mathrm{w} \cdot \rho_{\mathrm{S}} \cdot(1-\phi)
$$

and a similar expression holds for the other liquid, when present. When only water is present, the bulk density is

$$
\rho_{\text {bulk }}=\rho_{\mathrm{S}} \cdot(1-\phi) \cdot(1+\mathrm{w}) \text {. }
$$


Together, Equations 4.6 and 4.9 provide estimation of Equation 4.5 from measurements of bulk density and water mass fraction, w. If a volume of liquid $\mathrm{V}$ is infiltrated into moist soil over area $\mathrm{A}$, then the depth, $\mathrm{z}$, reached is given by

$$
\frac{\mathrm{V}}{\mathrm{A}}=\phi_{\mathrm{a}} \cdot \mathrm{z}
$$

This equation presumes that the water fraction does not move, which is generally false, and that the infiltration has just finished, so that the liquid has not yet redistributed downward. These presumptions are appropriate for the early stage of infiltration, while spreading is taking place.

Equation 4.10 is another means for determining the porosity required to use (Equation 4.1). If the depth, $\mathrm{z}$, is obtained visually, say by seeing the front location in an infiltration tube, and applied liquid amount is known, then the effective available porosity is found.

For a spill, available porosity controls how deep the liquid penetration is immediately after the spill vanishes by infiltration. Equation 4.1 represents the liquid sink that diminishes the surface spreading over time at each location. At each spreading location on a soil surface, a different $\mathrm{z}$, and perhaps different model parameters, $\phi$, $\mathrm{K}$, and $\mathrm{h}_{\mathrm{f}}$, may apply.

An objective of this spill study is to prove that the Green-Ampt model (Equation 4.1) applies and is adequate by demonstrating its calibration. Various solutions of the model for calibration are found in Appendix A. In some situations, the viscosity may not be known directly, or its value may be effective in the soil medium, especially if the spilled liquid is miscible with water. For instance, the effective viscosity of cut corn syrup and antifreeze are difficult to establish at a single value when these enter a moist soil. Calibration of Equation 4.1 is accomplished by fitting its solutions to measurements under specified boundary conditions. Appendix A provides solutions used for calibration under various controlling conditions. For instance, one particular condition is to cause infiltration under a constant applied liquid height, h. Another condition is to apply a certain volume quickly into an infiltration tube, and then measure the liquid-level decline with time. The latter condition is a falling head test. However, infiltration occurs also while the liquid is being poured onto the surface, and then head height rises to its maximum before the level begins to decline. Mathematical descriptions of rising and falling head conditions are treated in Appendix A. The mathematical derivations, however, are not essential for understanding the progression of a spill influenced by infiltration.

\subsection{Infiltration in Sand}

The sand was wetted initially to a moisture fraction, $w$, that varied from $4.5 \%$ to $8 \%$ by weight. It was never possible to set the packed bulk density and porosity at the same values from infiltration test to test. Various samples of moist sand had bulk density ranging from 1.33 to $1.48 \mathrm{gm} / \mathrm{ml}$. A typical sample had density $1.36 \mathrm{gm} / \mathrm{ml}$ and moisture $6.6 \%$. This corresponds to porosity of $0.527 \mathrm{~cm}^{3} / \mathrm{cm}^{3}$, based on solid density of $2.7 \mathrm{gm} / \mathrm{ml}$ for sand. The bulk density range specified gives a porosity range from 0.486 to 0.538 . The volumetric water content varies from 0.062 to $0.092 \mathrm{~cm}^{3} / \mathrm{cm}^{3}$. Thus, the available porosity varies from 0.394 to $0.456 \mathrm{~cm}^{3} / \mathrm{cm}^{3}$. 
The saturated hydraulic conductivity, $\mathrm{K}$, of the sand was measured as $0.0143 \mathrm{~cm} / \mathrm{sec}$ by a steady-state flow method. This value for $\mathrm{K}$ gives permeability, $\mathrm{k}$, equal to $1.46 \mathrm{E}-7 \mathrm{~cm}^{2}$. K was also measured by fitting Equation 4.1 to constant head infiltration test data (Appendix A). This method allows for a simultaneous optimization of $\mathrm{K}$ and front head, $\mathrm{h}_{\mathrm{f}}$. A constant head of water at $\mathrm{h}=3.5 \mathrm{~cm}$ was applied to the top of a sand-packed column, $60 \mathrm{~cm}$ long, and the wetting front was tracked along with measuring the amount of water infiltrated in time. An apparent water content is defined by dividing the infiltrated water depth (volume/area of column cross section) by the visible front depth. The column is transparent plastic to allow viewing of the wetting front. Figure 4.1 shows that the apparent water content begins with small values and increases asymptotically to a maximum. At first, the front does not saturate the porous volume where it is visible. As infiltration proceeds, the pore volume is filled; Figure 4.1 indicates about $0.455 \mathrm{~cm}^{3} / \mathrm{cm}^{3}$ for a final available porosity.

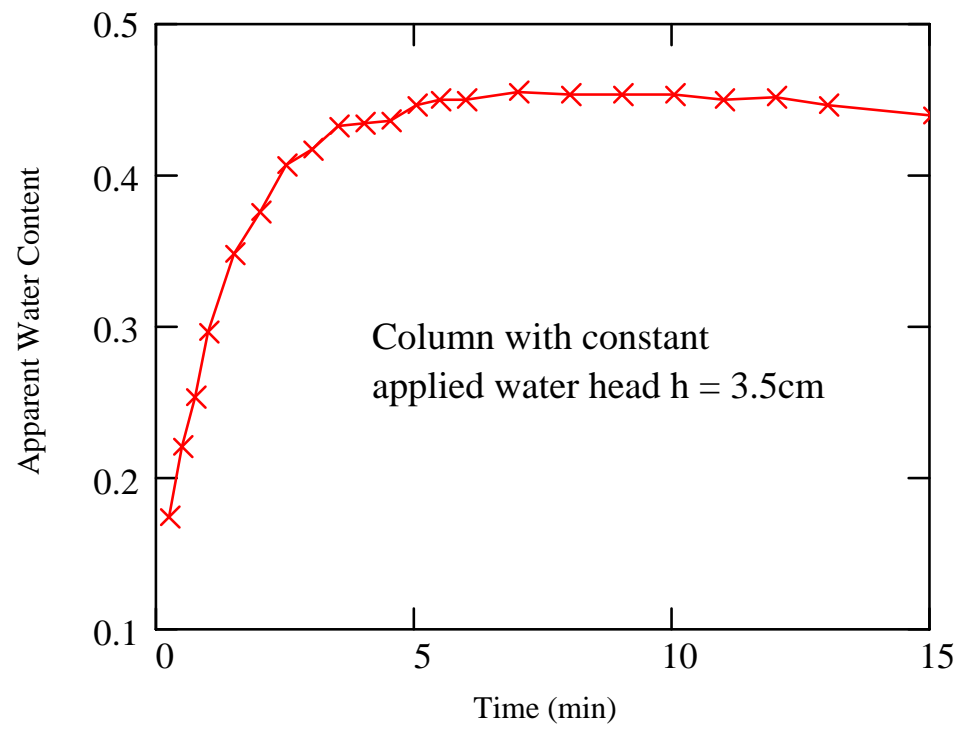

Figure 4.1. Apparent Water Content in Sand Column with Constant Head

Using this apparent porosity, $0.455 \mathrm{~cm}^{3} / \mathrm{cm}^{3}$, the Green-Ampt model parameters are determined as in Figure 4.2. The conductivity estimate is reasonably like the steady-state value, being nearly $16 \%$ smaller than the steady-state value. The conformity of the model with the measurements is very precise.

Because it is more typical to have only infiltrated volume measurements rather than direct observations of front depth, it is worth considering parameter estimation from this alternative perspective. Parameters, therefore, can be estimated instead by fitting infiltrated volume. A value of porosity based on bulk density is applied. A measured bulk density of $1.602 \mathrm{gm} / \mathrm{ml}$ and water fraction of $4.4 \%$ give available porosity equal to 0.364 . The model fit to measurements is less perfect than Figure 4.2 , but adequate and provides parameter estimates given in Table 4.1. Parameters based on porosity of $0.455 \mathrm{~cm}^{3} / \mathrm{cm}^{3}$ give front depth consistent with volume observations, but the bulk density-based value does not.

However, in using the infiltration model with the spill model, it is only necessary to model accurately the volume intake, regardless of actual front depth based on the presumed porosity. Usually, the actual front depth is not available. From Table 4.1, the appropriate value for front head is not apparent, although these values are all reasonably representative. To better estimate front head, an upward imbibing test was done, because capillarity then becomes more the driving force for water intake. The associated solution 
of Green-Ampt is given in Appendix A. The next section addresses finding the appropriate front head for the sand infiltration, in view of the range indicated by Table 4.1 .

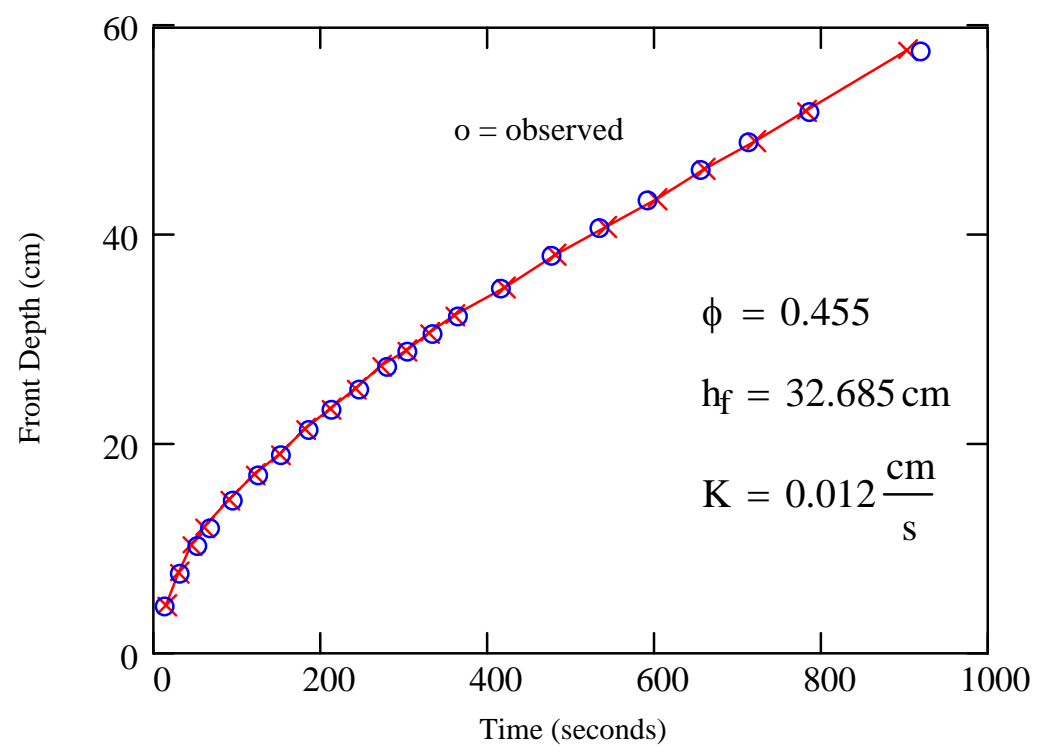

Figure 4.2. Green-Ampt Model Fit to Visible Wetting Front Depth. Curve is calculated with given parameters for constant head.

Table 4.1. Hydraulic Parameters for Sand using Green-Ampt Model

\begin{tabular}{||c|c|c|c||}
\hline \hline Conductivity $\mathbf{( c m} / \mathbf{s})$ & Front Head $\mathbf{( c m )}$ & Porosity & Data Type \\
\hline 0.0115 & 32.7 & 0.455 & Front depth \\
\hline 0.015 & 17.4 & 0.455 & Volume input \\
\hline 0.0152 & 22 & 0.364 & Volume input \\
\hline
\end{tabular}

\subsection{Front Head for Sand}

An upward infiltration test was done for sand to determine the front head. Note that this boundary condition requires a different solution of the Green-Ampt model as derived in Appendix A. In this test, the column packing was different. A similar test was also done with 3:1 cut corn syrup with the purpose of estimating the effective viscosity in sand for this more viscous liquid. In the column packed for the cut corn syrup, the bulk density was $1.43 \mathrm{~g} / \mathrm{ml}$ with moisture fraction of $4.4 \%$. These values indicate porosity of $0.493 \mathrm{~cm}^{3} / \mathrm{cm}^{3}$, and apparent porosity would be $0.433 \mathrm{~cm}^{3} / \mathrm{cm}^{3}$.

For the imbibition measurements, the intake volume is not known, but the front location is tracked, and the available porosity determines the implied amount of water drawn in.

According to Figure 4.3, the front head is estimated to be $24 \mathrm{~cm}$ for water, consistent with the range of values in Table 4.1 . 


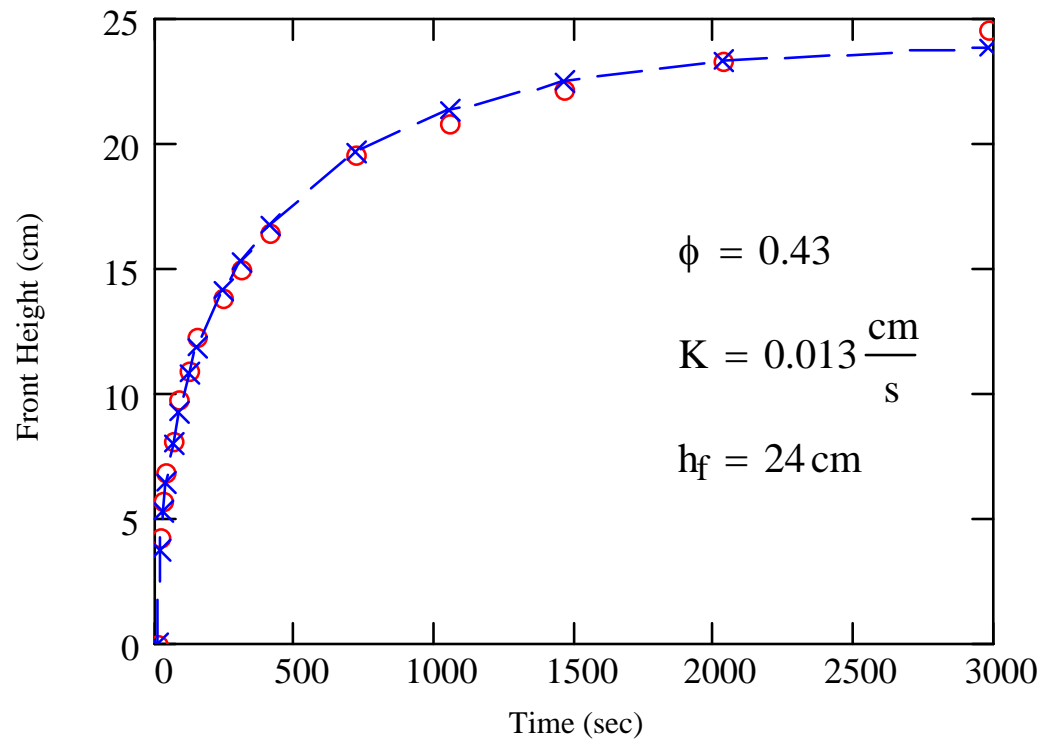

Figure 4.3. Green-Ampt Model Fit to Upward Imbibing of Water in Sand. Dashed line is computed model using shown parameters. Circles are data.

The front head values for cut corn syrup in Table 4.2 are likely more indicative of maximum visible capillary rise rather than a value that would be appropriate for downward infiltration.

The relative value of water conductivity in Table 4.2 and for cut corn syrup, for the porosity of 0.43 , indicate that viscosity of cut corn syrup is about 55 times greater than that for water, or 55 cPoise. The scaling Equation 4.4 used with Equation 4.2 is used to determine this value for viscosity. Note that the permeability $\mathrm{k}$ would be $1.31 \mathrm{E}-7 \mathrm{~cm}^{2}$.

Table 4.2. Green-Ampt Model Parameters from Imbibing Liquids in Sand

\begin{tabular}{||l|c|c|c||}
\hline \multicolumn{1}{|c|}{ Liquid } & Conductivity (cm/s) & Front Head (cm) & Porosity \\
\hline \hline Water & 0.013 & 24 & 0.43 \\
\hline Water & 0.011 & 24 & 0.364 \\
\hline Cut Corn Syrup & 0.0003 & 27.5 & 0.43 \\
\hline Cut Corn Syrup & 0.00025 & 27.5 & 0.364 \\
\hline
\end{tabular}

To conclude about the parameters for water, all estimates for conductivity are similar when obtained by different methods. An average $\mathrm{K}$ between methods of $0.0113 \mathrm{~cm} / \mathrm{s}$ is obtained with a standard deviation of $0.0017 \mathrm{~cm} / \mathrm{s}$. The front head as determined from the imbibition experiments is accepted as about $24 \mathrm{~cm}$.

\subsection{Infiltration Parameters for Non-Aqueous Liquids in Sand}

Parameters describing the infiltration behavior of cut corn syrup, pump oil, and antifreeze were obtained by performing a series of simple tests. The height of liquid is measured directly with a ruler (1/64-inch resolution) as it infiltrates following a quick pour of a specified amount. During a test, the 
rapid rise of liquid height as it is being poured cannot always be obtained manually. This first stage of infiltration while liquid is pouring lasts about 10 to 20 seconds. The second stage of infiltration, occurring while the level declines, is longer, depending on the viscosity of the particular liquid. Using the presumed porosity, the front depth can be related to the declining height.

Figure 4.4 shows a typical fit of the Green-Ampt model for a set of height measured for cut corn syrup. The first value of height, i.e., just as the liquid level begins to decline following the end of pouring, must be extrapolated from the model because it cannot be observed directly, unless a time-lapse photographic approach is used. The model solution for the declining head condition is given in Appendix A (Parts A.2 and A.3).

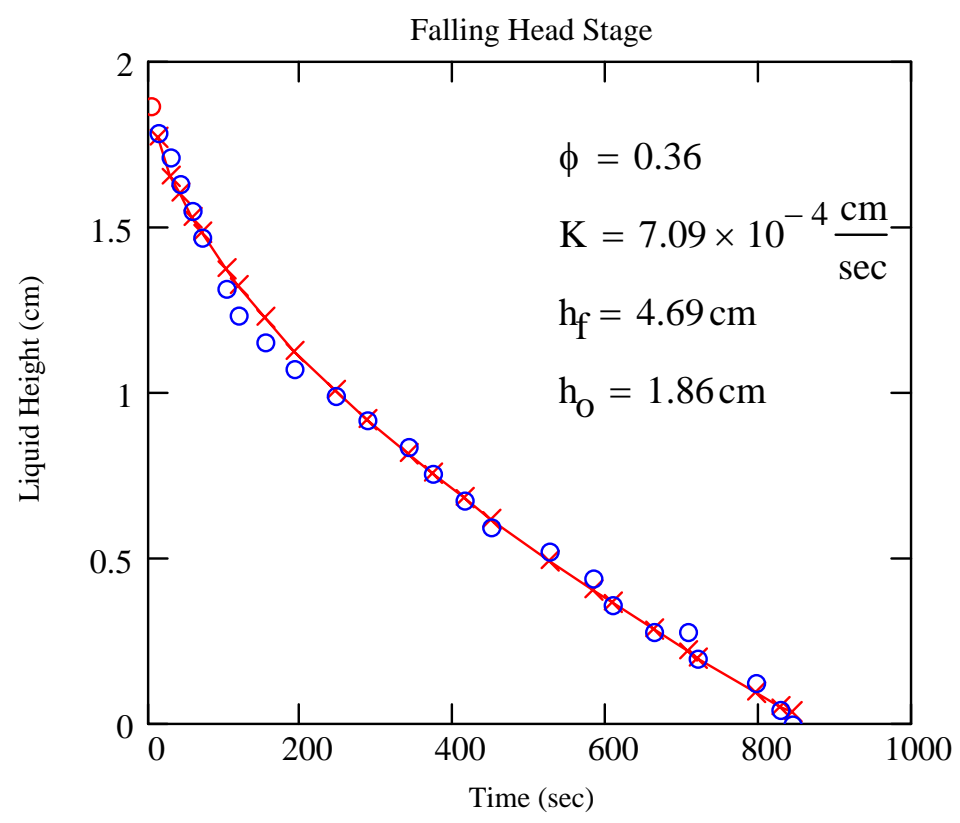

Figure 4.4. Parameters for Green-Ampt Infiltration Model for Cut Corn Syrup in Sand. Solid curve is model calculation. Circles are data.

Tables 4.3 and 4.4 provide various estimates of parameters for individual infiltration tests (replicates). The parameters, which are obtained using constrained values of front head determined to satisfy the surface tension scaling relation (Equation 4.3), are indicated. Otherwise, the fit allows all parameters, other than the assumed porosity, to be estimated together.

Tables 4.3 and 4.4 show that the estimation of infiltration parameters for liquids is subject to variability between tests. This is most likely a reflection of variable packing density for each soil column. Corn syrup and cut corn syrup do not have measured viscosity, whereas pump oil and antifreeze have known viscosity values. From the tables, it is apparent that larger conductivity and smaller front head values are found when the front head is not constrained. This is caused by the fit emphasizing the latter period of infiltration. It is known from exact analysis of the infiltration process that the front head must be a changing parameter, being greatest at the early stage and decreasing as infiltration depth increases. The present formulation of the Green-Ampt model neglects any change in the front head that depends on a prior infiltrated amount. The infiltration model as applied here presumes a constant front head is adequate. 
Table 4.3. Parameters for Green-Ampt Model fit to Infiltration of Corn Syrup and 3:1 Cut Corn Syrup in Sand

\begin{tabular}{|c|c|c|c|c|c|}
\hline Liquid & $\begin{array}{l}\text { Porosity }=0.364 \mathrm{~cm}^{3} / \mathrm{cm}^{3} \\
\text { Conductivity }(\mathrm{cm} / \mathrm{sec})\end{array}$ & $\begin{array}{l}\text { Porosity }=0.43 \mathrm{~cm}^{3} / \mathrm{cm}^{3} \\
\text { Conductivity }(\mathrm{cm} / \mathrm{sec})\end{array}$ & $\begin{array}{c}\text { Front } \\
\text { Head }(\mathrm{cm})\end{array}$ & $\begin{array}{l}\text { Initial Head } \\
\text { (cm) }\end{array}$ & $\begin{array}{c}\text { Volume } \\
\text { (mL) }\end{array}$ \\
\hline \multirow[t]{3}{*}{ 3:1 CC Syrup } & N/A & $8.41 \mathrm{E}-04$ & 2.7 & 1.856 & 21 \\
\hline & $7.10 \mathrm{E}-04$ & N/A & 4.7 & 1.863 & 21 \\
\hline & 6.87E-04 & $6.10 \mathrm{E}-04$ & $5^{\mathrm{a}}$ & 1.89 & 21 \\
\hline 3:1 CC Syrup & 5.67E-04 & $4.90 \mathrm{E}-04$ & $5^{\mathrm{a}}$ & 0.873 & 10 \\
\hline 3:1 CC Syrup & $6.47 \mathrm{E}-04$ & $5.90 \mathrm{E}-04$ & $5^{\mathrm{a}}$ & 0.79 & 10 \\
\hline 3:1 CC Syrup & $6.03 \mathrm{E}-04$ & $5.26 \mathrm{E}-04$ & $5^{a}$ & 0.955 & 10 \\
\hline 3:1 CC Syrup & N/A & 8.07E-04 & $5^{a}$ & 0.658 & 10 \\
\hline \multirow[t]{3}{*}{ Corn Syrup } & 4.91E-05 & N/A & 2.72 & 0.873 & 10 \\
\hline & N/A & 5.75E-05 & 1.65 & 0.873 & 10 \\
\hline & $4.60 \mathrm{E}-05$ & 4.06E-05 & $3^{\mathrm{a}}$ & 0.874 & 10 \\
\hline \multicolumn{6}{|c|}{$\begin{array}{l}\text { a. Constrained value under fit. } \\
\text { 3:1 CC Syrup = cut corn syrup, volume corn syrup:volume water. } \\
\text { N/A = not available }\end{array}$} \\
\hline
\end{tabular}

Table 4.4. Infiltration Parameters for Oil and Antifreeze in Sand

\begin{tabular}{|c|c|c|c|c|c|}
\hline Liquid & $\begin{array}{c}\text { Porosity }=0.364 \mathrm{~cm}^{3} / \mathrm{cm}^{3} \\
\text { Conductivity }(\mathrm{cm} / \mathrm{sec})\end{array}$ & $\begin{array}{c}\text { Porosity }=0.43 \mathrm{~cm}^{3} / \mathrm{cm}^{3} \\
\text { Conductivity }(\mathrm{cm} / \mathrm{sec})\end{array}$ & $\begin{array}{c}\text { Front } \\
\text { Head }(\mathrm{cm})\end{array}$ & $\begin{array}{l}\text { Initial Head } \\
\text { (cm) }\end{array}$ & $\begin{array}{c}\text { Volume } \\
\text { (mL) }\end{array}$ \\
\hline \multirow[t]{3}{*}{ Pump Oil } & 8.60E-04 & N/A & 1.05 & 1.2 & 15 \\
\hline & N/A & 7.40E-04 & 1.34 & $1.23^{\mathrm{a}}$ & 15 \\
\hline & 2.62E-04 & 2.10E-04 & $10.9^{\mathrm{a}}$ & 1.37 & 15 \\
\hline Pump Oil & $2.15 \mathrm{E}-04$ & $1.73 \mathrm{E}-04$ & $10.9^{\mathrm{a}}$ & 1.24 & 15 \\
\hline Pump Oil & $2.19 \mathrm{E}-04$ & $1.90 \mathrm{E}-04$ & $10.9^{\mathrm{a}}$ & 1.2 & 15 \\
\hline \multirow[t]{2}{*}{ Pump Oil } & $3.32 \mathrm{E}-04$ & $2.89 \mathrm{E}-04$ & $10.9^{\mathrm{a}}$ & 1.67 & 20 \\
\hline & N/A & $5.21 \mathrm{E}-04$ & 4.4 & 1.61 & 20 \\
\hline Pump Oil & $4.92 \mathrm{E}-04$ & N/A & 5.9 & 1.61 & 20 \\
\hline \multirow[t]{3}{*}{ Antifreeze } & $1.86 \mathrm{E}-03$ & N/A & 8.3 & 0.979 & 15 \\
\hline & N/A & 1.66E-03 & 8.1 & 0.983 & 15 \\
\hline & $1.88 \mathrm{E}-03$ & $1.64 \mathrm{E}-03$ & $8.2^{\mathrm{a}}$ & $0.986 / 0.993$ & 15 \\
\hline \multirow[t]{3}{*}{ Antifreeze } & $3.60 \mathrm{E}-03$ & N/A & 2.3 & 1.06 & 15 \\
\hline & N/A & $4.00 \mathrm{E}-03$ & 1.4 & 1.06 & 15 \\
\hline & $1.74 \mathrm{E}-03$ & $1.53 \mathrm{E}-03$ & $8.2^{\mathrm{a}}$ & $1.12 / 1.13$ & 15 \\
\hline
\end{tabular}


Tables 4.3 and 4.4 show that the 3:1 cut corn syrup was selected to have conductivity similar to the pump oil value. Antifreeze has a conductivity value about an order of magnitude greater than pump oil, and pure corn syrup has conductivity about an order of magnitude less.

By using the measured conductivity with known viscosity, the permeability of each sand pack could be estimated. If the viscosity is not known, then the presumed permeability could be used in conjunction with Equation 4.2 to estimate the apparent viscosity. An apparent viscosity would be a value that seems to describe the flow in this particular moist sand.

Table 4.5 gives an association of viscosity and permeability. For water and pump oil, the viscosity is known and assumed unchanged in the sand medium. These liquids give a definite permeability for the sand. Note that the oil gives a permeability about the same as that given by the downward and upward water infiltration tests in the long column, with the average permeability from pump oil being $1.45 \mathrm{E}-7 \mathrm{~cm}^{2}$ and standard deviation of $3.15 \mathrm{E}-8 \mathrm{~cm}^{2}$. The average permeability determined for pump oil in the small infiltration tubes is imposed on corn syrup and antifreeze to estimate their viscosity.

Table 4.5. Apparent Viscosity and Permeability for Liquid Infiltration in Sand. Values are based on conductivity for porosity of 0.43 .

\begin{tabular}{|c|c|c|c|c|c|}
\hline Liquid & $\begin{array}{c}\text { Test } \\
\text { Number }\end{array}$ & Test & $\begin{array}{c}\text { Permeability } \\
\left(\mathrm{cm}^{2}\right)\end{array}$ & $\begin{array}{l}\text { Viscosity } \\
\text { (cPoise) }\end{array}$ & $\begin{array}{l}\text { Density } \\
\text { (gm/ml) }\end{array}$ \\
\hline Water & 1 & $\begin{array}{c}\text { Downward - long } \\
\text { column }\end{array}$ & $1.3 \mathrm{E}-7$ & 1 & 1 \\
\hline Water & 1 & $\begin{array}{c}\text { Upward - long } \\
\text { column }\end{array}$ & $1.3 \mathrm{E}-7$ & 1 & 1 \\
\hline \multirow[t]{4}{*}{ 3:1 CC Syrup } & 1 & \multirow{4}{*}{$\begin{array}{c}\text { Downward - small } \\
\text { column }\end{array}$} & $2.67 \mathrm{E}-7$ & 55 & 1.28 \\
\hline & 2 & & $2.15 \mathrm{E}-7$ & 55 & 1.28 \\
\hline & 3 & & $2.59 \mathrm{E}-7$ & 55 & 1.28 \\
\hline & 4 & & $2.31 \mathrm{E}-7$ & 55 & 1.28 \\
\hline Corn Syrup & 1 & $\begin{array}{c}\text { Downward - small } \\
\text { column }\end{array}$ & $1.47 \mathrm{E}-7$ & 497 & 1.4 \\
\hline \multirow[t]{4}{*}{ Pump Oil } & 1 & \multirow{4}{*}{$\begin{array}{c}\text { Downward - small } \\
\text { column }\end{array}$} & $1.43 \mathrm{E}-7$ & 57.6 & 0.86 \\
\hline & 2 & & $1.18 \mathrm{E}-7$ & 57.6 & 0.86 \\
\hline & 3 & & $1.3 \mathrm{E}-7$ & 57.6 & 0.86 \\
\hline & 4 & & $1.97 \mathrm{E}-7$ & 57.6 & 0.86 \\
\hline \multirow[t]{2}{*}{ Antifreeze } & 1 & \multirow{2}{*}{$\begin{array}{l}\text { Downward - small } \\
\text { column }\end{array}$} & $1.47 \mathrm{E}-7$ & 9.7 & 1.1 \\
\hline & 2 & & $1.47 \mathrm{E}-7$ & 10.1 & 1.1 \\
\hline
\end{tabular}

Note that the viscosity of $55 \mathrm{cp}$ for 3:1 cut corn syrup, when applied to the small infiltration tube tests, gives a permeability about twice as large, suggesting that viscosity for this liquid is likely about half the value.

The infiltration of liquid involves two stages: 1) the liquid height rises as it pours onto a surface then 2) the liquid height declines from the initial height achieved after pouring stops. It was only possible to 
measure the liquid level decline in sand infiltration tests using the manual method. The Green-Ampt model could not be fit to actual measurements of liquid level rise during the first stage of an infiltration test because that period was usually so brief. An exception was for undiluted corn syrup. A theoretical evaluation of the first stage of infiltration indicates that the front head would have to be larger than during the longer second stage (Appendix A). This occurs because during the early stages of infiltration, just as liquid begins pouring or spreading onto a surface, the capillary-driven liquid intake is greatest. As infiltration progresses into the second stage, the standing liquid height dominates the infiltration, provided that the amount applied is sufficiently large. In the infiltration tests used in this study, it was intended that the amount spilled on the surface would produce only a relatively small height, and infiltration would be considerably influenced by capillarity intake.

Table 4.6 gives estimates of the first and second infiltration stage values of the front head. Other particular attributes of each infiltration test are also given. Table 4.6 shows that pouring finished in tens of seconds, whereas vanishing of liquid height occurred in hundreds of seconds. This held for spills with about a centimeter of liquid height. The values of front head are consistent with the liquid conductivity given for porosity of 0.43 , as given in Table 4.4 .

Table 4.6. Front Head for Liquid Infiltration Tests in Sand. Height max is equivalent to the amount of liquid applied in each specific tube.

\begin{tabular}{|c|c|c|c|c|c|c|c|}
\hline Liquid & $\begin{array}{c}\text { Test } \\
\text { Number }\end{array}$ & $\begin{array}{c}\text { Pour } \\
\text { Time } \\
\text { (s) }\end{array}$ & $\begin{array}{c}\text { Infiltrate } \\
\text { Time (s) }\end{array}$ & $\begin{array}{c}\text { Height } \\
\text { Max (cm) }\end{array}$ & $\begin{array}{c}\text { Height } \\
\text { Initial }(\mathbf{c m})\end{array}$ & $\begin{array}{c}\text { Front } \\
1^{\text {st }} \text { Rise }\end{array}$ & $\begin{array}{c}\text { Head }(\mathrm{cm}) \\
2^{\text {nd }} \text { Fall }\end{array}$ \\
\hline \multirow[t]{5}{*}{ 3:1 CC Syrup } & 1 & 10 & 842 & 2.006 & 1.786 & 8.2 & 5.9 \\
\hline & 2 & 8 & 247 & 0.955 & 0.772 & 9.5 & 6.6 \\
\hline & 3 & 11 & 231 & 0.955 & 0.684 & 12.7 & 5.6 \\
\hline & 4 & 9 & 244 & 0.955 & 0.898 & 0.3 & 7.7 \\
\hline & 5 & 7 & 187 & 0.955 & 0.658 & 17.7 & 5.0 \\
\hline Corn Syrup & 1 & 124 & 5064 & 0.955 & 0.80 & 5.1 & 3.6 \\
\hline \multirow[t]{4}{*}{ Oil } & 1 & 11 & 736 & 1.433 & 1.228 & 20.4 & 11.8 \\
\hline & 2 & 15 & 870 & 1.433 & 1.157 & 33.3 & 11.6 \\
\hline & 3 & 20 & 905 & 1.433 & 1.206 & 15.0 & 10.9 \\
\hline & 4 & 15 & 1020 & 1.910 & 1.663 & 15.4 & 10.3 \\
\hline \multirow[t]{3}{*}{ Antifreeze } & 1 & 5 & 106 & 1.433 & 0.908 & 21.8 & $8.2^{\mathrm{a}}$ \\
\hline & 2 & 8 & 119 & 1.433 & 0.947 & 24.2 & 9.4 \\
\hline & 3 & 8 & 134 & 1.433 & 0.955 & 25.2 & 9.7 \\
\hline
\end{tabular}

The values of front head given in Table 4.4 are first estimates for the second stage infiltration, generally imposed to be consistent with surface tension scaling relative to water. Values of front head in Table 4.6 can be regarded as corrections. The first stage front heads are typically larger than the second stage values. Only one exception occurred for cut corn syrup (test 4); it is attributed to an inaccurate trend in the original measurement of liquid level decline. For the size of spills performed in this study, the front head associated with the early first stage of infiltration should be considered most appropriate. 
The performed spills had only, at most, a few millimeters of maximum liquid height, and are most likely controlled by first stage infiltration as when liquid is applied.

\subsection{Infiltration Parameters for Non-Aqueous Liquids in Silt Loam}

Silt loam constitutes a much less permeable soil and an opportunity to further develop a photographic technique for obtaining infiltration parameters. Saturated hydraulic conductivity of silt loam was measured under steady-state flow conditions to be $2.33 \mathrm{E}-4 \mathrm{~cm} / \mathrm{sec}$ at bulk density of $1.6 \mathrm{~g} / \mathrm{ml}$. This indicates a permeability of $2.35 \mathrm{E}-9 \mathrm{~cm}^{2}$, about $1 / 100$ of that for sand. Dry, sifted silt loam is fine powderlike material, and a small amount of water needs to be mixed into it to make it possible to pack into containers. The packing density of this soil had to be managed to produce consistent permeability for measuring infiltration parameters.

Because silt loam has such small permeability compared with sand, it was apparent that only liquids with low viscosity would exhibit sufficiently rapid infiltration coupled with spills. Cut corn syrup diluted with water at a 1-to-1 volume ratio was selected to study infiltration. Infiltration was measured for water, dodecane, pump oil, antifreeze, and the 1:1 cut corn syrup. Some infiltration time measurements were also obtained for some other automotive liquids: power steering fluid, U.S. Department of Transportation \#3 brake fluid, and transmission fluid. The hypothesis is that even if spills were not done directly for these liquids on the soil, a capability to describe infiltration would be adequate to make predictions using the spill model. Unfortunately, small test spills of 1:1 cut corn syrup on pans packed with silt loam indicated that unstable spreading patterns would develop if poured rapidly on even a slightly inclined surface. Therefore, no mesoscale-size spills of low viscosity liquids, dodecane or 1:1 cut corn syrup, were performed on silt loam. Nevertheless, infiltration studies were performed for some low viscosity liquids.

The photographic technique was used to produce high-accuracy measurements of infiltration parameters for silt loam. Figure 4.5 shows the measured liquid height and front depth extracted from a timelapse move of water infiltration. The sample points shown were selected from photos taken at 30 frames per second. A subset of the total number of available move frames is adequate to track the front advance and liquid level decline with time. The specific time of each measurement is recorded on each selected photo frame.

The rate at which water is poured on the surface is shown in Figure 4.6. A constant rate of pouring was attempted, but this occurs only approximately, as indicated by Figure 4.6, which shows a straight line for constant rate. The mathematical technique devised here for fitting the Green-Ampt model takes into account the actual pouring rate variation in any case. An effective liquid content for infiltration during the first stage is determined by the liquid above the surface and absorbed in the soil at the end of pouring. That is, final amount $=$ height + porosity $\times$ depth, where porosity is the volume fraction filled with liquid. This estimate of porosity may differ from that appropriate for the second stage (falling head) infiltration.

Figure 4.7 shows the fit of the Green-Ampt model to the infiltration during the first stage with rising liquid height. The particular input trend in Figure 4.6 is accounted for (Appendix A, Part A.7). To determine the likely front head, the conductivity is constrained to the steady-state measurement. 

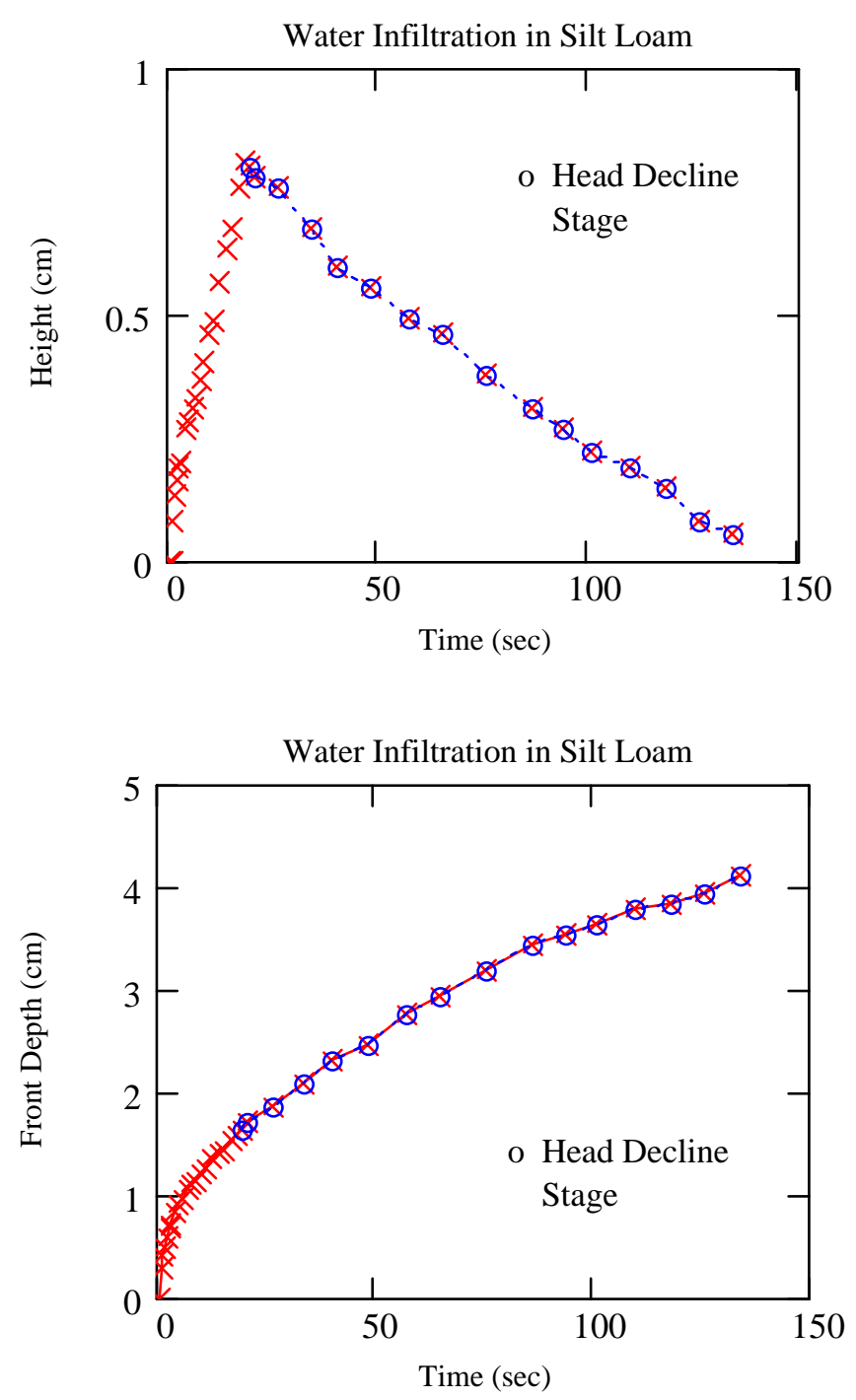

Figure 4.5. Infiltration Measurements of Water into Silt Loam. Two stages of infiltration are shown: 1) rising head during pouring and 2) falling head (circles) as liquid sinks into surface.

In general, neither the conductivity nor front head can be determined accurately by fitting them simultaneously because the data do not conform exactly to the model. In fact, certain systematic departures between model and trend in the measurements can be seen in Figure 4.7. A simultaneous optimal fit of the model yields $1.9 \mathrm{E}-4 \mathrm{~cm} / \mathrm{s}$ and $130 \mathrm{~cm}$ for conductivity and front head, respectively. But deviation from the data is reduced only insignificantly by this optimal fit. The fit of Figure 4.7 is adequate to describe the amount of liquid infiltrated as liquid first arrives on the surface.

Figure 4.8 shows the model fit for the falling head stage of infiltration. An unconstrained fit of both conductivity and front head would yield values not truly representative of the soil. Assuming the soil must manifest the same conductivity regardless of infiltration stage, the front head must decrease for the second stage. As noted before, typically the front head would have to decrease continuously to describe infiltration exactly for all times. Note also, the liquid saturated porosity, denoted phi, would increase into 
the second stage. In this effort to calibrate the infiltration model, the first stage infiltration is made much longer than is relevant for a spill. That exaggeration is done to demonstrate the first stage character relative to the second stage. Figure 4.8 shows that the simplified model is quite adequate to describe water infiltration during the remainder of time it takes the liquid to be completely infiltrated.

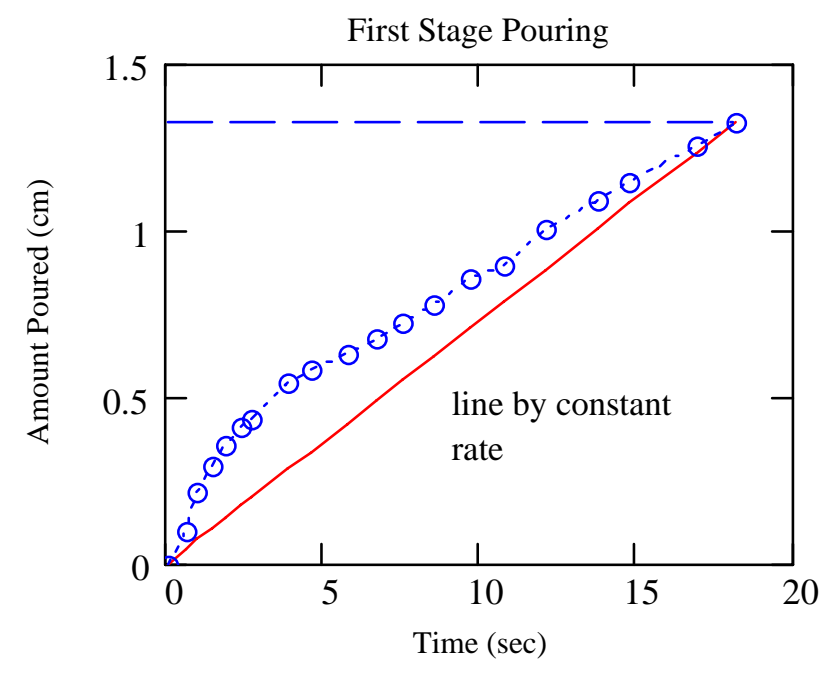

Figure 4.6. Pouring Rate of Water on Silt Loam Surface. Amount poured is equivalent height of liquid over infiltration tube's cross sectional area. Straight line shows a constant rate from start to finish. Circles indicate actual data.

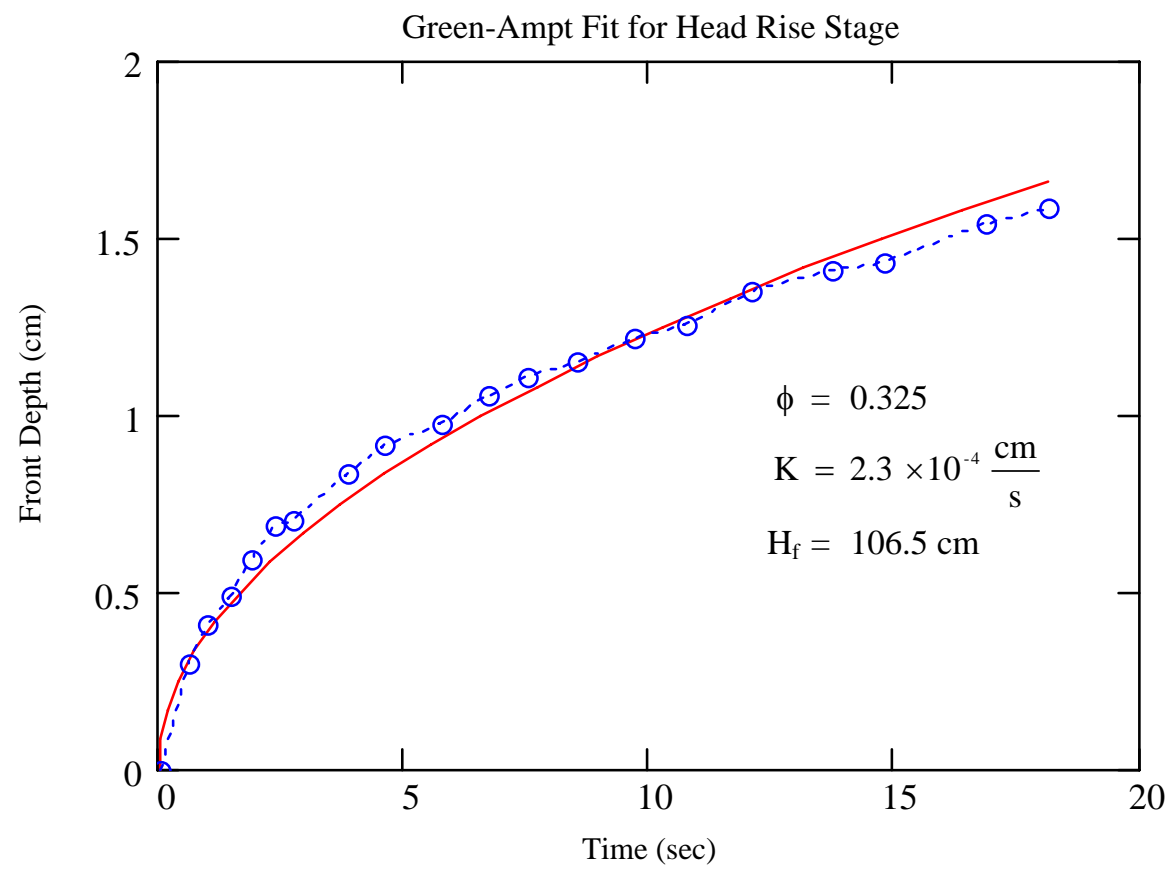

Figure 4.7. Green-Ampt Infiltration Model Fit for Water in Silt Loam. Data are circles. Solid line is model based on parameters for first stage rising head. 


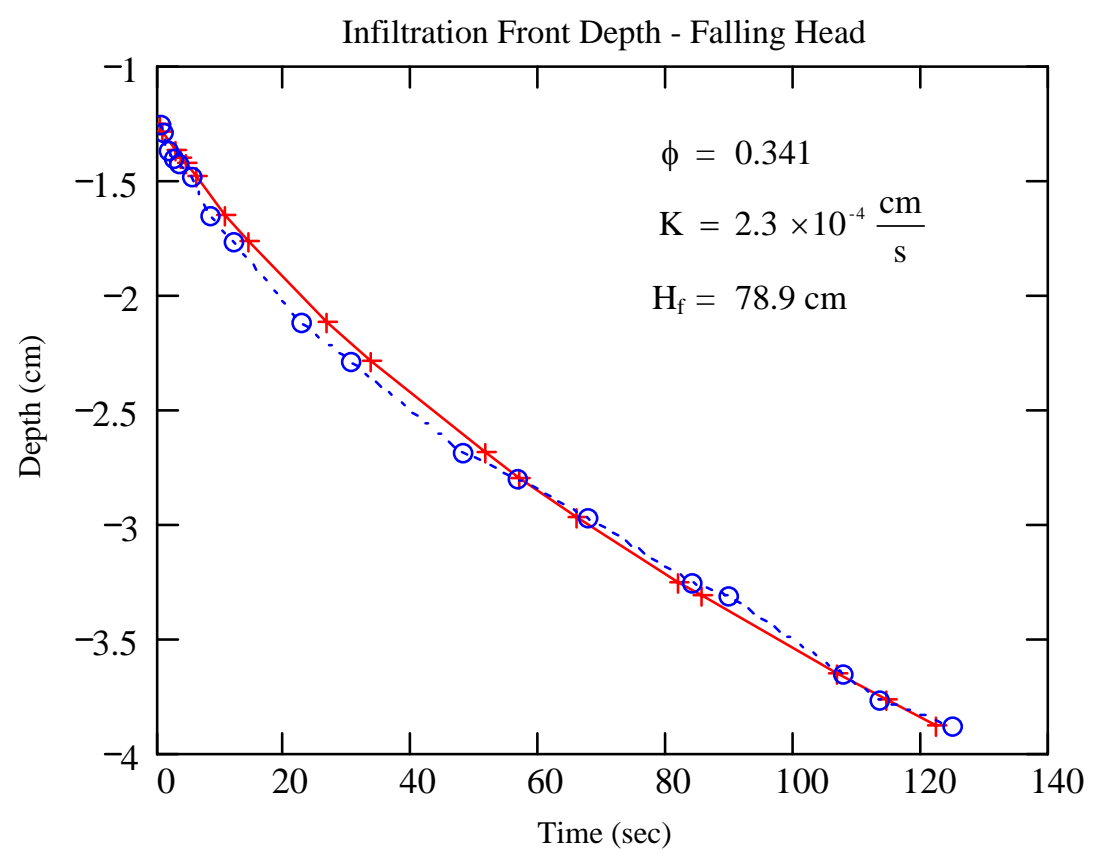

Figure 4.8. Front Depth for Water in Silt Loam for Falling Head Stage

The infiltration of liquids other than water was tested in silt loam to evaluate the correctness of the scaling hypothesis used to convert infiltration parameters for water into those appropriate to another liquid. Table 4.7 gives the names of liquids used in infiltration tests along with the attributes of the spill pouring.

Table 4.7. Attributes of Infiltration Tests in Silt Loam

\begin{tabular}{||c|c|c|c|c|c|c||}
\hline \multirow{2}{*}{ Liquid } & $\begin{array}{c}\text { Test } \\
\text { Number }\end{array}$ & $\begin{array}{c}\text { Pour Time } \\
\mathbf{( s e c )}\end{array}$ & $\begin{array}{c}\text { Vanish Time } \\
\mathbf{( s e c )}\end{array}$ & $\begin{array}{c}\text { Amount } \\
\text { Depth (cm) }\end{array}$ & $\begin{array}{c}\text { Height (cm) } \\
\text { End Stage 1 }\end{array}$ & $\begin{array}{c}\text { Bulk Density } \\
\text { (gm/ml) }\end{array}$ \\
\hline \multirow{3}{*}{ Water } & 1 & 2.87 & 68.4 & 0.825 & 0.762 & 1.293 \\
\cline { 2 - 7 } & 2 & 11.87 & 136.4 & 1.325 & 1.314 & 1.263 \\
\cline { 2 - 7 } & 3 & 18.1 & 133.6 & 1.325 & 0.811 & 1.252 \\
\hline \multirow{3}{*}{ Dodecane } & 1 & 33.1 & 121.2 & 1.325 & 0.608 & 1.261 \\
\cline { 2 - 7 } & 2 & 25.3 & 101.5 & 1.325 & 0.676 & 1.231 \\
\hline \multirow{2}{*}{ Antifreeze } & 1 & N/A & 660 & 0.825 & 0.825 & 1.182 \\
\cline { 2 - 7 } & 2 & N/A & 760 & 0.825 & 0.825 & 1.181 \\
\hline N/A = not available.
\end{tabular}

The photographic method of obtaining infiltration parameters by fitting the Green-Ampt model was applied to the liquids listed as described above for water. Table 4.8 gives the results for the estimation of parameters. The calculation for antifreeze, however, used the direct measurement method of using a ruler. This was adequate because antifreeze had relatively high viscosity and absorbed slowly in silt loam. 
Table 4.8. Infiltration Model Parameter Estimates for Silt Loam

\begin{tabular}{|c|c|c|c|c|c|c|c|c|c|}
\hline \multirow[b]{2}{*}{ Liquid } & \multirow{2}{*}{$\begin{array}{c}\text { Test } \\
\text { Number }\end{array}$} & \multicolumn{2}{|c|}{ Porosity } & \multicolumn{2}{|c|}{$\begin{array}{c}\mathrm{K} \\
(\mathrm{cm} / \mathrm{sec})\end{array}$} & \multicolumn{2}{|c|}{$\begin{array}{l}\text { Front Head } \\
\text { (cm) }\end{array}$} & \multicolumn{2}{|c|}{$\begin{array}{l}\text { Std Error } \\
\text { (cm) }\end{array}$} \\
\hline & & Stage 1 & Stage 2 & Stage 1 & Stage 2 & Stage 1 & Stage 2 & Stage 1 & Stage 2 \\
\hline \multirow[t]{6}{*}{ Water } & \multirow{2}{*}{1} & 0.16 & 0.28 & $2.29 \mathrm{E}-4$ & 2.17E-4 & 54.5 & 81.1 & 0.033 & 0.032 \\
\hline & & 0.16 & 0.28 & $2.30 \mathrm{E}-4^{\mathrm{a}}$ & $2.30 \mathrm{E}-4^{\mathrm{a}}$ & 54.2 & 76.6 & 0.033 & 0.032 \\
\hline & \multirow{2}{*}{2} & 0.37 & 0.34 & $2.39 \mathrm{E}-4$ & $9.20 \mathrm{E}-5$ & 99.3 & 201.0 & 0.04 & 0.056 \\
\hline & & 0.37 & 0.34 & $2.30 \mathrm{E}-4^{\mathrm{a}}$ & $2.30 \mathrm{E}-4^{\mathrm{a}}$ & 102.7 & 78.7 & 0.04 & 0.056 \\
\hline & \multirow{2}{*}{3} & 0.325 & 0.31 & $1.88 \mathrm{E}-4$ & $9.47 \mathrm{E}-5$ & 130.6 & 205.4 & 0.052 & 0.045 \\
\hline & & 0.325 & 0.31 & $2.30 \mathrm{E}-4^{\mathrm{a}}$ & $2.30 \mathrm{E}-4^{\mathrm{a}}$ & 106.5 & 83.0 & 0.052 & 0.046 \\
\hline \multirow[t]{4}{*}{ Dodecane } & \multirow{2}{*}{4} & 0.382 & 0.37 & $9.45 \mathrm{E}-5$ & 8.18E-5 & 233.0 & 294.3 & 0.078 & 0.037 \\
\hline & & 0.382 & 0.37 & $1.15 \mathrm{E}-4^{\mathrm{a}}$ & $1.15 \mathrm{E}-4^{\mathrm{a}}$ & 191.5 & 208.6 & 0.078 & 0.038 \\
\hline & \multirow{2}{*}{5} & 0.35 & 0.39 & $1.18 \mathrm{E}-4$ & $5.76 \mathrm{E}-5$ & 205.4 & 343.5 & 0.049 & 0.028 \\
\hline & & 0.35 & 0.39 & $1.15 \mathrm{E}-4^{\mathrm{a}}$ & $1.15 \mathrm{E}-4^{\mathrm{a}}$ & 211.2 & 170.9 & 0.049 & 0.028 \\
\hline \multirow[t]{3}{*}{ Antifreeze } & 6 & -- & 0.289 & -- & $2.70 \mathrm{E}-5$ & -- & 64.7 & -- & 0.054 \\
\hline & \multirow{2}{*}{7} & -- & 0.281 & -- & $3.50 \mathrm{E}-5$ & -- & 41.4 & -- & 0.034 \\
\hline & & -- & 0.281 & -- & $2.70 \mathrm{E}-5^{\mathrm{a}}$ & -- & 54.4 & -- & 0.035 \\
\hline
\end{tabular}

Table 4.8 reveals that fluid-medium property scaling does not work for dodecane because a much greater front head is required to predict infiltration rate. It is interesting that magnified pictures of the dodecane fronts showed fingering in the front advance at a small length scale. Unstable infiltration behavior may contribute to the lack of conformity to the scaling principle. Antifreeze indicated that the effective viscosity was only about half of the $20 \mathrm{cp}$ reported for room temperature. In addition, the front head scaling indicates that surface tension was effectively twice than the $26.5 \mathrm{dyne} / \mathrm{cm}$ expected. The change in the apparent physical properties may have been influenced by the presence of water in the silt loam, which included about $6 \%$ water by dry weight.

\subsection{Receding Spill Perimeter}

The continual advance of the spill area as seen on the wetted soil surface is emphasized by Figures 3.1 through 3.6. This wetted area is actually the subsurface domain indicating where liquid has sunk into the soil. This wetted area always increases over time until reaching a maximum. Liquid seen on the surface, however, increases to a maximum area and then diminishes to the vanishing point as the surface liquid recedes.

Figures 4.9 through 4.11 show a sequence of snap shots of antifreeze poured quickly on an inclined sand surface. Refer to Table 2.1 (second antifreeze spill for April 22) for details about this spill.

In Figure 4.9, directly at the end of pouring $400 \mathrm{ml}$ quickly, the reflective liquid covers essentially the entire subsurface area. Then in Figure 4.10, 6 seconds after the pouring stopped, the trailing edge of the standing liquid is seen. By 9 seconds after the pouring, Figure 4.11 shows the liquid is about to vanish. The standing liquid area is well inside the maximum subsurface area wetted, seen as a regular, dark elliptical shape. The reflective liquid area is now very irregular in shape and reveals locations where 
liquid infiltration was apparently more rapid, leaving dried spots. This variation in drying indicates variability in the hydraulic properties of the packed sand even though the sand surface was rolled to produce a smooth, evenly packed surface.

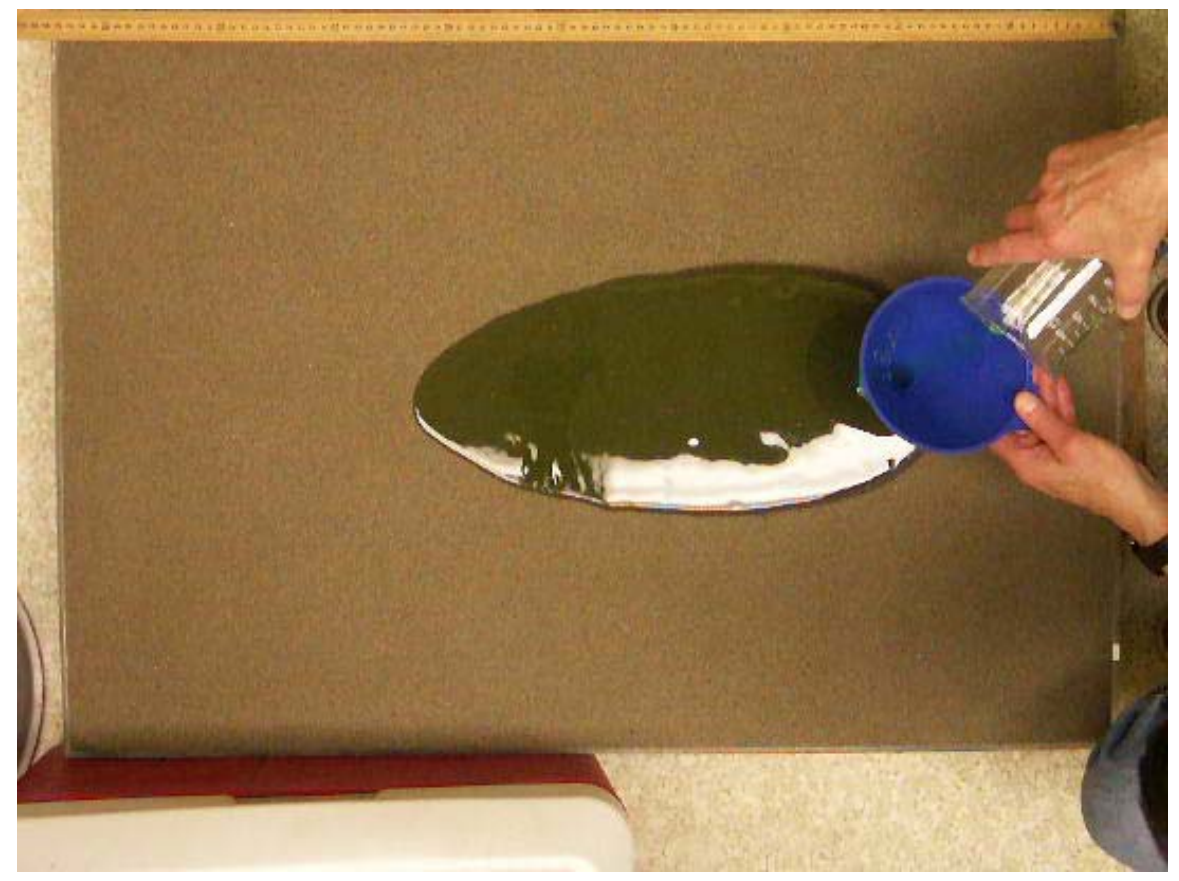

Figure 4.9. Spill of Antifreeze on Sand Surface Tilted 4.8 Degrees. Shown at end of a 10 -second pouring of $400 \mathrm{ml}$. (Date: April 22, 2005)

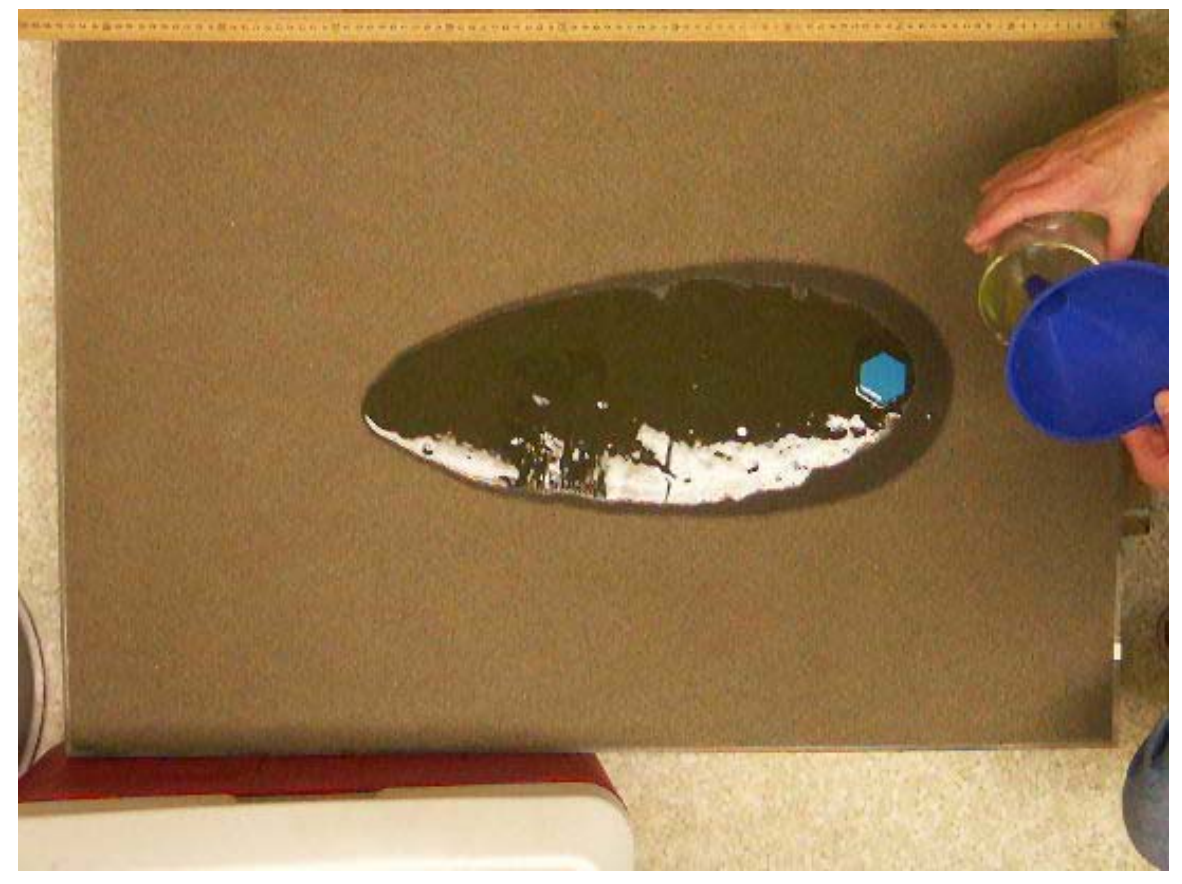

Figure 4.10. Spill of Antifreeze on Sand Surface Tilted 4.8 Degrees. Surface liquid is shown 16 seconds after start of pour: 6 seconds after end of pour. (Date: April 22, 2005) 


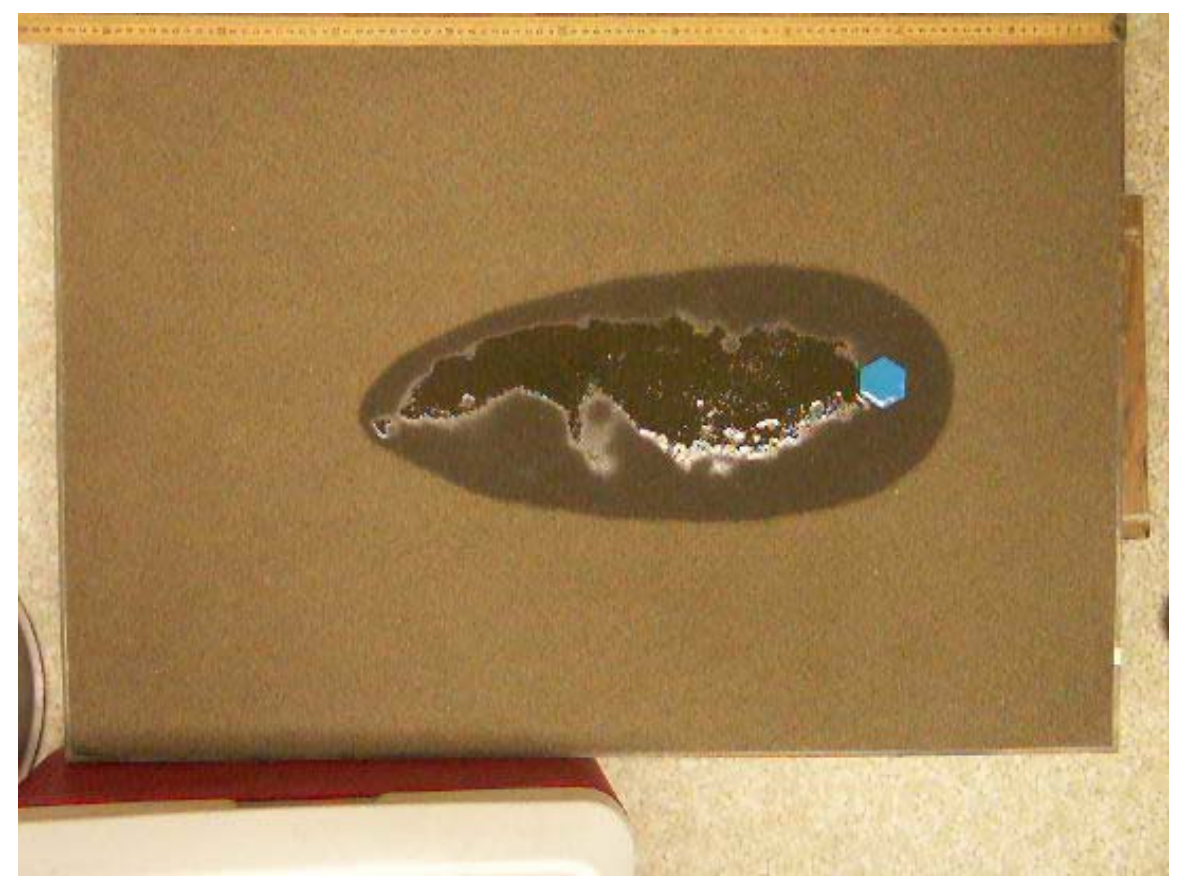

Figure 4.11. Spill of Antifreeze on Tilted Sand Surface. Surface liquid is shown 9 seconds after end of pour. (Date: April 22, 2005)

The spill model to be demonstrated in the next section is designed so that both the development of the subsurface area and progression of the standing liquid are predicted. Accuracy of such predictions, however, must be expected to be less than perfect because of the unknown and unaccounted hydraulic variability affecting each spill.

\subsection{Unstable Spill Progression}

Spills do not always develop in a regular symmetrical shape. Figure 4.12 shows the first antifreeze spill on April 22, as listed in Table 2.1. As seen in the time lapse photographs, jets or streams of liquid shoot outward from the pointed edges of the small blue pad used to deflect the pour from the funnel's tip. These streams produce protrusions in the spill shape as it progressed. A stream is seen jetting in the direction of ten o'clock. Definite layers of liquid are seen also as reflections from the raised surfaces. Eventually, as the short-duration spill finished, the final area became more regular in shape, but still did not take the ideal elliptical pattern. This phenomenon is complex beyond the capabilities of the current modeling theory because it is not characterized or predictable. Even so, it is consistent with a replicate test that advanced in a more predictable fashion (Figures 4.9 through 4.11). In the second spill case for antifreeze that day, we learned to pour the liquid into the funnel more slowly, and not to allow the liquid to swirl around on the side of the funnel as it ran out. Note that slow pours of liquid were controlled by limited flow rate through a small funnel (see Figure 2.1), whereas fast pours were done through a larger outlet funnel, which never actually filled as liquid was poured through it (Figure 4.12). These fast pours were more subject to aberrations in the outlet liquid stream. These observations demonstrated the importance of having a controlled pouring stream when attempting to create a regular-shaped spill. 


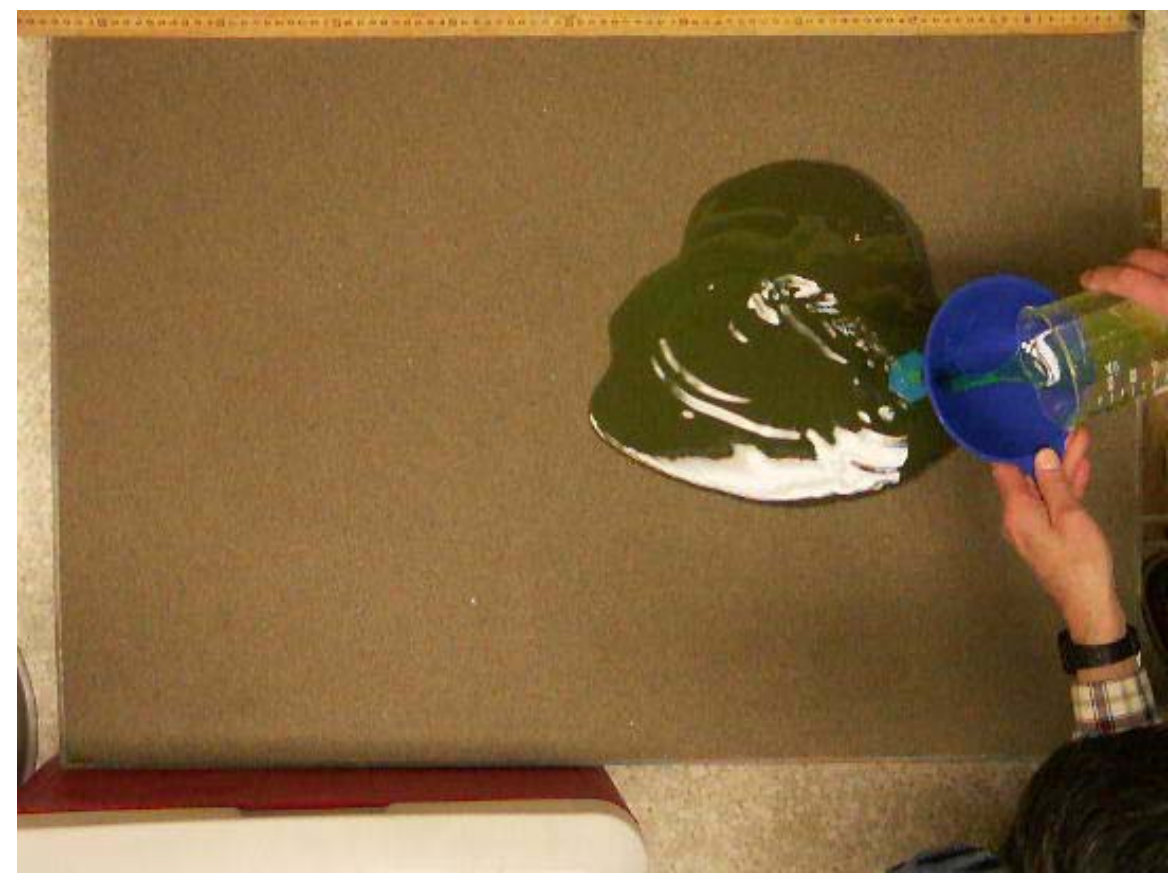

Figure 4.12. Spill of Antifreeze on Sand Surface Inclined 4.8 Degrees. Pour is 6 seconds in duration and 400 ml. (Date: April 22, 2005) 


\subsection{Comparing Observed Spills with Model Simulations}

A spill model for special circumstances was developed and tested, as previously discussed, by Keller and Simmons (2005). The model is based on coupling between gravity, current flow, and infiltration (Green-Ampt model) of a liquid into a porous substrate. Presently, the spill model does not account for surface irregularity and certain interfacial phenomena occurring at the leading edge (nose) of a spill. An objective of this study is to determine what modifications are potentially required to make the model's prediction capability commensurate with observations of spill propagation behavior.

\subsection{Simulations and Comparisons}

This section demonstrates comparisons of the spill experiments and predictions made with the model. The comparisons demonstrate a validation of the model's capabilities and its limitations.

\subsubsection{Cut Corn Syrup Spill on Sand}

A spill of cut corn syrup on the sand surface is the first example simulated. The $600 \mathrm{ml}$ pour is slow over 150 seconds. Figure 5.1 shows the liquid height and depth below surface defining the spill area.
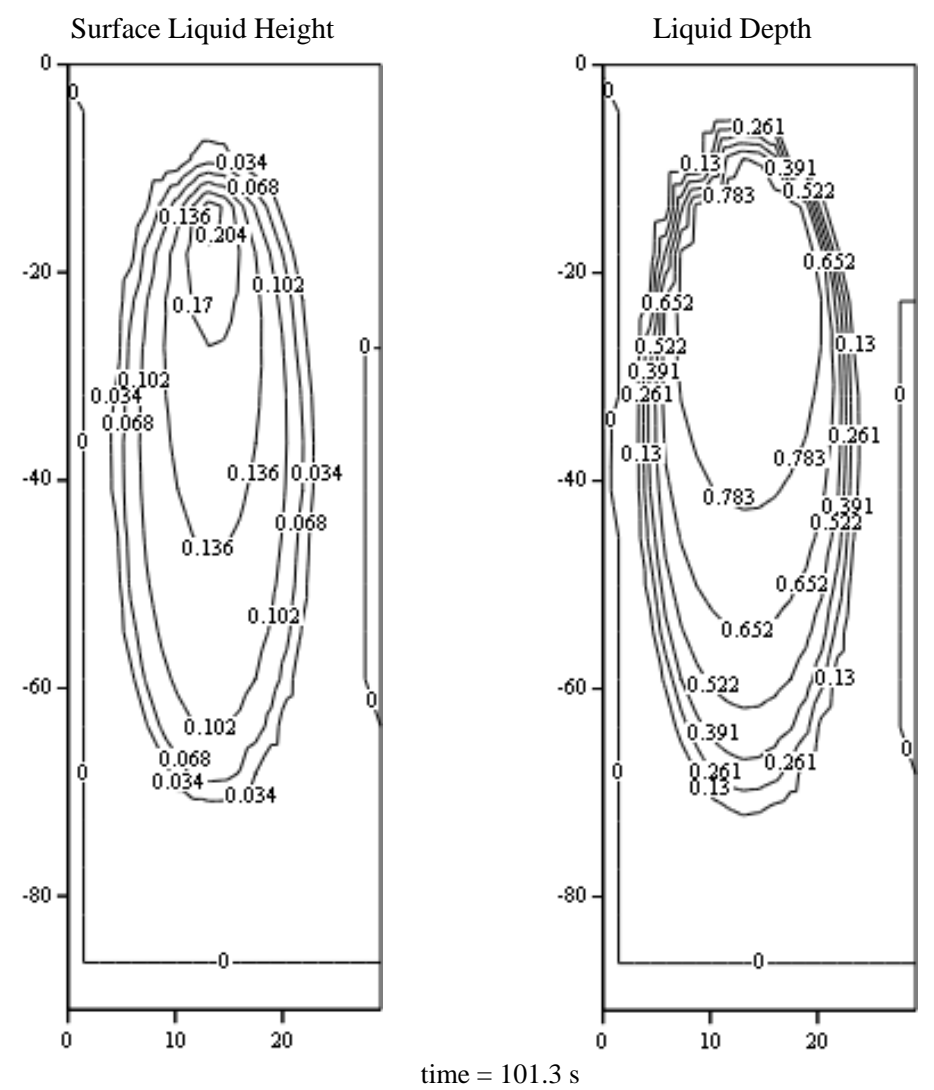

Figure 5.1. Spill Contours of 3:1 Cut Corn Syrup on Sand Surface Tilted 4.8 Degrees. Liquid level above surface is shown on left, depth on right. All units are $\mathrm{cm}$. Spill is $600 \mathrm{ml}$ with duration of 150 seconds. 
The greater height of the pour location is seen at the top, left side of the figure. At a time before the pouring is completed, the areas above and below soil surface are about the same. Those areas are delimited by the outer contours in each plot.

In Figure 5.2, the surface liquid remains mostly at the front leading edge of the spill, the lower portion of the left contour plot. The standing liquid area is diminished compared with the subsurface area. Also, the liquid thickness or height is very small, at less than a millimeter.

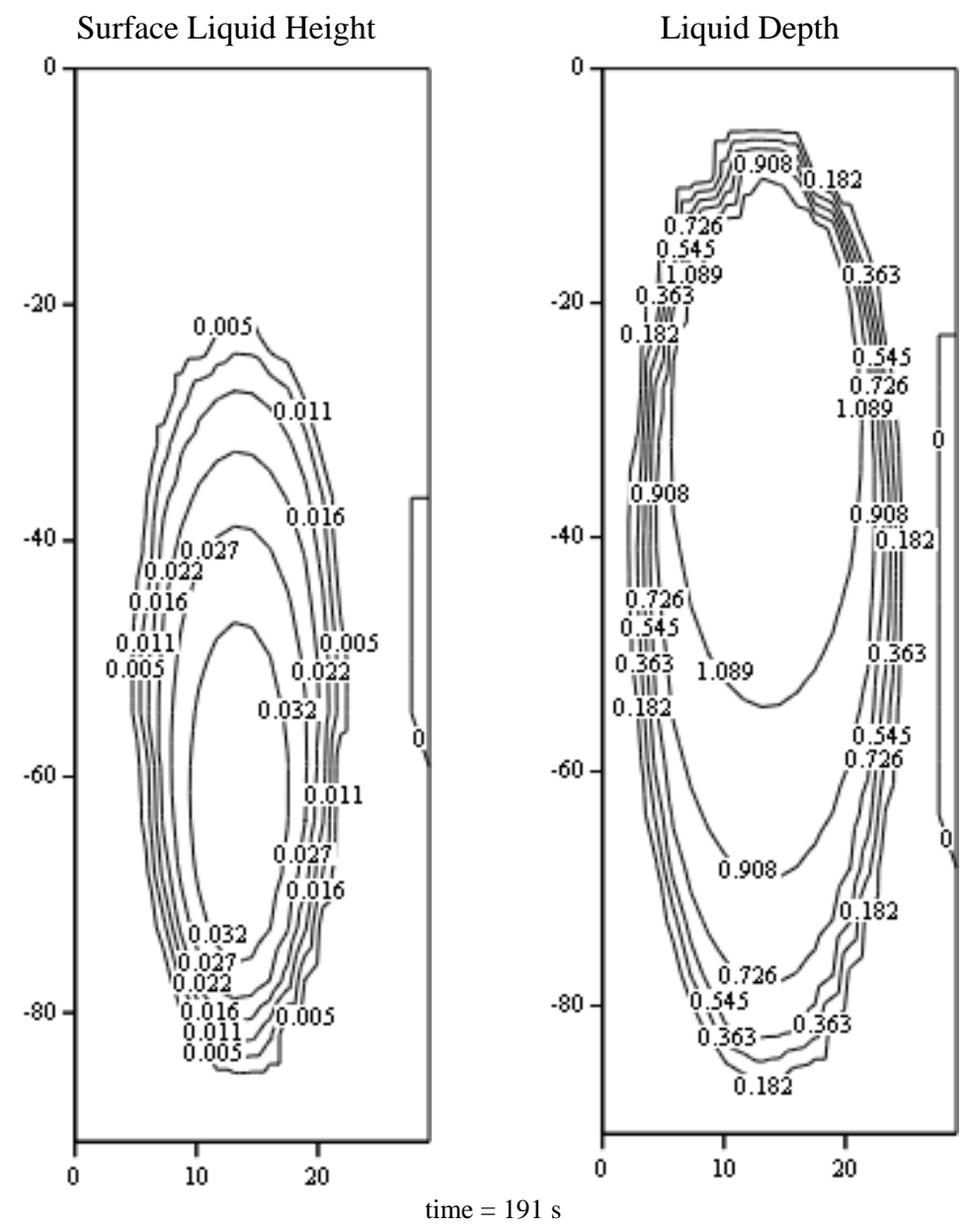

Figure 5.2. Spill Contours of Cut Corn Syrup on Sand. Regions are shown 41 seconds after the end of pouring.

Plots such as Figures 5.1 and 5.2 provide a visualization of the simulation region, but do not adequately quantify how major spill attributes evolve with time. In view of the typical irregular shape of actual spills, only the major geometrical features can be relevantly compared. These defining spill features might be the overall length and width, measured along the widest parts of the spill area and the visible spill area on the surface covering the infiltrated depth.

In Figure 5.3, the liquid present on the surface is shown compared with the total amount spilled. The surface liquid vanishes in about 50 seconds after the pouring stops. Note that 200 seconds for the spill to vanish is a value similar to that found in Table 2.1. 


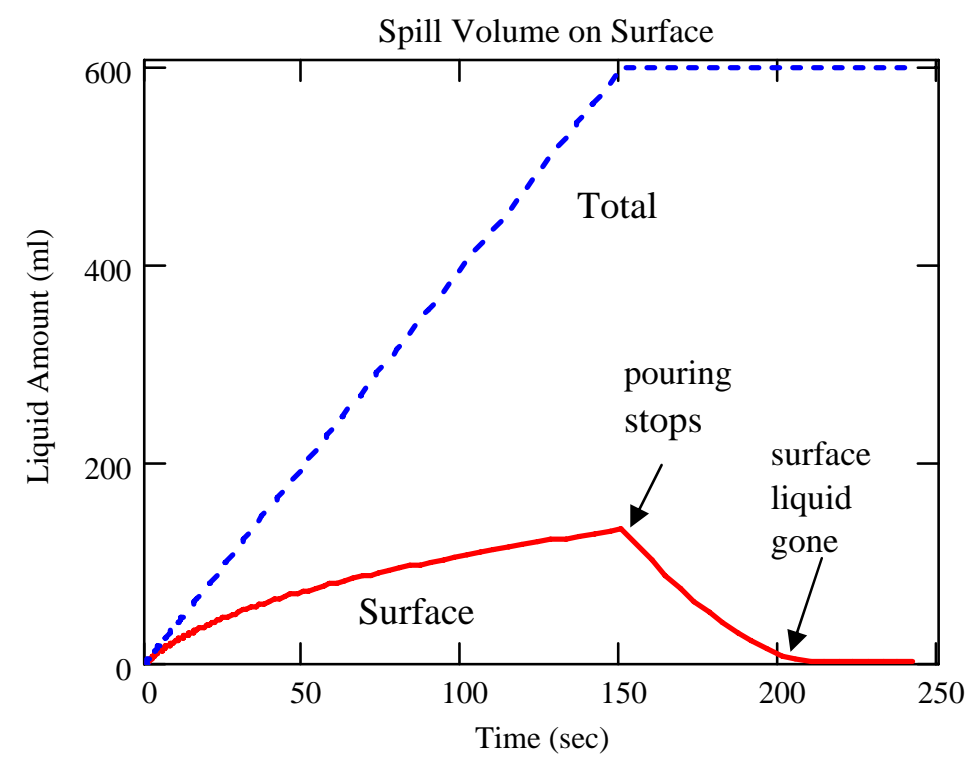

Figure 5.3. Volume of Total Liquid Spilled and on Surface. Amounts are for the spill of cut corn syrup on a sand surface tilted 4.8 degrees, $600 \mathrm{ml}$ poured during 150 seconds.

Figure 5.4 provides a plot of the spreading areas above and below surface over time. The predicted areas are considerably larger than actually observed. Aside from the influence of the particular development of the area's geometrical shape, the actual cut corn syrup apparently infiltrated more quickly into the sand than predicted.

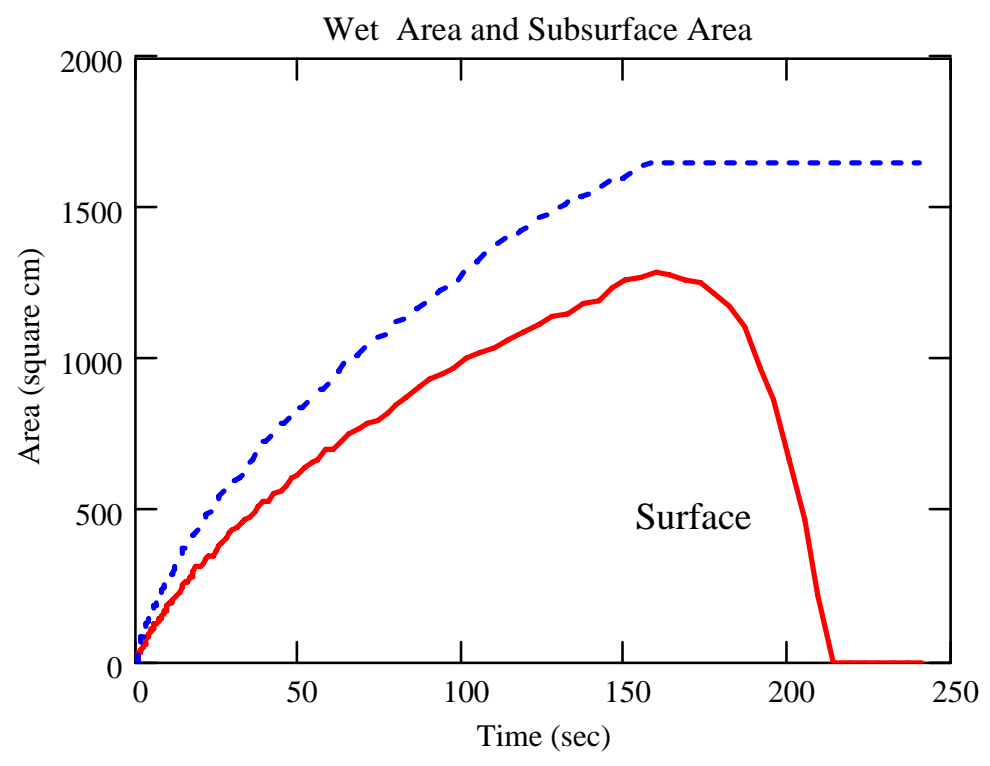

Figure 5.4. Spill Area of Cut Corn Syrup on a Sand Surface. Wet area on the surface is shown as a solid red curve. 
The cut corn syrup spill simulation shown in Figures 5.1 through 5.4 is based on using a front head of about $5 \mathrm{~cm}$, as indicated by the second stage infiltration test. Presuming that the permeability was applicable to the actual spill, the front head strongly influenced the spreading prediction. A much greater front head estimated by the first stage infiltration test in sand representing an increased capillary suction may be more applicable. Using that greater front head, which is increased to $20 \mathrm{~cm}$, the curves in Figure 5.4 are lowered so that about $1000 \mathrm{sq} \mathrm{cm}$ is the resulting subsurface area, and $750 \mathrm{sq} \mathrm{cm}$ is the maximum area with standing liquid. The time dependent characteristics of the area curves are not changed by an increase in front head, so another set of plots is not shown. The latter area predictions based on an increased front head are more comparable with those given in Table 2.1.

Figure 5.5 does give the increase-in-spill dimensions, i.e., length versus width, associated with using the increased front head estimate. From Figure 5.5, it is apparent that the actual spill length is longer, and the width is narrower. The actual spill was more elongated than the model predicted, as verified by

Figure 3.6.

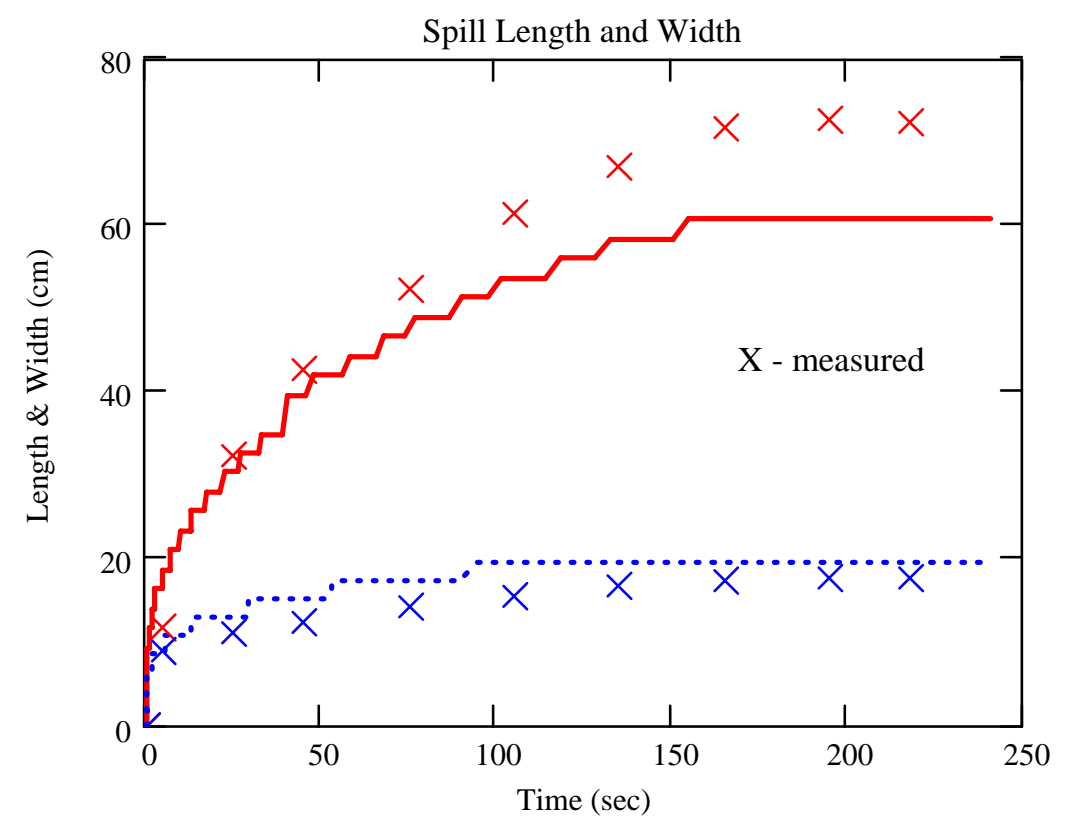

Figure 5.5. Spill Dimensions for Cut Corn Syrup on Sand Tilted 4.8 Degrees. Simulation based on front head of $20 \mathrm{~cm}$. Spill volume is $600 \mathrm{ml}$ over 150 seconds.

When the tilt angle is decreased to 2.4 degrees, spill dimensions respond as shown in Figure 5.6. The same infiltration parameters are used in the simulation. Clearly, the spill at less tilt is wider and shortened. The model still predicts a longer spill. The predicted maximum area is about $1000 \mathrm{sq} \mathrm{cm}$, again. This is a larger area than that given in Table 2.1, about $800 \mathrm{sq} \mathrm{cm}$ larger. An error of approximately $25 \%$ is indicated. The actual spill seems to be absorbed more based on its measured smaller area. 


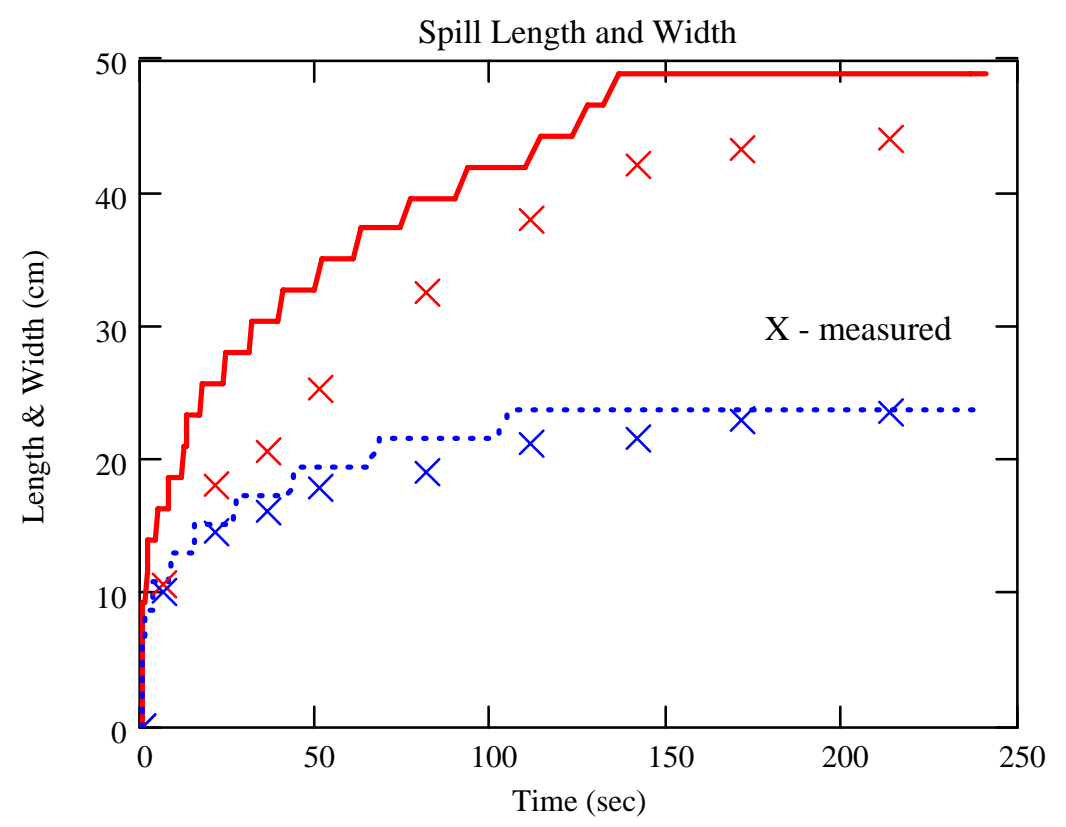

Figure 5.6. Spill Dimensions of Cut Corn Syrup on Less-Tilted Sand. Tilt angle is 2.4 degrees. Pour is $600 \mathrm{ml}$ during 150 seconds.

\subsubsection{Fast Spill of Antifreeze on Sand}

In Table 2.1, the antifreeze spill over sand during about 4 seconds is the fastest pour. For the larger tilt of 4.8 degrees, the spill vanished in only 15 seconds. This constitutes a different simulation situation than the previous slower pour of cut corn syrup. It was found that a viscosity of $20 \mathrm{cp}$, as reported in a materials properties report published by the manufacturer, could not explain the infiltration, although this viscosity value was appropriate for the liquid moving on the surface. In fact, it was found by the infiltration tests that a viscosity of about $10 \mathrm{cp}$ or less was characteristic of this liquid in moist sand (see Table 4.5 for the results for this liquid). A speculation is that the effective viscosity in the wet interstices of sand is altered by microscopic dilution by water. The manufacturer's information indicates that a $20 \%$ by volume addition of water to the antifreeze would decrease its value to about $10 \mathrm{cp}$, at room temperature. So a modified modeling approach was applied for this liquid: surface motion was presumed controlled by the greater viscosity of $20 \mathrm{cp}$, while subsurface infiltration was treated as determined by a reduced effective porosity of $10 \mathrm{cp}$.

The front head determined for antifreeze from the falling head stage of infiltration could not explain the spill absorption. As indicated in Table 4.4, the front head was about $8 \mathrm{~cm}$, but simulation calibration, consistent with the finding that the rising head stage has a much greater front head, suggested a value of about $25 \mathrm{~cm}$.

Figure 5.7 shows how the simulated spill dimensions progress when the greater front head is applied. 


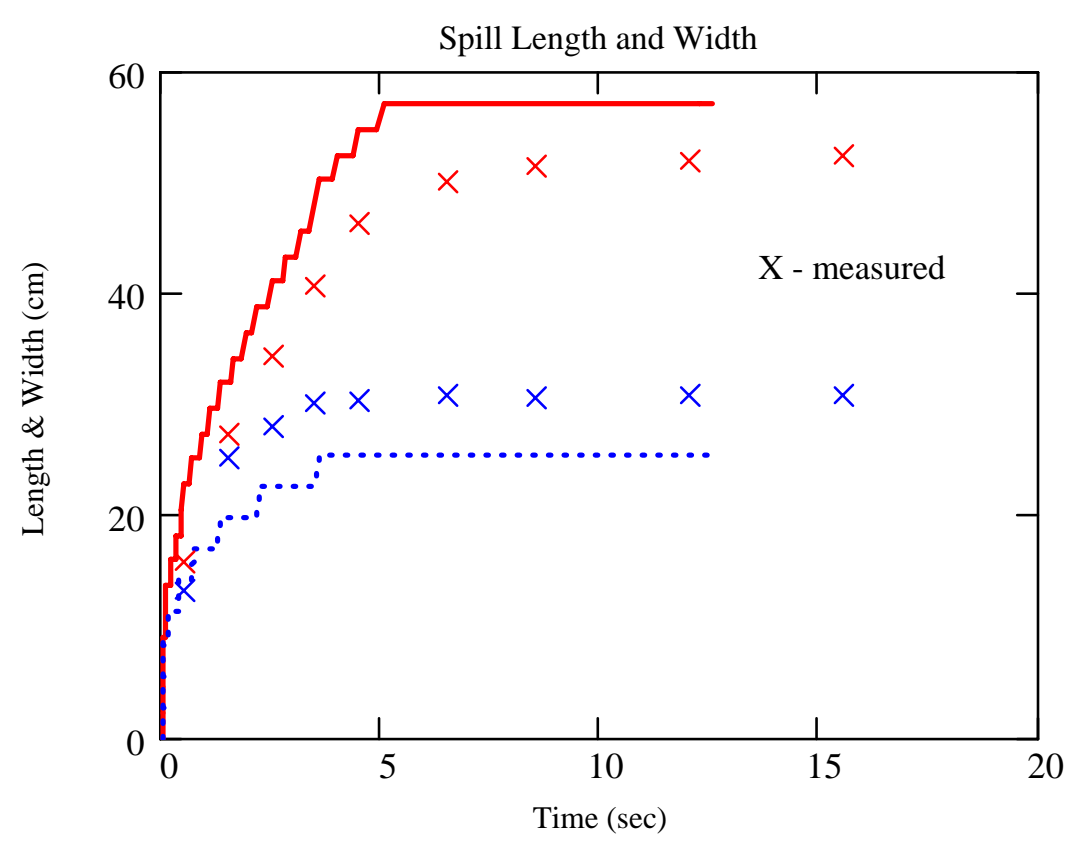

Figure 5.7. Spill Dimensions of Antifreeze on Sand Surface Tilted 4.8 Degrees. Pour is $400 \mathrm{ml}$ during 4 seconds. Simulation is based on front head of $25 \mathrm{~cm}$.

The actual fast spill of antifreeze clearly was wider and shorter in size dimensions. This could be attributed to an effectively wider input zone than used in the simulation, given that the fast-pour deflected substantially outward from the source pad. The outline of this spill in time is given in Figure 3.2. It is suspected that this very short-duration spill had indicated times about a half second shorter than that given in Figure 3.2. Figure 5.8 compares the simulated spill area over time with experimentally measured spill areas, presuming a half-second adjustment.

Figure 5.8 shows a good conformity in the predicted and measured area, and an equivalent elliptical area is given that indicates the area is reasonably consistent with this shape. The error of the model predicted area is $4 \%$. Apparently, from these two figures, the spill hardly progressed further once the pouring ceased, as is easily seen in the video of the spill.

\subsubsection{Fast Spill of Pump Oil on Sand}

A relatively fast spill of pump oil produced the symmetrical pattern shown in Figure 3.1. Toward the end of the spill just before being infiltrated, it developed a neck, or protrusion, in the direction of downhill flow. This tendency, as best seen in the videos, is believed to reflect the action of surface tension. At the leading edge, the oil resists wetting the soil, and surface tension of the oil tends to contract its width. This phenomenon of finger formation discussed by Schwartz (1989) is believed to require another term in the spreading equation to describe the influence of surface tension. It may also depend on there being a substantial wetting angle between the oil and moist sand, at least at the leading edge. 


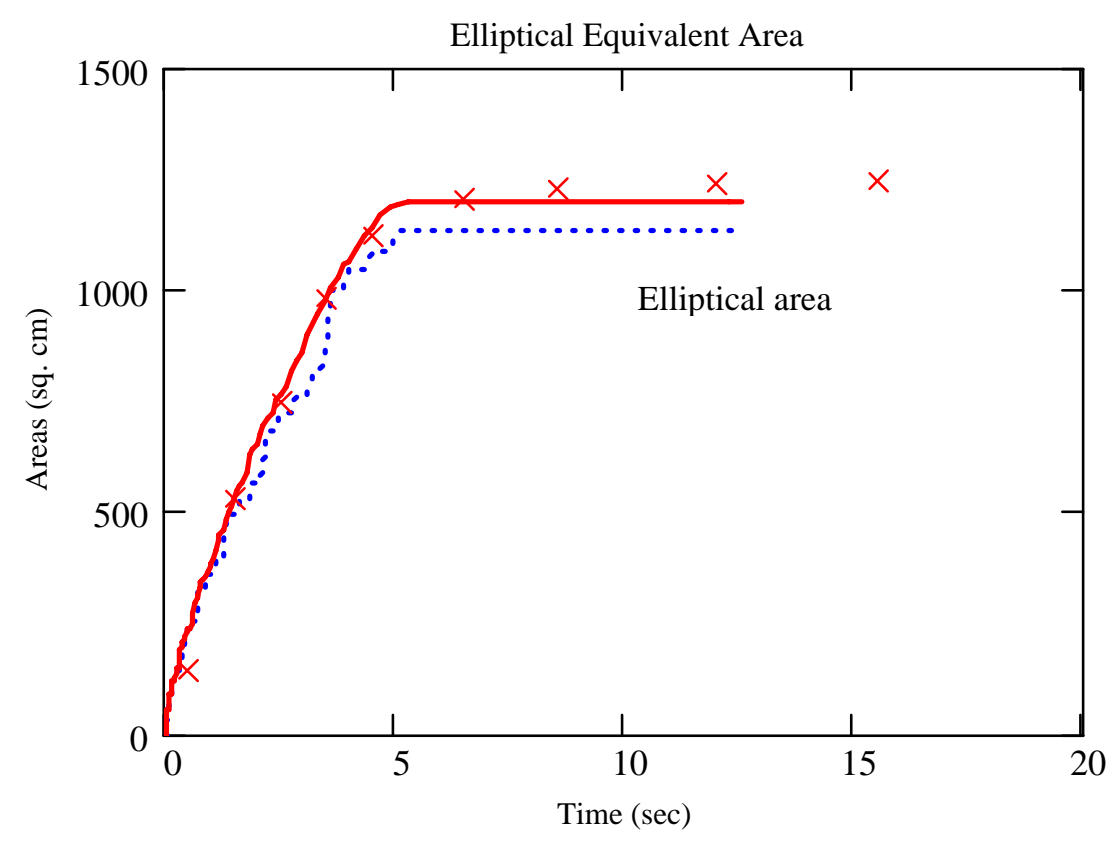

Figure 5.8. Spill Area Progression for Antifreeze on Sand. Red Xs are area data and solid red curve is the model. The blue dash curve is based on an elliptical area with length and width dimensions as simulated.

Based on preliminary simulations and calibration, the source area was widened to about $10 \mathrm{~cm}$ across, orthogonal to flow because the oil appeared to deflect smoothly beyond the pouring pad in all directions. In particular, the oil always poured out of the funnel in a regular, smooth pattern compared with the more unstable deflection exhibited by antifreeze.

Figures 5.9 and 5.10 show the simulated oil spill on sand. Again, the front head was increased to $25 \mathrm{~cm}$, instead of the 11-cm value, indicated by surface tension scaling to water. The simulation predicts a more rapid or abrupt progress to the final shape, whereas the spill actually spreads more slowly after the pouring ceased. Recall that the spill dimensions are measured on the subsurface area, not from the surface liquid distribution, which recedes. Nonetheless, the model-predicted and observed final spill areas are similar, with error in the model prediction being $8 \%$.

Figure 5.10 shows that the oil spill continues moving slowly downhill as much as 30 seconds after the start of the spill, whereas the simulation terminated movement by 15 seconds or less. It appears that the finger or neck formation at the front edge contributes to a longer-term spreading behavior, and is not accurately modeled.

Figure 5.11 shows the liquid height and depth 16.8 seconds after the spill started, 10 seconds after the pouring stopped. Most of the surface oil has moved toward the front. Most of the subsurface oil remains nearer the source. Note that the simulation region's width is not taken as the available $66 \mathrm{~cm}$ for the actual box. That is, Figure 3.1 matches the actual box dimensions, but Figure 5.11 does not. The region shown in Figure 5.11 is sufficient to confine the simulated spill width. 


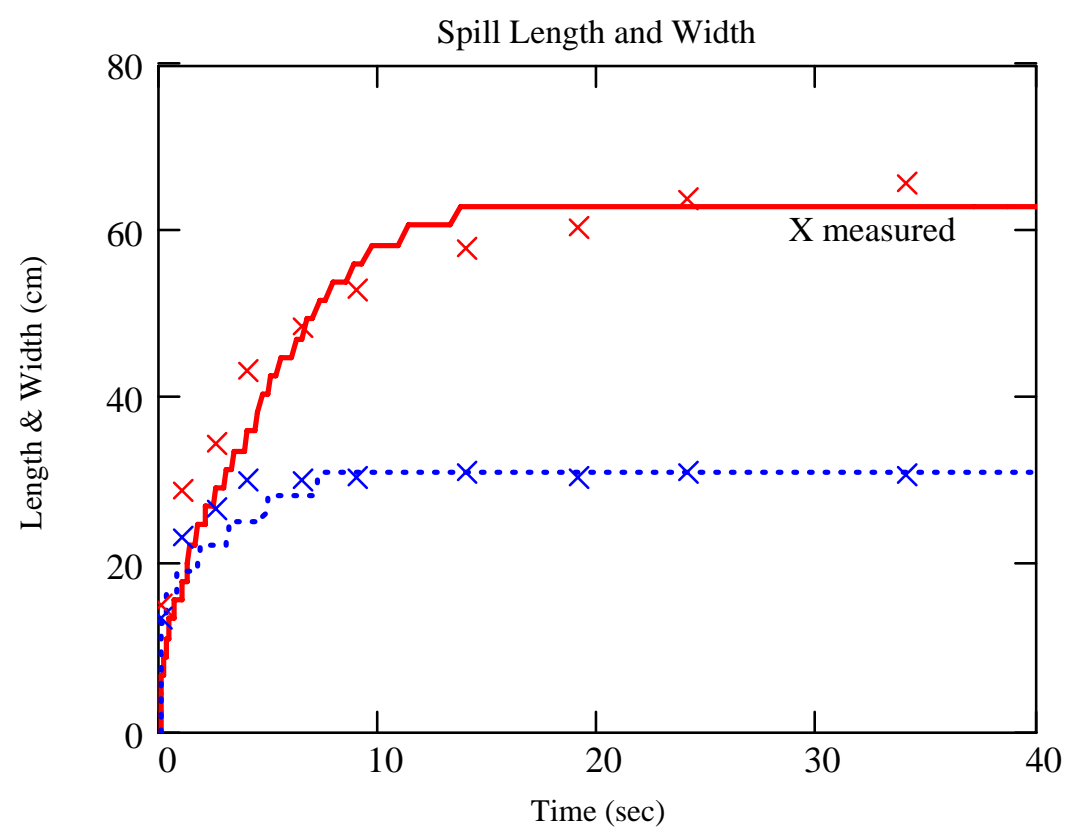

Figure 5.9. Spill Dimensions of Oil on Sand Surface Tilted 4.8 Degrees. Pour is $400 \mathrm{ml}$ during 7 seconds. Red and blue curves indicate length and width, respectively.

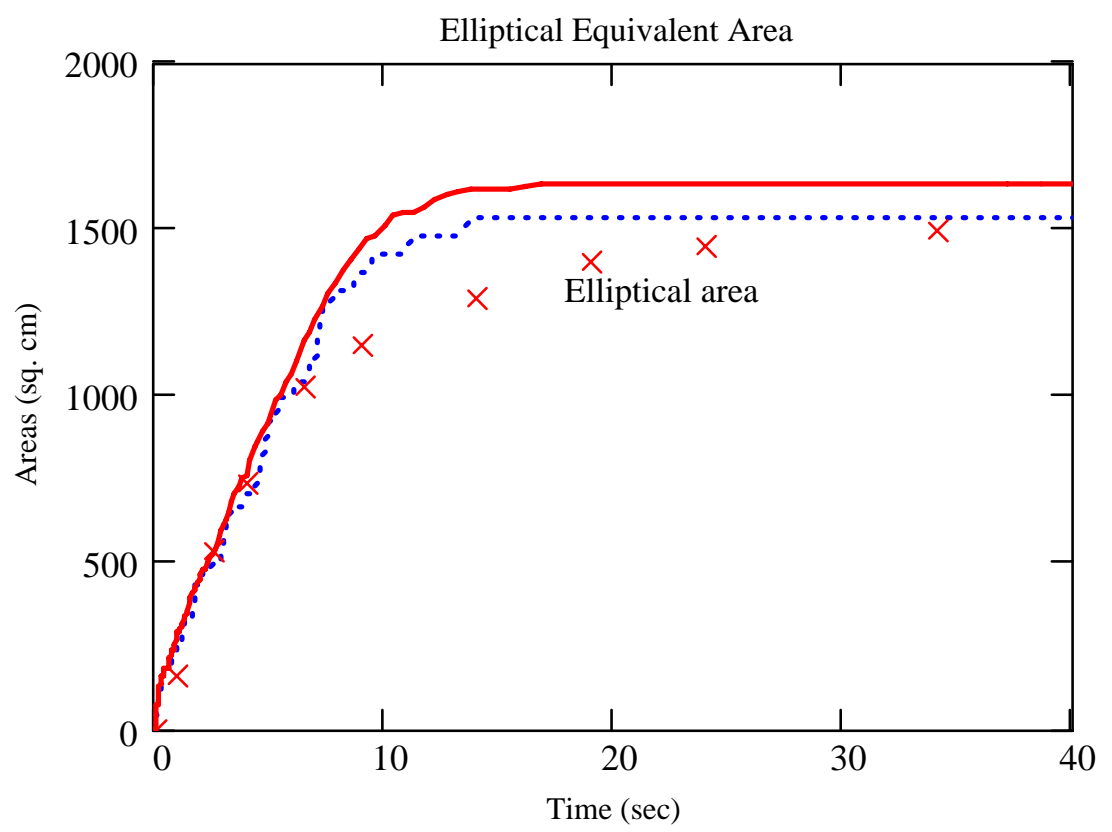

Figure 5.10. Spill Area Progression of Oil on Sand. Pour is $400 \mathrm{ml}$ during 7 seconds. Front head is $25 \mathrm{~cm}$. Dotted line indicates an equivalent elliptical area based on predicted dimensions. 

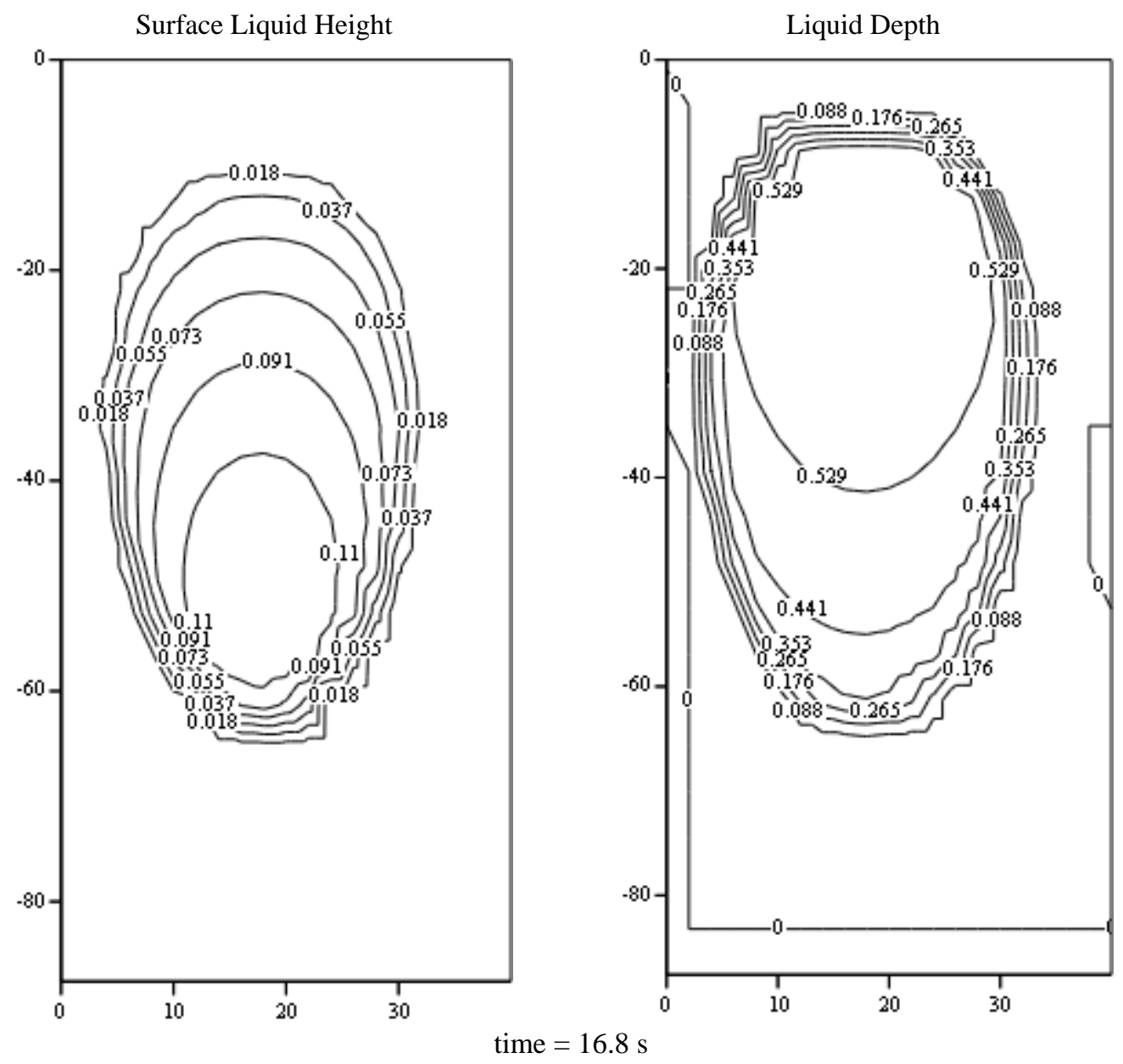

Figure 5.11. Oil Spill Contours on Sand for Liquid Height and Depth

\subsubsection{Spills on Silt Loam}

Silt loam is much less permeable than the sand, so it is anticipated that a spill of the same volume would spread more. Moreover, with less permeability, liquids of high viscosity might not be limited to the bottom boundary of the tilted tray, if the angle was too large. With this possibility in view, and considering the spreading behavior of 1:1 cut corn syrup on tilted small pans packed with silt loam, the selected test angle was reduced to 2.4 degrees over the 1-meter run of the mesoscale-size tray.

Even with this precaution, a 400-ml spill of antifreeze quickly ran to the bottom of the tilted silt loam surface when poured relatively quickly in 16 seconds. The size of the source funnel had been reduced to slow the spill rate. Figures 5.12 and 5.13 show the results for antifreeze spilled on silt loam.

The actual spill is shown in Figure 3.4. It reached the bottom edge by 29 seconds. Figure 5.12 indicates a similar progression in length, but the width of the actual spill is much narrower. Further test simulations found that an angle of at least 5 degrees tilt would be required to create a hypothetical spill with this narrower width. However, it was certain the tilt was less than 2.4 degrees, so the model predicted width did not develop. Moreover, corresponding to the predicted dimension the area would 
have to be much greater than actual measured, as shown in Figure 5.13. The actual spill also showed a much slower spreading progression as it elongated. Clearly, the spill model could not explain the progress of the actual spill.

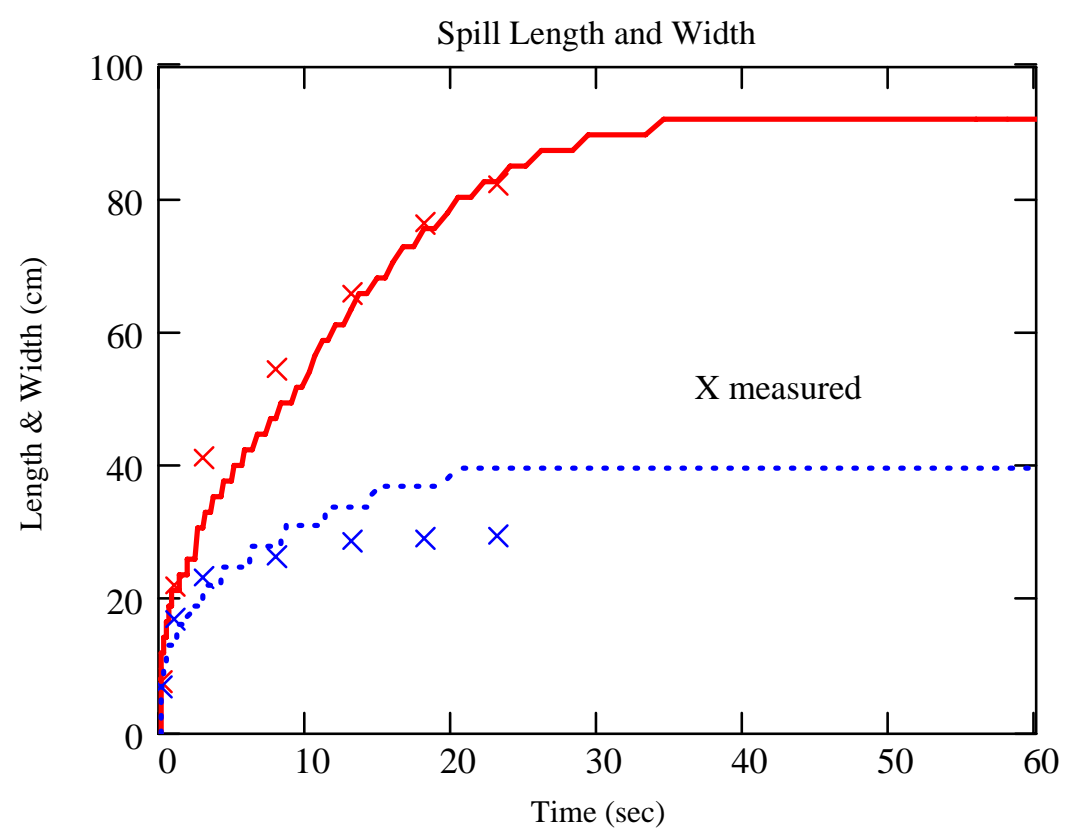

Figure 5.12. Spill Dimensions of Antifreeze on Silt Loam Tilted 2.4 Degrees. Pour is $400 \mathrm{ml}$ during 16 seconds.

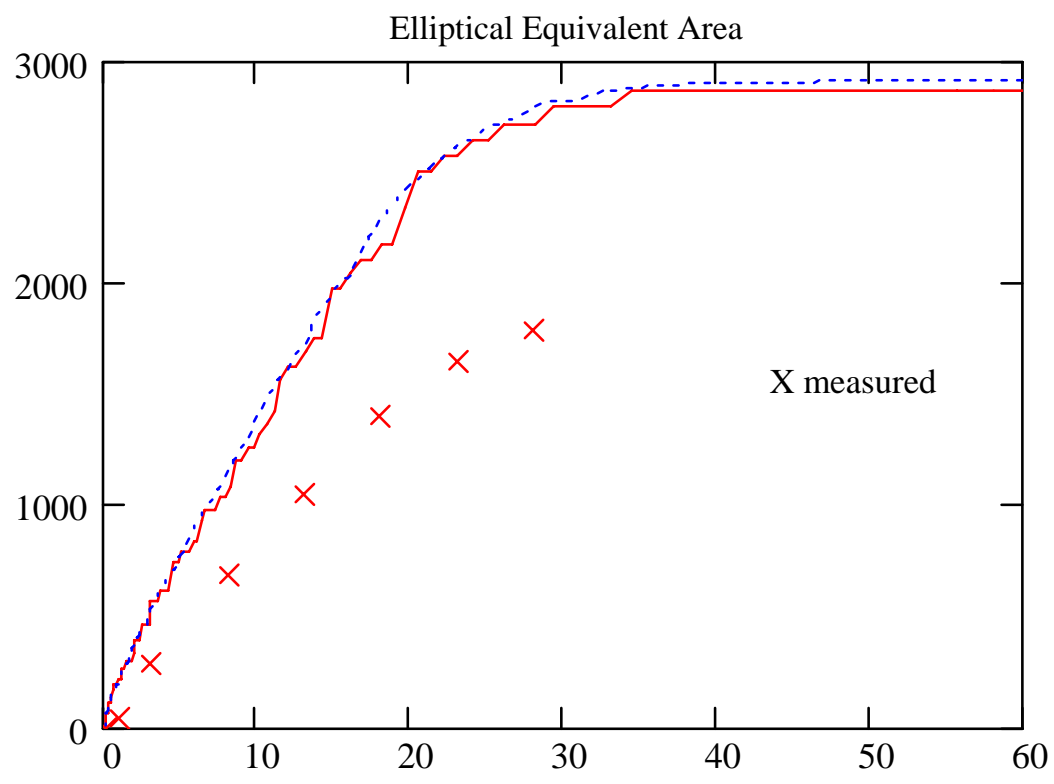

Figure 5.13. Spill Area of Antifreeze on Silt Loam. Dashed line is an equivalent elliptical area with the major dimensions as simulated. 
A smaller spill of antifreeze, $300 \mathrm{ml}$, was tried to avoid reaching the tray bottom. Results are given in Table 2.1. The pour rate was reduced to 19 seconds duration as well. However, the source initially displayed irregular fingering, which was believed responsible for creating a wider pattern than the $400 \mathrm{ml}$ spill. Figure 5.14 shows outlines in time of the $300 \mathrm{ml}$ spill of antifreeze on silt loam. During most of the last contour times, the spill exhibited a long single finger or leading edge protrusion down-slope. The spill vanished in about 104 seconds, which was almost the same time required for the $400 \mathrm{ml}$ spill to vanish, even though the larger spill pooled at the bottom edge. In view of the elongated shape of this $300 \mathrm{ml}$ spill, it was accepted that the model could not predict this behavior. Such behavior is believed to result from source instability, an irregular input pattern, when combined with an unaccounted for interfacial phenomenon. That is, the liquid lens is drawn up to a greater height and seems to resist wetting the soil at the leading edge. This protrusion grows most after the pour is complete. But, nevertheless, it does appear in earlier area contours (see Figure 5.14). It is necessary to view the time lapse video to appreciate this behavior.

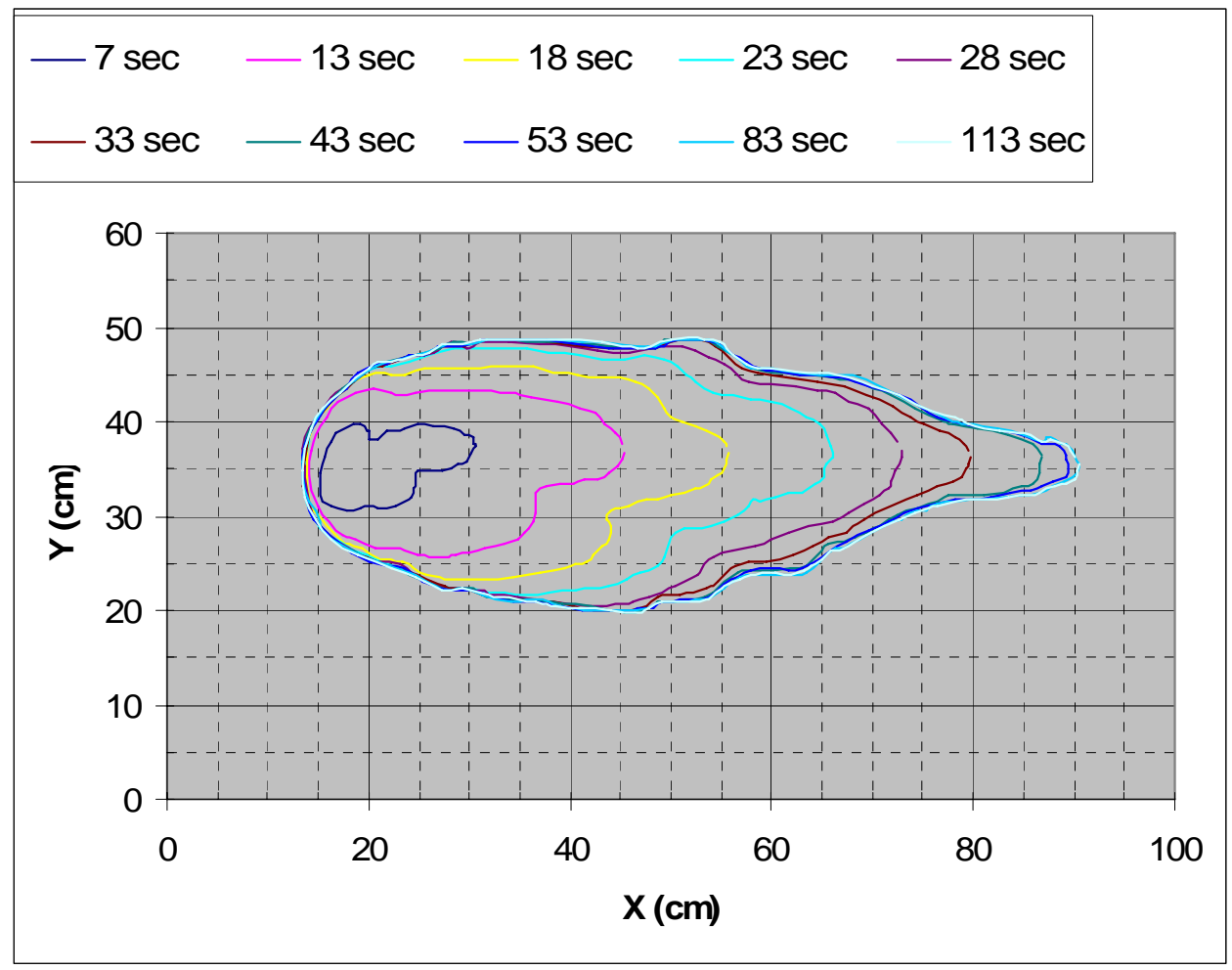

Figure 5.14. Spill of Antifreeze on Silt Loam Tilted 2.4 Degrees. Pour is $300 \mathrm{ml}$ during 19 seconds. (Date: May 17, 2005)

\subsubsection{Oil Spill on Silt Loam}

Because the liquid properties of oil are well defined, it was expected that an oil spill on silt loam would behave predictably according to the model. However, this was not the case because on this surface, oil was apparently influenced strongly by surface tension, not just viscosity. Apparently, the absorption of the liquid was consistent with observations (see Figure 5.15 and Table 2.1). Thus, the measured permeability and given viscosity described the infiltration appropriately. However, the given viscosity was not representative of the surface flow, and the progression of the area with the known 
viscosity was much too rapid. Further, the observed width of the spill was much narrower than predicted. To better represent the spill progression, the effective viscosity acting on the surface was augmented with a factor of ten. With a slight increase in tilt, it was also possible to decrease the predicted spill width to better match measurements.

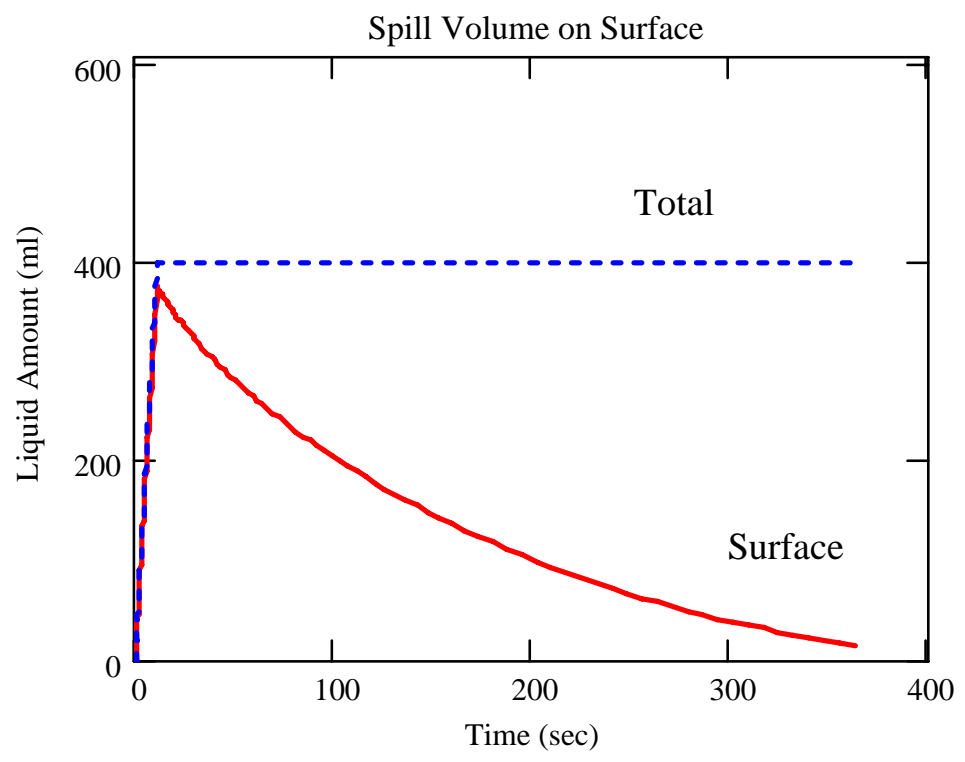

Figure 5.15. Oil Spill Amount on Silt Loam. Front head is $67 \mathrm{~cm}$. Viscosity of the oil over the surface is made a factor of 10 greater. Spill of $400 \mathrm{ml}$ is 11 seconds.

Figure 5.16 shows the adjusted prediction by giving oil on the surface an amplified effective viscosity. This apparently compensates for the influence of interfacial phenomena lacking in the present model. The correction suggests a need to implement a more representative spreading theory.

Figure 5.17 shows that the areas predicted with the same adjustment are consistent with measurements, with a calculated error of $7 \%$.

Note that the spill model predicts that it will vanish at about the same time as measured, after 380 seconds. The prediction of infiltration rate is consistent with the Green-Ampt model. The shape of the liquid distribution is shown in Figure 5.18. Clearly the model does not predict the narrow down-slope nose that developed in the actual spill, as seen in Figure 3.3.

\subsection{Summary on Model Comparisons}

The previous comparisons showed that the model could not always be made to conform to measured behavior. The appropriate estimate of front head, which controls how rapidly the infiltration of a spill takes place, was not easily identified. This uncertainty results because the first and second stages of infiltration are usually described by values that decrease into the second stage of falling head. The model includes only a single front head, assumed to hold during all conditions. 


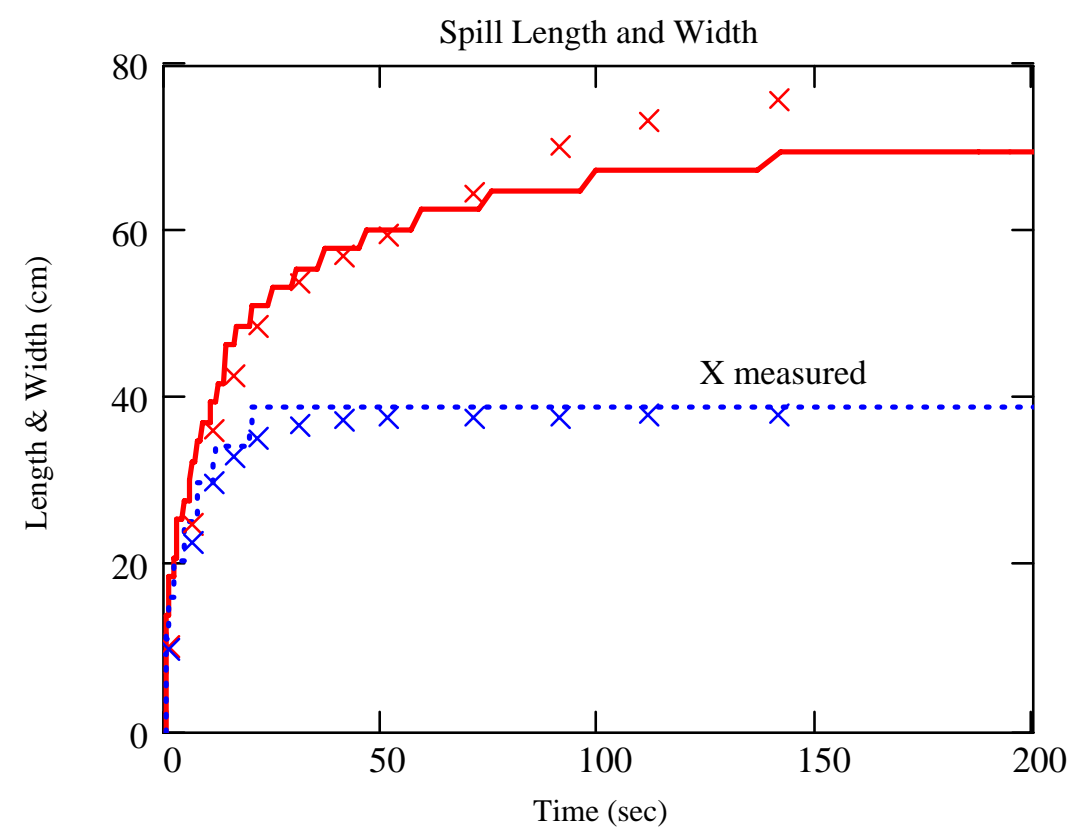

Figure 5.16. Oil Spill Dimensions on Silt Loam. Surface viscosity is amplified by a factor of 10 .

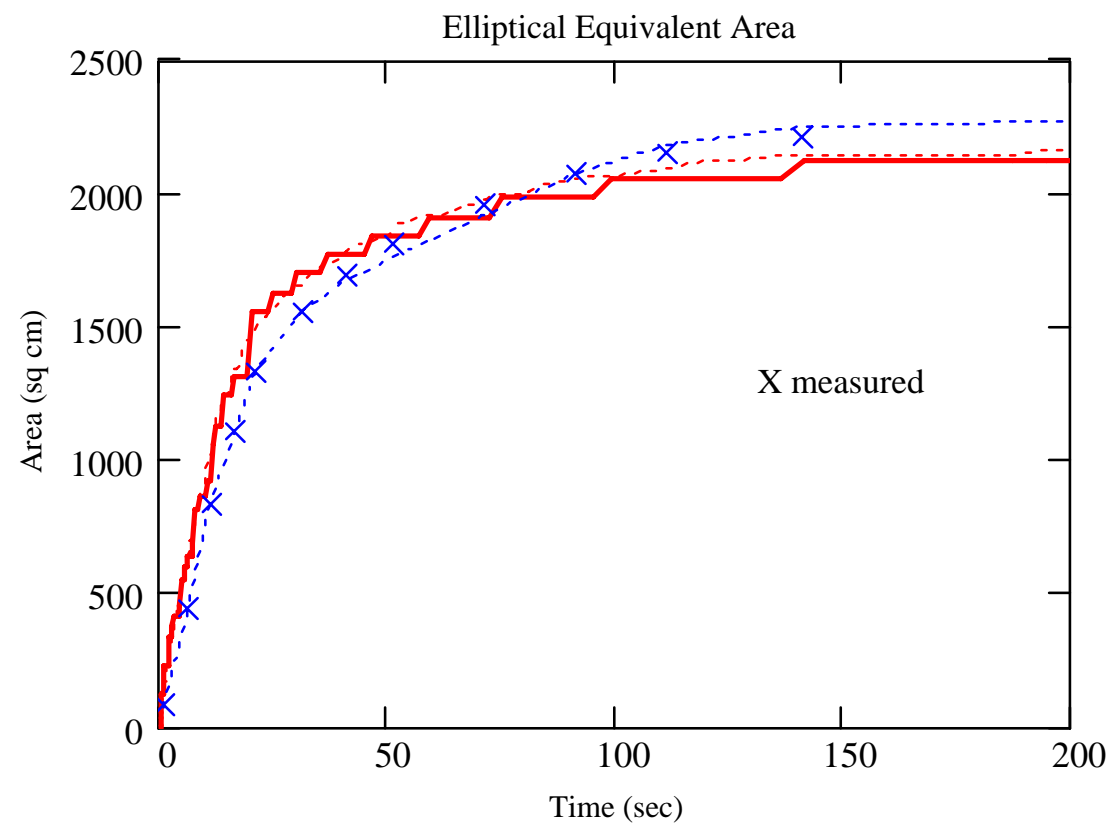

Figure 5.17. Spreading Area of Oil Spill on Silt Loam. Dot curves are elliptical areas based on major extents of the spill. 


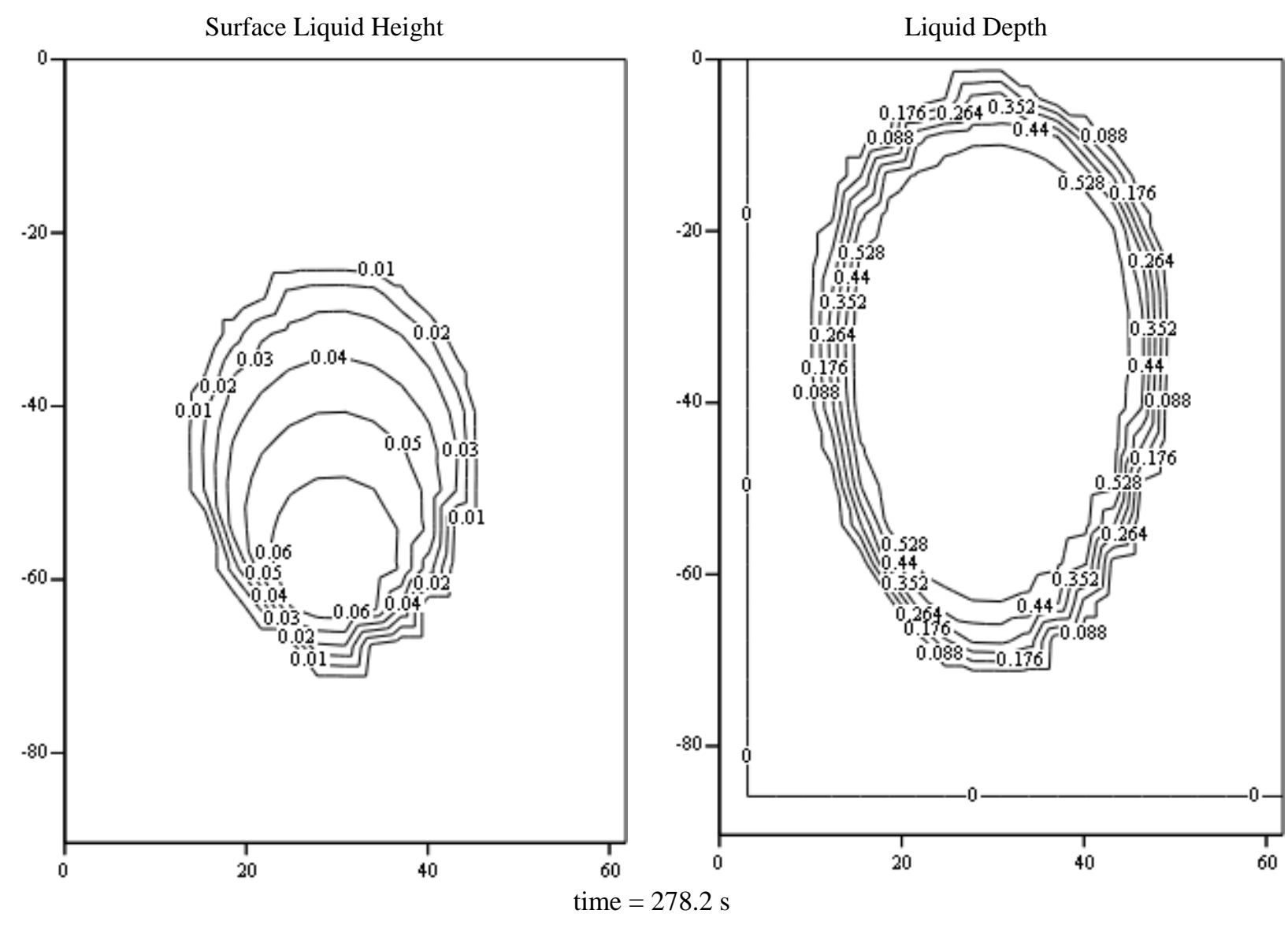

Figure 5.18. Oil Spill Contours on Silt Loam. Pour was 11 seconds and vanished in 380 seconds.

The effective viscosity for both the surface spreading and infiltration are not always the same either. For a corn syrup, which constitutes a miscible liquid, the viscosity applied to the infiltration needs to be less than manifested in the surface movement. This was a possibility not anticipated in the original development of the spill model. A modification was made to allow a distinction between a surface and an infiltration liquid viscosity.

Generally, the simulation of oil spreading on a sand soil is more accurate than on less-permeable silt loam soil. On sand, spreading is controlled more by infiltration into the surface than by surface tension acting on spreading. Fingering and unstable spreading behavior are more pronounced on the lesspermeable soil. Greater infiltration appears to stabilize the ideal spreading so that it is more controlled by viscosity than by surface tension or by the wetting contact angle acting on the surface.

The uniformity of the pouring affects the development of an actual spill compared with an ideal predicted pattern, which tends to develop elliptically. When liquid streams or jets out in variable direction from the spill source, the area pattern may develop unevenly and not ideally. This behavior can then have substantial impact on shape and area progression of an actual spill. It is found that the predicted final and measured areas are, nevertheless, similar. An approximately equal final area, regardless of actual shape, is an interesting attribute of spills on smooth permeable surfaces. On a rough or substantially contoured surface this generality may not hold true. Further experimental work with rough surfaces is needed to draw conclusions. 
It is not obvious how predictability relates to all physical parameters controlling spill progression and the final area. The degree of accuracy found in these few example spill tests should not be generalized readily to "real-world" topography. Most importantly, the model simulations give a useful connection between area and liquid amount below the soil surface. The general qualitative connection between amount and area is more certain than the quantitative prediction accuracy. This incomplete theoretical model helps more with understanding the relation between processes rather than with making accurate predictions.

The accuracy of the major length and width dimensions and their progression is remarkable. Even though the actual spill shape and simulated elliptical pattern may differ, the dimensions progress similarly. This was observed in most plots of dimensions when model parameters were adjusted adequately. This observation is also a reflection of selecting only those spills for analysis that did progress in a preferred way, rather than those that had irregular progression. The intent of this work, however, was to study the relationship between model parameters, and not to address the influence of irregularity or topography. 


\subsection{Conclusions on Predictability of Spills}

By its validation against experimental observations, the spill model is shown to reasonably simulate spill progression and final surface area. This validation applies to ideally smooth soil surfaces as prepared in the laboratory, and is not readily extended to real-world or rough topography. Adjustment of model parameters improved predictions with errors in spill area ranging from $4 \%$ to $25 \%$. Obstacles encountered with modeling the experimental spills include:

1. Variability of the soil conductivity and surface smoothness. Variation of the soil properties was observable directly in the spill tests showing the uneven disappearance of liquid. This phenomenon is not modeled accurately because the variation of porosity and conductivity cannot be known in great detail before a spill is performed.

2. Input variation. Any variation in the spill input, geometry, or rate may result in unstable flow, which is an impediment to making accurate predictions of progression. But an ideal spill, as that arranged in the laboratory, has a reasonably predictable progression, as simulated by the model.

3. Uncertainty in effective spill parameters. Spill parameters could be adjusted to improve model predictions. Using different viscosities for surface and subsurface liquid movement provided improved modeling. Changing the dimensions and surface tilt provided a means for testing the model's sensitivity to parameters.

4. Surface tension effects. Surface tension and lack of soil wettability cause the spill front to contract at the leading edge nose, and this influence results in elongation of a spill from an ideal elliptical shape. An additional term describing the influence of surface tension is needed in the model to improve its accuracy.

Regardless of predictive obstacles, the model captures the main dynamical relationships between liquid and soil properties that determine spill progression on an ideal surface. In particular, the total area appears to be consistent, regardless of spill shape.

Additional work is needed to implement a more complete surface spreading theory, such as that described by Schwartz (1989), as could account for contraction of the spill due to surface tension. An ability to create a domain of actual surface variation in the soil hydraulic properties is needed in the model to encompass realistic topography. Further study is needed to address surface roughness and topography features that control overland flow behavior. Depending on the spill volume, micro-relief features may introduce negligible influence on resulting overland flow, but that might change as surface features become more pronounced or the spill volume decreases. These aspects would need to be included in the spill model to evaluate their impact on prediction accuracy for real-world topography. 


\subsection{References}

Keller JM and CS Simmons. 2005. The Influence of Selected Liquid and Soil Properties on the Propagation of Spills over Flat Permeable Surfaces. PNNL-15058, Pacific Northwest National Laboratory, Richland, Washington.

Prestone Products Corporation. 1999. Prestone Physical Properties Data. Prestone Automotive Research \& Development Laboratory, Thirteenth edition, Danbury, Connecticut.

Schwartz LW. 1989. “Viscous Flows Down an Inclined Plane: Instability and Finger Formation.” Phys. Fluids A. 1(3):443-445. 


\section{Appendix A}

\section{Solutions of Green-Ampt Model}




\section{Appendix A}

\section{Solutions of Green-Ampt Model}

This appendix provides various solutions of the Green-Ampt infiltration model as used to calibrate with measurements. The definition of the model was given in Section 4, and the relationship of the model to the entire spill model is described in Keller and Simmons (2005). The liquid height, $h$, is that of the spill at each location as it progresses or spreads over an area. Headings of each derivation below refer to boundary conditions that are applicable to each situation for which the parameters of conductivity and front head are determined. The model is stated as

$$
\phi \cdot\left(\frac{\mathrm{d}}{\mathrm{dt}} \mathrm{z}\right)=\mathrm{K} \cdot\left(\frac{\mathrm{h}+\mathrm{z}}{\mathrm{z}}\right)
$$

where total head is $h=h_{o}+h_{f}, h_{f}$ is the front head representing capillary absorption, and $h_{o}$ is the applied head. Applied head is variable or time-dependent in many situations.

\section{A.1 Solution for Constant Head}

Under this condition, the applied head or liquid height is held constant, while the infiltration front advances. An infiltration test of this type was used to evaluate conductivity of the sand (see Section 4.1).

In terms of dimensionless variables, the model equation becomes

$$
\frac{\mathrm{d}}{\mathrm{d} \tau} \eta=\frac{\eta+1}{\eta}
$$

with

$$
\eta=\frac{\mathrm{z}}{\mathrm{h}} \text { and } \tau=\frac{\mathrm{K}}{\phi \cdot \mathrm{h}} \cdot \mathrm{t} \text {. }
$$

Direct integration gives

$$
\eta-\ln (\eta+1)=\tau
$$

When $\eta$ is small relative to 1 , a Taylor's series expansion is used to obtain an important approximation from the above exact solution,

$$
\tau=\frac{1}{2} \cdot \eta^{2}
$$


or in terms of original variables

$$
\mathrm{z}=\sqrt{2 \cdot \frac{\mathrm{K} \cdot \mathrm{h}}{\phi}} \cdot \sqrt{\mathrm{t}}
$$

This is the famous result that infiltration depth advances as the square root of time under constant applied head. The result is also used to obtain simple solution or estimation of depth at very early stages of infiltration.

\section{A.2 Constant Initial Amount - Declining Head}

These derivations are used in Sections 4.1 through 4.4. For the infiltration tube measurement of liquid conductivity, the applicable condition is a fixed amount of liquid poured on the surface that then infiltrates. After the liquid amount is introduced into an infiltration tube, the head declines, while infiltration proceeds. This is the "second stage" of infiltration when liquid addition is complete. When the liquid level is rising, while liquid is being applied, this condition is called the "first stage" of infiltration.

Suppose then the conservation of the liquid applied is given by

$$
\mathrm{S}_{\mathrm{o}}=\mathrm{h}_{\mathrm{o}}+\phi \cdot \mathrm{z}_{\mathrm{o}}=\mathrm{h}+\phi \cdot \mathrm{z}
$$

where $S_{o}$ is the constant amount of liquid present initially. Liquid, as height or depth, is $h_{o}$ and $z_{0}$. The infiltration equation can then be written as

$$
\frac{\mathrm{d}}{\mathrm{d} \tau^{\prime}} \eta^{\prime}=\frac{\eta^{\prime}+1}{\eta^{\prime}}
$$

with

$$
\eta^{\prime}=\frac{(1-\phi)}{\mathrm{S}_{\mathrm{o}}} \cdot \mathrm{z} \text { and } \quad \tau^{\prime}=\frac{(1-\phi)^{2}}{\mathrm{~S}_{\mathrm{O}}} \cdot \frac{\mathrm{K}}{\phi} \cdot \mathrm{t}
$$

Integration is

$$
\int_{\eta_{0}}^{\eta} \frac{\eta}{\eta+1} d \eta=\tau
$$

The primes on variables are dropped to simplify notation. Transformations between original variables, $\mathrm{z}$ and t, still apply for the following solution:

$$
\eta-\ln (\eta+1)-\tau_{0}=\tau \quad \text { with } \quad \tau_{0}=\eta_{0}-\ln \left(\eta_{0}+1\right)
$$


$\eta_{\mathrm{o}}$ is determined by $\mathrm{z}_{0}$. A special case holds when $\phi$ approaches 1 . Then

$$
\tau=\frac{1}{2} \cdot \eta^{2}
$$

which gives

$$
\mathrm{z}^{2}=\frac{2 \cdot \mathrm{K} \cdot \mathrm{S}_{\mathrm{o}}}{\phi} \cdot \mathrm{t}
$$

The square root of time law is obtained again under this condition.

\section{A.3 Modified Constant Initial Amount to Include a Front Head}

The prior case did not include a front head, which must in general be accounted for during infiltration of a spill. This solution applies for the declining head or second stage of infiltration. This is the derivation used to determine conductivity and front head by fitting the model to infiltration measurements. Note that this is the solution used during each time step in the complete spill model to diminish the surface level as liquid spreads based on gravity current propagation.

The Green-Ampt equation becomes

$$
\phi \cdot\left(\frac{\mathrm{d}}{\mathrm{dt}} \mathrm{z}\right)=\mathrm{K} \cdot\left[\frac{\mathrm{S}_{\mathrm{o}}+\mathrm{h}_{\mathrm{f}}+(1-\phi) \cdot \mathrm{z}}{\mathrm{z}}\right] .
$$

Then the following are the transformations to dimensionless variables

$$
\eta=\frac{\mathrm{z}}{\mathrm{b}} \quad \text { and } \quad \tau=\frac{\mathrm{a}}{\mathrm{b}} \cdot \mathrm{t}
$$

with

$$
\mathrm{a}=(1-\phi) \cdot \frac{\mathrm{K}}{\phi} \quad \text { and } \quad \mathrm{b}=\frac{\mathrm{S}_{\mathrm{o}}+\mathrm{h}_{\mathrm{f}}}{1-\phi} .
$$

Define the solution function $G$ by

$$
G(\eta)=\eta-\ln (\eta+1)
$$

with $\tau_{0}=G\left(\eta_{0}\right)$. The solution is

$$
\mathrm{G}(\eta)=\tau+\tau_{0}
$$


Let $F(\tau)$ denote the inverse function of $G$. It inverts the function $G$ to obtain depth as a function of time. The solution in terms of height of liquid instead of depth can be given as

$$
h(t)=S_{0}-\phi \cdot b \cdot F\left[\left(\frac{a}{b}\right) \cdot t+\tau_{0}\right]
$$

Now, when $\mathrm{z}=\mathrm{S}_{\mathrm{o}} / \phi$ the final time, $\mathrm{t}_{\mathrm{f}}$, when infiltration is done, is given by

$$
\frac{\mathrm{a}}{\mathrm{b}} \cdot \mathrm{t}_{\mathrm{f}}=\mathrm{G}\left(\frac{\mathrm{S}_{\mathrm{o}}}{\phi \cdot \mathrm{b}}\right)-\tau_{0}
$$

When this final time is measured, the above equation defines a constraint on parameters, a and $b$.

This solution is the basis for finding the parameters, $\mathrm{K}$ and $\mathrm{h}_{\mathrm{f}}$, from the second stage of an infiltration test during which the height, $h_{i}$, is measured at a set of times, $t_{i}$. At $t=0$, the first value is $h_{0}$. First, a and $b$ can be determined by minimizing the sum of squares of deviations in $h(t)$ from measurements $h_{i}$. That is, minimize the total squared deviations as

$$
\sum_{i}\left(\mathrm{~S}_{\mathrm{o}}-\phi \cdot \mathrm{b} \cdot \mathrm{F}\left(\frac{\mathrm{a}}{\mathrm{b}} \cdot \mathrm{t}_{\mathrm{i}}+\tau_{\mathrm{o}}\right)-\mathrm{h}_{\mathrm{i}}\right)^{2}
$$

subject to the constraint that $\tau_{0}$ depends on a and $\mathrm{b}$.

\section{A.4 Solution for Specified Input Rate}

In some cases, liquid is poured onto the surface at a constant rate, and infiltration under this condition is evaluated to determine parameters, instead of the previous situation. For instance, it was convenient to assume that liquid was poured into an infiltration tube at approximately a constant rate while measurements were taken. This derivation applies to the first stage for an infiltration tube test. The solution below was applied in Section 4.4. The derivations here found use in Table 4.6 estimates.

Suppose liquid is input to the surface at a constant rate, $\mathrm{R}$, as $\mathrm{Q}=\mathrm{R} \cdot \mathrm{t}$ over an area, A. Given a volume, $\mathrm{V}$, added over a time, $\mathrm{T}_{0}$, the rate defines a rate per unit area as $\mathrm{q}=\mathrm{R} / \mathrm{A}$. Then

$$
\mathrm{h}+\phi \cdot \mathrm{z}=\mathrm{q} \cdot \mathrm{t}
$$

The Green-Ampt infiltration can then be written as

$$
\phi \cdot\left(\frac{\mathrm{d}}{\mathrm{dt}} \mathrm{z}\right)=\mathrm{K} \cdot(1-\phi) \cdot\left[\frac{\mathrm{q} \cdot \mathrm{t}+\mathrm{h}_{\mathrm{f}}}{(1-\phi) \cdot \mathrm{z}}+1\right] .
$$


Define

$$
\mathrm{A}=\frac{(1-\phi)}{\phi} \cdot \mathrm{K} \quad \text { and } \quad \alpha=(1-\phi) \cdot \frac{\mathrm{A}}{\mathrm{q}} \quad \text { and } \quad \beta=\frac{\mathrm{q}}{\mathrm{h}_{\mathrm{f}}}
$$

Transformed variables are

$$
\eta=\frac{(1-\phi)}{h_{\mathrm{f}}} \cdot \mathrm{z} \quad \tau=\beta \cdot \mathrm{t} .
$$

In terms of these variables, the model becomes

$$
\frac{\mathrm{d}}{\mathrm{d} \tau} \eta=\alpha \cdot\left(\frac{\tau+1}{\eta}+1\right)
$$

Note that the variables and parameter, $\alpha$, are dimensionless. This infiltration case does not allow a simple analytical solution. The above differential equation must be solved numerically in general, given values for $\alpha$.

At an early time, the infiltration can be approximated. When $\eta$ is near zero, consider solutions when $(\tau+1) / \eta>1$, much larger than one. This situation yields

$$
\frac{\eta^{2}}{2}=\alpha \cdot\left(\frac{\tau^{2}}{2}+\tau\right)
$$

An approximate solution can be re-expressed in terms of $\mathrm{z}$ and $\mathrm{t}$, using $\mathrm{z}=\frac{\mathrm{q} \cdot \mathrm{t}-\mathrm{h}}{\phi}$. It is

$$
\frac{1}{b^{2}} \cdot\left(\frac{\mathrm{q} \cdot \mathrm{t}-\mathrm{h}}{\phi}\right)^{2}=\alpha \cdot\left(\beta^{2} \cdot \mathrm{t}^{2}+2 \cdot \beta \cdot \mathrm{t}\right)
$$

with

$$
\mathrm{b}=\frac{\mathrm{h}_{\mathrm{f}}}{(1-\phi)}=\frac{\mathrm{q}}{(1-\phi)} \cdot \frac{1}{\beta}
$$

The objective is to obtain a relationship between $\mathrm{K}$ and $\mathrm{h}_{\mathrm{f}}$ for a given $\mathrm{q}$. Substituting for $\mathrm{b}$ gives (h and $t$ are the variables)

$$
\alpha=\beta \cdot \frac{\left(\mathrm{t}-\frac{\mathrm{h}}{\mathrm{q}}\right)^{2} \cdot\left(\frac{1-\phi}{\phi}\right)^{2}}{\left(\beta \cdot \mathrm{t}^{2}+2 \cdot \mathrm{t}\right)}
$$


This gives for $\mathrm{K}$, after substituting in the definition for $\alpha$

$$
K=\beta \cdot\left(t-\frac{h}{q}\right)^{2} \cdot \frac{q}{\phi} \cdot\left(\beta \cdot t^{2}+2 \cdot t\right)^{-1}
$$

letting

$$
\gamma=\frac{\mathrm{q}}{\phi} \cdot\left(\mathrm{t}-\frac{\mathrm{h}}{\mathrm{q}}\right)^{2}
$$

and solving for $\beta$ gives

$$
\beta=\frac{2 \cdot t \cdot K}{\left(\gamma-K \cdot t^{2}\right)} .
$$

This expression, relating $\beta=\mathrm{q} / \mathrm{h}_{\mathrm{f}}$ to $\mathrm{K}$ for all $\mathrm{h}$ and $\mathrm{t}$, is to be satisfied specifically when $\mathrm{t}=\mathrm{T}_{\mathrm{o}}$ and $\mathrm{h}$ $=\mathrm{h}_{\mathrm{o}}$. This then yields

$$
\mathrm{h}_{\mathrm{f}}=\mathrm{q} \cdot \frac{\gamma_{\mathrm{o}}-\mathrm{K} \cdot\left(\mathrm{T}_{\mathrm{o}}\right)^{2}}{2 \cdot \mathrm{T}_{\mathrm{o}} \cdot \mathrm{K}}
$$

where $\gamma_{0}$ is evaluated at $\mathrm{T}_{\mathrm{o}}$ as

$$
\gamma_{0}=\frac{q}{\phi} \cdot\left(\mathrm{T}_{0}-\frac{\mathrm{h}_{\mathrm{o}}}{\mathrm{q}}\right)^{2} .
$$

These last two expressions determine a relation between front head and conductivity for the first stage of infiltration when liquid is poured onto a surface. Recall that this relation is derived from an approximate solution and holds only for sufficiently early times or a short pouring period, $\mathrm{T}_{\mathrm{o}}$.

\section{A.5 Solution for Long-Term Second-Stage of Infiltration}

The following is a solution that can be better applied to explain the relationship of infiltration depth measurements to passage of time in some cases.

It is observed that for sufficiently long infiltration during the second stage, while the liquid level declines to vanishing, that the front depth advances approximately linearly. During this situation the liquid hydraulic gradient is approximately constant. For this condition, the model is 


$$
\phi \cdot\left(\frac{\mathrm{d}}{\mathrm{dt}} \mathrm{z}\right)=\mathrm{K} \cdot\left(\frac{\mathrm{h}_{\mathrm{f}}}{\mathrm{z}_{\mathrm{m}}}+1\right)
$$

where

$$
\mathrm{z}_{\mathrm{m}}=\frac{\mathrm{z}_{\mathrm{o}}+\mathrm{Z}_{\max }}{2}
$$

and $\mathrm{Z}_{\max }$ is the maximum depth when liquid just vanishes from the surface, given by $\mathrm{s}_{0}=\phi \mathrm{Z}_{\max }$. It is assumed that $h_{0}$ is small compared with $h_{f}$. These assumptions give a linear front progression in time

$$
\mathrm{z}=\mathrm{A} \cdot \mathrm{t}+\mathrm{z}_{\mathrm{O}}
$$

with a constant

$$
\mathrm{A}=\frac{\mathrm{K}}{\phi} \cdot\left(\frac{\mathrm{h}_{\mathrm{f}}}{\mathrm{z}_{\mathrm{m}}}+1\right) .
$$

In terms of liquid height rather than front depth, this trend is

$$
h=-\phi \cdot A \cdot t+h_{0} .
$$

But when liquid vanishes at time, $T_{f}$, $h$ is zero. This gives $h_{o}=\phi A \cdot T_{f}$ and

$$
h=-\phi \cdot A\left(t-T_{f}\right) .
$$

Thus, a linear regression holds for $\mathrm{h}$ in terms of time, and the estimated slope, $\phi \cdot \mathrm{A}$, determines a relationship between $\mathrm{K}$ and $\mathrm{h}_{\mathrm{f}}$.

\section{A.6 First-Stage Approximate Front Head}

The relationship between $\mathrm{K}$ and $\mathrm{h}_{\mathrm{f}}$ obtained for the first stage of infiltration can be modified to appear similar to that obtained for the second stage with falling head.

Expressions derived below help estimate the front head during first-stage infiltration while liquid is being poured on. Sections 4.3 and 4.4 make use of these relationships.

First note that

$$
\mathrm{q}=\frac{\text { Volume }}{\text { Area } \cdot \mathrm{T}_{\mathrm{o}}}=\frac{\mathrm{S}_{\mathrm{o}}}{\mathrm{T}_{\mathrm{o}}} \cdot \phi
$$

Then evaluation gives 


$$
\gamma_{\mathrm{o}}=\left(\mathrm{S}_{\mathrm{o}}-\mathrm{h}_{\mathrm{o}}\right)^{2} \cdot \frac{\mathrm{T}_{\mathrm{o}}}{\phi \cdot \mathrm{S}_{\mathrm{o}}}
$$

Defining

$$
\phi \cdot \mathrm{A}_{\mathrm{o}}=\frac{\gamma_{\mathrm{o}}}{\left(\mathrm{T}_{\mathrm{o}}\right)^{2}} \quad \text { and } \quad \mathrm{z}_{\mathrm{m}}=\frac{\mathrm{q} \cdot \mathrm{T}_{\mathrm{o}}}{2}=\frac{\mathrm{S}_{\mathrm{o}}}{2}
$$

gives

$$
\mathrm{h}_{\mathrm{f}}=\mathrm{z}_{\mathrm{m}}\left(\frac{\phi \cdot \mathrm{A}_{\mathrm{o}}}{\mathrm{K}}-1\right)
$$

with

$$
\phi \cdot \mathrm{A}_{\mathrm{o}}=\frac{\left(\mathrm{S}_{\mathrm{o}}-\mathrm{h}_{\mathrm{o}}\right)^{2}}{\phi \cdot \mathrm{S}_{\mathrm{O}} \cdot \mathrm{T}_{\mathrm{o}}}
$$

These equations above are similar to the expressions for the second stage in terms of A. But note that the front depth does not necessarily advance linearly in time for the first stage.

\section{A.7 General Solution for Rising Head First-Stage Infiltration}

Section 4.4 and data such as those given in Figure 4.6 make use of the derivations given here. When the best possible constant application rate during an infiltration test cannot be achieved, the following allows the solution to be adjusted for the actual variable input rate.

When the pouring rate is variable, which is usually the case during the first stage of infiltration, a general solution can be derived iteratively as follows. The situation is

$$
\mathrm{h}+\phi \cdot \mathrm{z}=\mathrm{Q}(\mathrm{t})
$$

and the Green-Ampt model is

$$
\phi \cdot\left(\frac{\mathrm{d}}{\mathrm{dt}} \mathrm{z}\right)=\mathrm{K} \cdot(1-\phi) \cdot\left[\frac{\mathrm{Q}(\mathrm{t})+\mathrm{h}_{\mathrm{f}}}{(1-\phi) \mathrm{z}}+1\right] .
$$

Note that $\mathrm{Q}(\mathrm{t})=\mathrm{q} \cdot \mathrm{t}$ is a special situation that need not hold here. Define constants as

$$
\mathrm{a}=\frac{\mathrm{K}}{\phi} \quad \text { and } \quad \mathrm{b}=\frac{\mathrm{K} \cdot \mathrm{h}_{\mathrm{f}}}{\phi} \quad \text { and } \quad \mathrm{c}=\mathrm{K} \cdot \frac{(1-\phi)}{\phi} \text {. }
$$


The front advance equation is then integrated once in time to give

$$
\frac{z^{2}}{2}=a \cdot \int_{0}^{t} Q(t) d t+b \cdot t+c \cdot \int_{0}^{t} z d t
$$

This is a non-linear expression relating $\mathrm{z}(\mathrm{t})^{2}$ at any time to its integral over time. Let $\mathrm{z}_{\mathrm{n}}(\mathrm{t})$ denote a sequence of approximate solutions, then

$$
\frac{\left[\mathrm{z}_{\mathrm{n}}(\mathrm{t})\right]^{2}}{2}=\mathrm{a} \cdot \int_{0}^{\mathrm{t}} \mathrm{Q}(\mathrm{t}) \mathrm{dt}+\mathrm{b} \cdot \mathrm{t}+\mathrm{c} \cdot \int_{0}^{\mathrm{t}} \mathrm{z}_{\mathrm{n}-1}(\mathrm{t}) \mathrm{dt}
$$

starting with $\mathrm{z}_{0}(\mathrm{t})=0$. And then

$$
\frac{\left[\mathrm{z}_{1}(\mathrm{t})\right]^{2}}{2}=\mathrm{a} \cdot \int_{0}^{\mathrm{t}} \mathrm{Q}(\mathrm{t}) \mathrm{dt}+\mathrm{b} \cdot \mathrm{t}
$$

which is

$$
z_{1}(t)=\sqrt{2 \cdot a \cdot \int_{0}^{t} Q(t) d t+2 \cdot b \cdot t}
$$

The second iteration is

$$
z_{2} \cdot(t)=\sqrt{2 \cdot\left(a \cdot \int_{0}^{t} Q(t) d t\right)+2 \cdot b \cdot t+2 \cdot c \cdot \int_{0}^{t} z_{1} \cdot(t) d t}
$$

By comparison with the exact numerical solution of the Green-Ampt differential equation, the second iteration is found to be a very good approximation; even the first is adequate in many cases. The advantage of this approximation is that an analytical solution is obtained that can be fitted directly to measurements of the front depth with time and used to estimate the parameters a, b, and c. Notice, however, that only a and $\mathrm{b}$ are independent.

\section{A.8 Scaling the Falling Head Stage of Infiltration}

This discussion is generally employed, as described in Section 4, to help estimate parameters for a particular liquid given measurements for water as a reference. It demonstrates how fluid-media scaling is accomplished.

The conductivity of one liquid relative to another infiltrating into the same soil can be estimated by simply recording how long a time is required for each to infiltrate during falling head. Initially 


$$
\mathrm{h}_{\mathrm{O}}+\phi \cdot \mathrm{z}_{\mathrm{o}}=\mathrm{S}_{\mathrm{O}}
$$

Every solution of the Green-Ampt front advance has the same dimensionless form

$$
G(\eta)-G\left(\eta_{0}\right)=\tau
$$

where

$$
G(\eta)=\eta-1 n(\eta+1) \quad \text { and } \quad \eta=\frac{(1-\phi) \cdot z}{S_{o}+h_{f}} \quad \text { and } \quad \tau=\frac{(1-\phi)^{2} \cdot K}{\phi \cdot\left(S_{o}+h_{f}\right)}
$$

The infiltration is complete when $\mathrm{h}=0$ and $\phi \cdot \mathrm{Z}_{\mathrm{m}}=\mathrm{S}_{\mathrm{o}}$. Let $\eta_{\mathrm{m}}$ correspond to this maximum depth when attained. The maximum time or final time of the falling head stage is $t_{m}$. Now suppose that for two liquids (prime denotes a different one), the geometry of infiltration is nearly the same with $\eta_{0}{ }^{\prime}=\eta_{0}$ and $\eta_{\mathrm{m}}{ }^{\prime}=\eta_{\mathrm{m}}$, then

$$
\tau_{\mathrm{m}}=\frac{(1-\phi)^{2} \cdot \mathrm{K}}{\phi \cdot\left(\mathrm{S}_{\mathrm{o}}+\mathrm{h}_{\mathrm{f}}\right)} \cdot \mathrm{t}_{\mathrm{m}}=\frac{\left(1-\phi^{\prime}\right)^{2} \cdot \mathrm{K}^{\prime}}{\phi^{\prime} \cdot\left(\mathrm{S}_{\mathrm{o}}^{\prime}+\mathrm{h}_{\mathrm{f}}^{\prime}\right)} \cdot \mathrm{t}_{\mathrm{m}} .
$$

In particular, if the pouring is very quick so that initial depth is nearly zero and the final depth is the same, then scaling is applicable. The amounts of both liquids might not be the same. But supposing all variables are the same, i.e., porosity, front head, and amount, then

$$
\mathrm{K} \cdot \mathrm{t}_{\mathrm{m}}=\mathrm{K}^{\prime} \cdot \mathrm{t}_{\mathrm{m}}
$$

and because permeability is presumed invariant regardless of the liquid, this implies

$$
\frac{\rho}{\rho^{\prime}} \cdot \frac{\mu^{\prime}}{\mu}=\frac{\mathrm{t}_{\mathrm{m}}^{\prime}}{\mathrm{t}_{\mathrm{m}}}
$$

Thus, viscosity is directly a reflection of how long a liquid requires to just vanish. A more general scaling requires that

$$
\frac{h_{f}^{\prime}}{h_{f}}=\frac{\rho}{\rho^{\prime}} \cdot \frac{\sigma^{\prime}}{\sigma}
$$

and requires using

$$
\tau_{m}^{\prime}=G\left(\eta_{m}^{\prime}\right)-\tau_{o}^{\prime} .
$$

Here the scaled times, $\tau_{\mathrm{m}}$, may not be equal. 


\section{A.9 Upward Imbibing Solution}

The Green-Ampt model may be applied for upward imbibing liquid as well as downward infiltration. In some cases, it is experimentally more convenient to perform an upward flow measurement, especially to stabilize the front advance to better estimate parameters. This condition was used in Section 4.2 and Table 2.3, for instance, to estimate parameters for the sand.

Infiltration may occur upward against the downward pull of gravity. The modified model with the direction of gravity reversed is

$$
\phi \cdot\left(\frac{\mathrm{d}}{\mathrm{dt}} \mathrm{z}\right)=\mathrm{K} \cdot\left(\frac{\mathrm{h}-\mathrm{z}}{\mathrm{z}}\right)
$$

with

$$
h=h_{o}+h_{f}
$$

The solution is

$$
\mathrm{U}(\eta)-\mathrm{U}\left(\eta_{\mathrm{O}}\right)=\tau
$$

with

$$
U(\eta)=-(\eta+\ln (1-\eta)) \text { for } \eta<1
$$

and dimensionless variables are

$$
\eta=\frac{\mathrm{z}}{\mathrm{h}} \quad \text { and } \quad \tau=\frac{\mathrm{K}}{\phi \cdot \mathrm{h}} \cdot \mathrm{t} .
$$

This solution is, of course, used to determine parameters from an upward imbibing test. 


\section{Appendix B}

\section{Beaver Bark Sand Particle-Size Distribution and Water Retention}




\section{Appendix B}

\section{Beaver Bark Sand Particle-Size Distribution and Water Retention}

The particle-size distribution of Beaver Bark sand was measured for purposes of obtaining its textural designation and to understand how the physical characteristics of Beaver Bark sand compare to the grainsize characteristics of Accusand and Quincy sand reported by Keller and Simmons (2005). Particle-size distribution was measured using the methods of Gee and Or (2002). Figure B.1 shows the measured particle-size distribution curve for Beaver Bark. The U.S. Department of Agriculture texture designation and grain size statistics are presented in Table B.1.

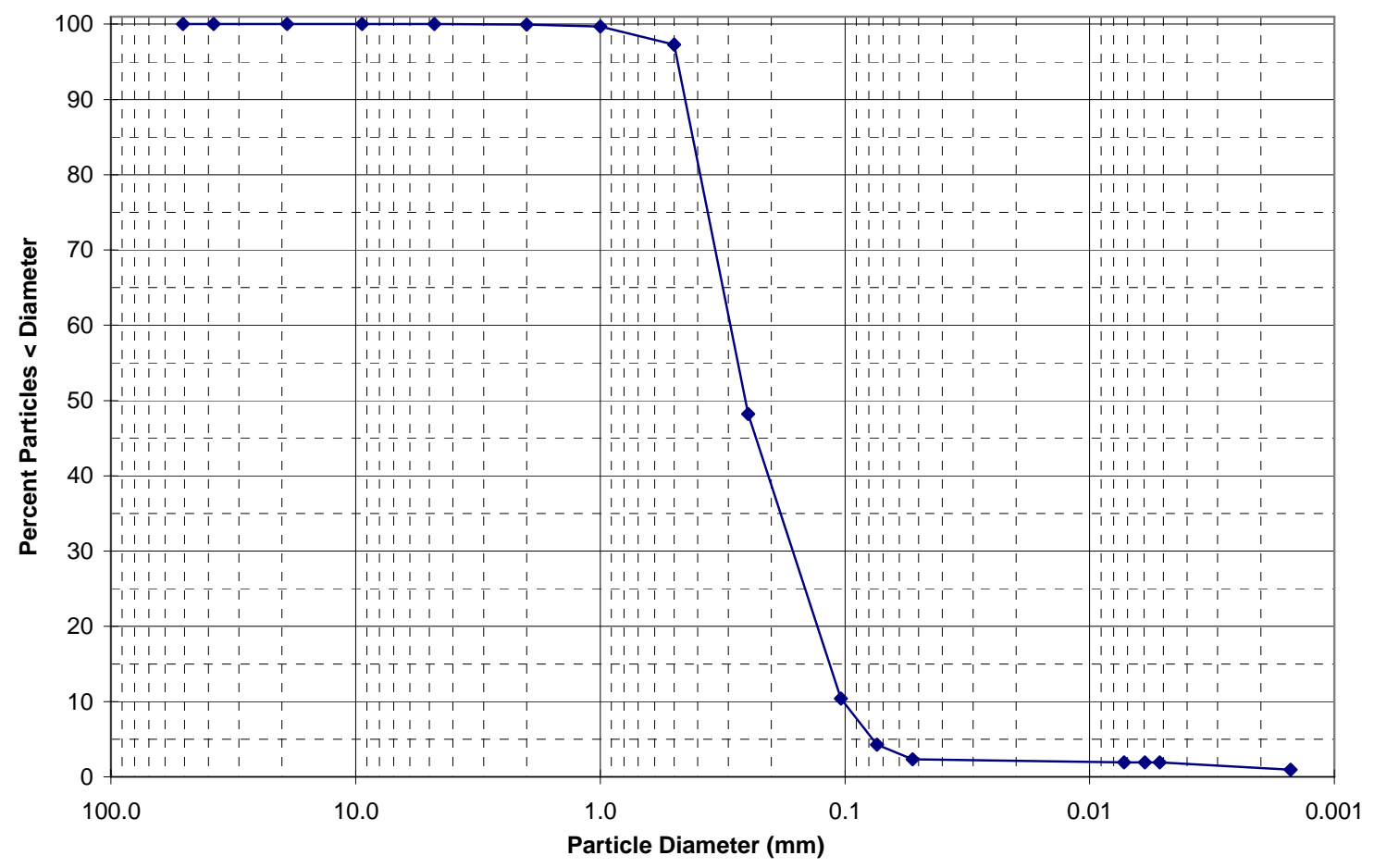

Figure B.1. Particle-Size Distribution Curve for Beaver Bark Sand

Table B.1. Grain-Size Statistics and U.S. Department of Agriculture Texture Classification

\begin{tabular}{|c|c|c|c|c|}
\hline Soil & USDA Texture & $\begin{array}{c}\text { Percent Sand } \\
(2-\mathrm{mm}>0.05-\mathrm{mm})\end{array}$ & $\begin{array}{c}\text { Percent Silt } \\
(0.05-\mathrm{mm}>0.002-\mathrm{mm})\end{array}$ & $\begin{array}{l}\text { Percent Clay } \\
(<0.002-\mathrm{mm})\end{array}$ \\
\hline Beaver Bark & Sand & 97.7 & 1.1 & 1.2 \\
\hline
\end{tabular}

The soil-moisture retention curve was measured for Beaver Bark sand using the hanging water column method (Dane and Hopmans 2002). The sample was packed to a bulk density of $1.72 \mathrm{~g} / \mathrm{cm}^{3}$. Figure B.2 shows both the wetting and drying soil-water retention characteristic curves. As is typical, the drying curve possesses a higher moisture content at a given matric potential than the wetting curve. For a spill with infiltration, a wetting scenario would be occurring. Fitted Brooks and Corey (1964) and van Genuchten (1980) parameters for the drainage curve are presented in Table B.2. 


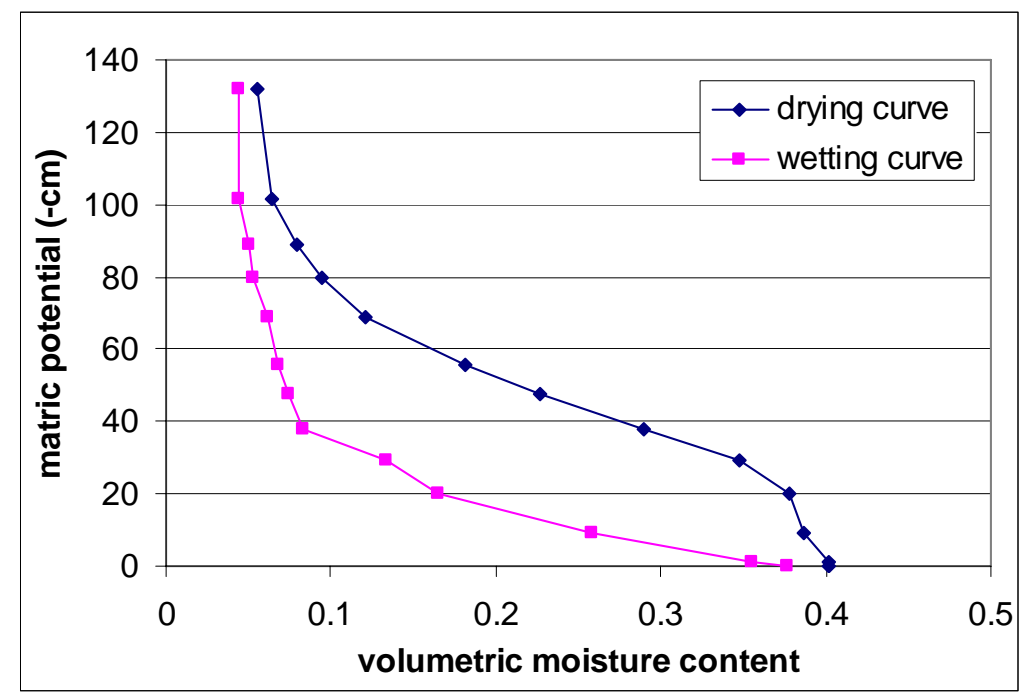

Figure B.2. Wetting and Drying Soil-Water Characteristics Curves for Beaver Bark Sand

Table B.2. Fitted Brooks and Corey and van Genuchten Parameters for the Soil-Water Drainage Curve

\begin{tabular}{||c|c|c|c|c|c|c|c|}
\hline \hline \multicolumn{4}{|c|}{ Brooks-Corey } & \multicolumn{4}{c||}{ van Genuchten } \\
\hline $\begin{array}{c}\theta_{\mathbf{s}} \\
\left(\mathbf{c m}^{3} \mathbf{c m}^{-3}\right)\end{array}$ & $\begin{array}{c}\theta_{\mathbf{r}} \\
\left(\mathbf{c m}^{3} \mathbf{~ m}^{-3}\right)\end{array}$ & $\begin{array}{c}\lambda \\
(-)\end{array}$ & $\begin{array}{c}\psi_{\mathbf{b}} \\
(\mathbf{c m})\end{array}$ & $\begin{array}{c}\theta_{\mathrm{s}} \\
\left(\mathbf{c m}^{3} \mathbf{c m}^{-3}\right)\end{array}$ & $\begin{array}{c}\theta_{\mathbf{r}} \\
\left(\mathbf{c m}^{3} \mathbf{c m}^{-3}\right)\end{array}$ & $\begin{array}{c}\alpha \\
\left(\mathbf{c m}^{-1}\right)\end{array}$ & $\begin{array}{c}\mathbf{n} \\
(-)\end{array}$ \\
\hline 0.383 & 0 & 1.478 & 32.166 & 0.394 & 0.047 & 0.023 & 4.119 \\
\hline \hline
\end{tabular}

\section{B.1 References}

Brooks RH and AT Corey. 1964. "Hydraulic Properties of Porous Media.” Hydrol. Paper 3. Colorado State University, Fort Collins, Colorado.

Dane JH and JW Hopmans. 2002. "Water Retention and Storage.” In J Dane and C Topp (eds.), Ch 2, pp. 671-717, Methods of Soil Analysis, Part 4. Physical Methods. Book Series 5, Soil Sci. Soc. Am., Madison, Wisconsin.

Gee GW and D Or. 2002. Particle-Size Analysis. In J Dane and C Topp (eds.), Ch 2, pp. 255-293, Methods of Soil Analysis, Part 4. Physical Methods. Book Series 5, Soil Sci. Soc. Am., Madison, Wisconsin.

Keller JM and CS Simmons. 2005. The Influence of Selected Liquid and Soil Properties on the Propagation of Spills over Flat Permeable Surfaces. PNNL-15058, Pacific Northwest National Laboratory, Richland, Washington.

van Genuchten M Th. 1980. "A Closed-Form Equation for Predicting the Hydraulic Conductivity of Unsaturated Soils.” Soil Sci. Soc. Am. J. 44:892-898. 


\section{Distribution}

\section{OFFSITE}

Steve Homeyer

National Geospatial-intelligence Agency

Innovision, Basic and Applied Research (IB) DN-11

12310 Sunrise Valley Drive

Reston, VA 20191-3449

Jeff Mirick

National Geospatial-intelligence Agency

Innovision, Sensor Physics (IJ) DN MS-15

12310 Sunrise Valley Dr.

Reston VA 20191 - 3449

Ernie Reith

National Geospatial-intelligence Agency

Innovision, Sensor Physics (IJ) DN MS-15

12310 Sunrise Valley Dr.

Reston VA 20191 - 3449

Paul Salamonowicz

National Geospatial-intelligence Agency

Innovision, Basic and Applied Research (IB) DN-11

12310 Sunrise Valley Drive

Reston, VA 20191-3449

Chris Simi (6)

National Geospatial-intelligence Agency

Innovision, Sensor Physics (IJ) DN MS-15

12310 Sunrise Valley Dr.

Reston VA 20191 - 3449

Bryan Albers

National Geospatial-intelligence Agency

Innovision, Sensor Physics (IJ) MS N-06

1200 First Street SE

Washington DC 20303 
Joe Bobby

National Geospatial-intelligence Agency

Innovision, Sensor Physics (IJ) MS N-06

1200 First Street SE

Washington DC 20303

Wayne Hallada

National Geospatial-intelligence Agency

Innovision, Sensor Physics (IJ) MS N-06

1200 First Street SE

Washington DC 20303

Ron Holmes

National Geospatial-intelligence Agency

Innovision, Sensor Physics (IJ) MS N-06

1200 First Street SE

Washington DC 20303

Herb Mitchell

National Geospatial-intelligence Agency

Innovision, Sensor Physics (IJ) MS N-06

1200 First Street SE

Washington DC 20303

\section{ONSITE}

\section{Pacific Northwest National Laboratory}

$\begin{array}{ll}\text { J.L. Hylden (10) } & \text { K8-41 } \\ \text { C.S. Simmons (3) } & \text { K9-33 } \\ \text { J.M. Keller (2) } & \text { K9-36 } \\ \text { Information Release Office (2) } & \text { P8-55 }\end{array}$

